\title{
Effects of morphine, d-amphetamine, and food deprivation on temporally organized behavior
}

\author{
Todd William Knealing \\ West Virginia University
}

Follow this and additional works at: https://researchrepository.wvu.edu/etd

\section{Recommended Citation}

Knealing, Todd William, "Effects of morphine, d-amphetamine, and food deprivation on temporally organized behavior" (2002). Graduate Theses, Dissertations, and Problem Reports. 1593.

https://researchrepository.wvu.edu/etd/1593

This Dissertation is protected by copyright and/or related rights. It has been brought to you by the The Research Repository @ WVU with permission from the rights-holder(s). You are free to use this Dissertation in any way that is permitted by the copyright and related rights legislation that applies to your use. For other uses you must obtain permission from the rights-holder(s) directly, unless additional rights are indicated by a Creative Commons license in the record and/ or on the work itself. This Dissertation has been accepted for inclusion in WVU Graduate Theses, Dissertations, and Problem Reports collection by an authorized administrator of The Research Repository @ WVU.

For more information, please contact researchrepository@mail.wvu.edu. 
Effects of Morphine, $d$-Amphetamine, and Food Deprivation on Temporally Organized Behavior

by

Todd W. Knealing

Dissertation submitted to the Eberly College of Arts and Sciences at West Virginia University

in partial fulfillment of the requirements

for the degree of

Doctor of Philosophy

in

Psychology

David W. Schaal, Ph.D., Chair

Christina D. Adams, Ph.D.

Kristine M. Krajnak, Ph.D.

Kennon A. Lattal, Ph.D.

Michael T. Perone, Ph.D.

Department of Psychology

Morgantown, West Virginia

2002

Keywords: morphine, $\underline{\mathrm{d}}$-amphetamine, fixed-interval schedule, peak procedure, temporal discrimination, timing, key peck, pigeons

Copyright 2002 Todd W. Knealing 


\begin{abstract}
Effects of Morphine, $d$-Amphetamine, and Food Deprivation on

Temporally Organized Behavior
\end{abstract}

Todd W. Knealing

Two experiments examined the effects of morphine and $\underline{\mathrm{d}}$-amphetamine on behavior that was temporally organized under several schedule arrangements. Two body weights were assessed for each experiment. Experiment 1 made use of fixed-interval (FI) schedules, the peak procedure, and a two-key (free-operant psychophysical) procedure. Indexes of timing performance under each of these schedules were assessed and compared. Timing indexes were decreased by both drugs in the two-key procedure, but were not reliably altered in the peak procedure. Both drugs produced clear rate-dependent effects on behavior in both procedures. In Experiment 2, FI performance was assessed both alone and with a concurrently available variable-interval (VI) schedule to determine whether drugs would cause a pigeon to leave a potential source of reinforcement early in order to respond to a future source of reinforcement. Although reductions in the index of curvature were obtained, there was no clear difference in FI performance based on whether or not a VI schedule was concurrently available. The results of Experiment 1 are inconsistent with the theory of a sped-up pacemaker, but are consistent with explanations involving a decrease in attention. The data also are consistent with the rate-dependency hypothesis, which states that rates of responding following drug administration tend to be determined in large part by rates of responding under baseline conditions. 


\section{Acknowledgments}

Several individuals, who contributed to the development of this dissertation and to my graduate training, deserve mention. I am grateful to my dissertation committee members, Drs. Christina Adams, Kristine Krajnak, Kennon Lattal, Michael Perone, and David Schaal. Their helpful suggestions improved the quality of this dissertation both in its execution and in the finished product. In particular, I am grateful to my advisor, Dr. David Schaal. He has helped to guide and shape my development as a behavior analyst during my five years at West Virginia University. He was always available for me to ask questions of, to bounce ideas off of, and to receive advice regarding any problem that might be vexing me. Were it not for him, I would not be the same person today. Thank you, Dave. I am also grateful to Dr. Kennon Lattal. He shaped my early behavior at WVU, both methodologically and theoretically. His knowledge and understanding of behavior analysis was inspiring to me and I was glad to always know that he was available. Finally, Dr. Michael Perone deserves my recognition for the support he has provided during my years at WVU, both inside and outside of the classroom. He always made himself available to discuss matters of my classroom education, my teaching prospects, and what lies beyond the gates of WVU. I am indebted to all three of these individuals for their time, knowledge, and expertise, which they made available to me. Thank you. 
Table of Contents

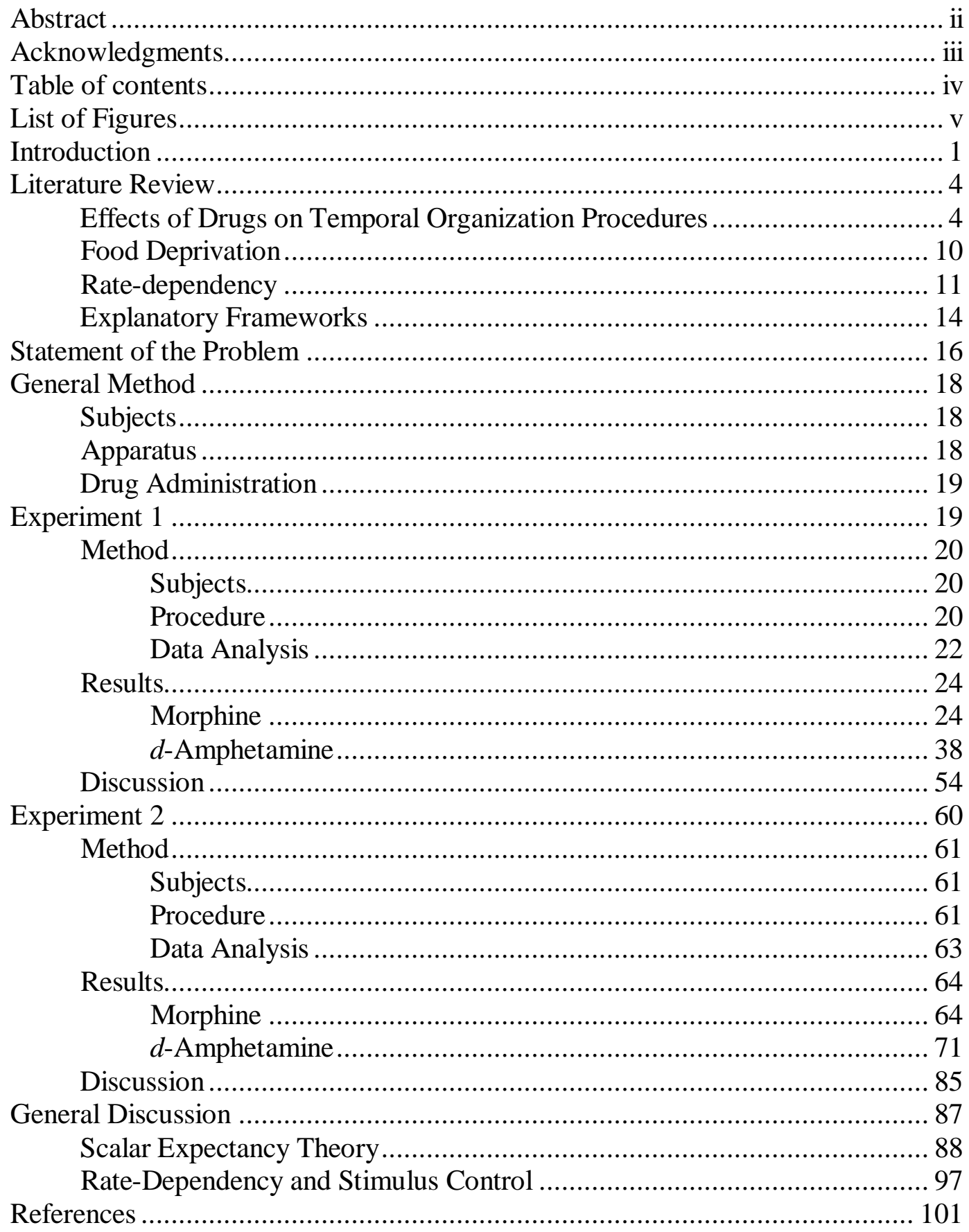




\section{LIST OF FIGURES}

Figure 1. Response rates as a function of dose of morphine for each pigeon

responding on each procedure under both levels of food deprivation.

Figure 2. Response rates in consecutive 2.5-s bins of FI 25-s trials for saline and morphine conditions for each pigeon.

Figure 3. Indexes of curvature in FI 25-s trials for saline and morphine conditions for each pigeon.

Figure 4. Response rates in consecutive 2.5-s bins of PI trials for saline and morphine conditions for each pigeon.

Figure 5. Times of peak response rates and the $70 \%$ spread around that peak in PI trials for saline and morphine conditions for each pigeon.

Figure 6. Percent of right-key pecks per 2.5-s bin of two-key trials for saline and morphine conditions for each pigeon.

Figure 7. Times of 50\% right-key responding and difference limens in two-key trials for saline and morphine conditions for each pigeon.

Figure 8. Rate-dependency plots for fixed-interval and peak-interval trials for each pigeon following morphine administration......

Figure 9. Rate-dependency plots for two-key trials for each pigeon following morphine administration. 36

Figure 10. Response rates as a function of dose of $\underline{\mathrm{d}}$-amphetamine for each pigeon responding on each procedure under both levels of food deprivation.

Figure 11. Response rates in consecutive 2.5-s bins of FI 25-s trials for saline and low doses of $\underline{\mathrm{d}}$-amphetamine for each pigeon.

Figure 12. Response rates in consecutive 2.5-s bins of FI 25-s trials for saline and high doses of $\underline{\mathrm{d}}$-amphetamine for each pigeon.

Figure 13. Indexes of curvature in FI 25-s trials for saline and $\underline{\mathrm{d}}$-amphetamine for each pigeon.

Figure 14. Response rates in consecutive 2.5-s bins of PI trials for saline and low doses of $\underline{\mathrm{d}}$-amphetamine for each pigeon. 
Figure 15. Response rates in consecutive 2.5-s bins of PI trials for saline and high doses of $\underline{\mathrm{d}}$-amphetamine for each pigeon. 45

Figure 16. Times of peak response rates and the $70 \%$ spread around that peak in PI trials for saline and $\underline{\mathrm{d}}$-amphetamine conditions for each pigeon.

Figure 17. Percent of right-key pecks per 2.5-s bin of two-key trials for saline and low doses of $\underline{\mathrm{d}}$-amphetamine conditions for each pigeon.

Figure 18. Percent of right-key pecks per 2.5-s bin of two-key trials for saline and high doses of $\underline{\mathrm{d}}$-amphetamine conditions for each pigeon.

Figure 19. Times of 50\% right-key responding and difference limens in two-key trials for saline and $\underline{\mathrm{d}}$-amphetamine conditions for each pigeon.

Figure 20. Rate-dependency plots for fixed-interval and peak-interval trials for each pigeon following $\underline{\mathrm{d}}$-amphetamine administration. 52

Figure 21. Rate-dependency plots for two-key trials for each pigeon following $\underline{\mathrm{d}}$-amphetamine administration.

Figure 22. Response rates as a function of dose of morphine for each pigeon responding on each schedule under both levels of food deprivation.

Figure 23. Response rates in consecutive 30-s bins of FI 5-min intervals for saline and morphine conditions for each pigeon.

Figure 24. Response rates in consecutive 30-s bins of concurrent FI 5-min intervals for saline and morphine conditions for each pigeon.

Figure 25. Indexes of curvature in FI 5-min and concurrent FI 5-min intervals for saline and morphine conditions for each pigeon.

Figure 26. Response rates in consecutive 30-s bins of concurrent VI 150-s intervals for saline and morphine conditions for each pigeon. 70

Figure 27. Rate-dependency plots for fixed-interval, concurrent fixed-interval, and concurrent variable-interval schedules for each pigeon following morphine administration.

Figure 28. Response rates as a function of dose of $\underline{\mathrm{d}}$-amphetamine for each pigeon responding on each schedule under both levels of food deprivation.

Figure 29. Response rates in consecutive 30-s bins of FI 5-min intervals for saline and low doses of $\underline{\mathrm{d}}$-amphetamine for each pigeon. 
Figure 30. Response rates in consecutive 30-s bins of FI 5-min intervals for saline and high doses of $\underline{\mathrm{d}}$-amphetamine for each pigeon.

Figure 31. Response rates in consecutive 30-s bins of concurrent FI 5-min intervals for saline and low doses of $\underline{\mathrm{d}}$-amphetamine for each pigeon.

Figure 32. Response rates in consecutive 30-s bins of FI 5-min intervals for saline and high doses of $\underline{\mathrm{d}}$-amphetamine for each pigeon.

Figure 33. Indexes of curvature in FI 5-min and concurrent FI 5-min intervals

for saline and $\underline{\mathrm{d}}$-amphetamine conditions for each pigeon.

Figure 34. Response rates in consecutive 30-s bins of concurrent VI 150-s intervals for saline and low doses of $\underline{\mathrm{d}}$-amphetamine for each pigeon.

Figure 35. Response rates in consecutive 30-s bins of concurrent VI 150-s intervals for saline and high doses of $\underline{\mathrm{d}}$-amphetamine for each pigeon. 82

Figure 36. Rate-dependency plots for fixed-interval, concurrent fixed-interval, and concurrent variable-interval schedules for each pigeon following d-amphetamine administration. 84

Figure 37. Comparison of obtained data in the two-key procedure with hypothetical data where a hypothetical clock had been sped up by $5 \mathrm{~s}$.

Figure 38. Comparison of obtained data in the peak procedure with hypothetical data where a hypothetical clock had been sped up by $5 \mathrm{~s}$. 


\section{Introduction}

Time, or duration, like other stimulus properties such as intensity, wavelength, or position may be a discriminable property of a stimulus (Skinner, 1938; Stubbs, 1968). That is, behavior can change as a function of time. Given this characterization, one can discuss the effects of schedules with strong temporal properties in terms of temporal stimulus control and temporal discrimination. Such discrimination is generally inferred from differential responding as time elapses, such as in a fixed-interval (FI) schedule, or differential responding following stimuli of different durations, such as in a choice paradigm arranged by an interval bisection task (Meck, 1983).

Time, unlike other stimulus properties, is often given some measure of special consideration. It has three unique properties that set it apart (Catania, 1970). First, time is irreversible. It cannot be rewound, it cannot be repeated, and it cannot be reversed. Second, it flows continuously. Time does not function in a discrete fashion. It cannot be flipped off or on like a light can. Its "speed" cannot be increased or decreased as one might increase or decrease the wavelength of light. It is ever present and it steadily continues. Lastly, time involves no readily obvious receptor, unlike other things that we sense. Given the characterization as a discriminable stimulus property with no known receptor, it is not surprising that the literature on "timing" is rife with hypothetical constructs. In these three ways, time is conceptually distinct from other stimuli such as color, noise, flavor, texture, and scent. However, its function remains the same, that of a discriminable stimulus property; the behavioral effects of which can be studied.

The FI schedule of reinforcement is one of the procedures most commonly used to study temporal discrimination. The FI schedule arranges for reinforcement to be delivered following a 
single response after a set interval of time. In rats and pigeons, responding under such a schedule generally produces a scalloped pattern, characterized by a pause at the start of the interval followed by a gradually increasing rate of responding until delivery of the reinforcer (Ferster \& Skinner, 1957). If the organism were behaving optimally, each interval would result in a single response, after the critical interval of time had passed. However, this does not occur. Ferster and Skinner (1957) suggested that the pattern of behavior on an FI schedule may be mediated by the organism's own behavior, which functioned metaphorically as an imperfect clock. A "perfect" clock would produce behavior that consisted of just the single response after the elapsed interval of time.

Schedules such as the FI that arrange for behavior to be organized across time are common within behavior pharmacology. For example, Dews (1955a) trained pigeons to peck a key under a multiple FI 15-min fixed-ratio (FR) 50 schedule of food reinforcement. Following acquisition of a stable baseline, pentobarbital was administered. Behavior was differentially affected by pentobarbital in the two schedules. Low doses of pentobarbital produced increases in rate relative to those obtained following saline administration, under both the FI and FR schedules. However, the FR schedule maintained high response rates even at doses that suppressed behavior under the FI schedule (i.e., 1 and $2 \mathrm{mg}$ ). Dews also reported that following pentobarbital administration, the typical concave scallop produced under an FI schedule was lost. In fact, sometimes, the shape of the function showing responding across time had an upward convexity, or inverted scallop. This sort of effect would be shown in future experiments as well and eventually be characterized as a rate-dependent effect (Dews, 1958).

Rate-dependent effects on behavior under FI schedules are characterized by increases in low rates at the beginning of an interval after administration of a drug, and high rates at the end 
of the interval decreasing or being less affected (Dews \& Wenger, 1977; Kelleher \& Morse, 1968). The rate-dependent effect is observed following administration of drugs from several classes. Further, this effect is more robust and reliable when subjects are maintained at higher levels of food deprivation, at least with morphine (Odum, Haworth, \& Schaal, 1998) and cocaine (Schaal, Miller, \& Odum, 1995). The reasons for the rate-dependent effect of drugs are not well understood, but several possibilities (Robbins, 1981) will be reviewed below. Rate-dependent effects are typically illustrated by plotting the ratio of response rate following drug administration to response rate following saline administration within different portions of an interval on a logarithmic axis. This ratio is plotted as a function of the mean saline response rate of the corresponding segment, also on a logarithmic axis. A linear regression line is then fitted to the data. These plots typically show a decrease as mean saline response rates increase.

In studying temporal discrimination, rate-dependency is rarely considered. Rather, the focus generally has been more directed towards the study of various indexes of timing behavior that can be produced by manipulations such as changes in rate of reinforcement (e.g., Bizo \& White, 1994a, 1994b, 1995; Machado \& Guilhardi, 2000) or the administration of drugs (e.g., Meck, 1983; Bayley, Bentley, \& Dawson, 1998; Chiang, et al., 2000). These indexes of timing behavior are then used to infer changes in hypothetical timing constructs such as pacemakers. It is, however, possible that observed changes in indexes of timing might be related to control rates of responding.

The present study was designed to assess whether changes in indexes of temporal discrimination might be due, in part, to rate-dependent effects following administration of morphine and $\underline{\mathrm{d}}$-amphetamine. The generality of changes in indexes was assessed by comparing indexes under several different timing tasks. Finally, two levels of food restriction were 
examined for each combination of drug and procedure to assess whether drugs produce more robust alterations in timing behavior when pigeons are maintained at lower body weights.

\section{Literature Review}

This review describes the effects of a variety of drugs and drug classes, including morphine and $\underline{\mathrm{d}}$-amphetamine, on behavior produced by several timing procedures and by FI schedules of reinforcement. These effects can be characterized as largely rate-dependent in nature. Following the description of rate-dependency, studies of food restriction and its interaction with drugs are characterized. Finally, two frameworks are presented through which these effects can be explained, stimulus control and scalar expectancy theory. The review of literature throughout this dissertation includes experiments using a variety of drugs due to a limited number of relevant experiments using morphine and to a lesser extent $\underline{\mathrm{d}}$-amphetamine, and because alterations in temporally organized behavior can be produced by drugs from several pharmacological classes (McKearney, 1981).

\section{Effects of Drugs on Temporal Organization Procedures}

Typical FI performance consists of a pause at the start of the interval, followed by a gradual (or abrupt) acceleration in response rate until reinforcement is delivered. Low to moderate doses of morphine have been shown to produce large increases in the low-rate behavior of pigeons at the beginning of FI intervals (Odum, Haworth, \& Schaal, 1998; Odum \& Schaal, 1999). Higher doses of morphine have been shown to have largely rate-suppressive effects on behavior throughout the interval. Overall rates of responding (taken as an aggregate across an entire session) show either decreases in overall rates of responding with increasing doses of morphine, or a slight increase at low doses followed by dose-dependent decreases. 
Similar effects have been observed following administration of $\underline{\mathrm{d}}$-amphetamine in pigeons (McMillan, 1969; Branch \& Gollub, 1974) and rats (Heffner, Drawbaugh, \& Zigmond, 1974). McMillan broke fixed intervals into thirds and compared average response rates across saline and drug doses. He observed increases in early-interval, low-rate response rates at low doses, and decreases in higher rate, late-interval responding. He also showed inverted u-shaped functions relating overall session response rates to $\underline{\mathrm{d}}$-amphetamine dose. That is, response rates increased across a range of low doses, then decreased across the range of moderate to high doses. Branch and Gollub computed mathematical indexes of curvature and compared the indexes at different doses of drug. An index of curvature of zero indicates a constant rate of responding across the interval while a positive index indicates a pattern of acceleration across an interval. The index was found to consistently decrease as a function of increasing dose of $\underline{\mathrm{d}}$-amphetamine. This was primarily due to large rate increases in the beginning of the interval, and some rate decreases towards the end of the interval. Overall response rates were an inverted u-shaped function of dose as in McMillan's study. Heffner and colleagues also found that low-rate responding at the beginning of FI intervals was increased by $\underline{\mathrm{d}}$-amphetamine and that the size of the increase was dependent on the baseline (saline) rate of responding for any given portion of the interval. They also found that overall rates of responding were maintained or increased slightly at low doses, then decreased with progressively higher doses.

The FI schedule, in and of itself, does not always allow for the clearest indications of alterations in timing behavior, but procedures other than the FI schedule have been developed to study temporal discrimination, or "timing." For present purposes, the most notable procedures to come out of the timing literature are the peak procedure, the interval bisection task, and the free operant psychophysical procedure. Each of these timing procedures provides a unique index of 
timing. It is commonly assumed that each procedure reflects the same underlying timing process. That is to say, a similar change in performance under each of these procedures is thought to reflect a similar change in an underlying timing mechanism.

The peak procedure (or peak-interval procedure) is an extension of the fixed-interval schedule (Catania, 1970; Roberts, 1981). In a peak procedure, an organism is first trained to respond under an FI schedule. When performance is stable, empty (or "peak") trials are introduced. During peak trials the stimulus normally associated with the FI schedule is presented, however, responding has no scheduled consequences. The stimulus remains on for a fixed interval of time, often 3 to 4 times the duration of the fixed-interval schedule, and then terminates without reinforcement. After exposure to such a schedule, behavior in the peak trials takes on a characteristic bell-shaped pattern. Low or zero rates of responding occur at the start of the trial. These rates then accelerate to a maximal (peak) rate of responding that occurs around the time when reinforcement would ordinarily be produced under the FI schedule. Response rates then decrease, eventually falling to low or zero levels for the remainder of the interval. The time when this peak rate occurs, the "peak time", is the principal index of timing in this procedure. Often, a secondary rise in rates of responding is observed in the latter part of the trial.

Like the FI schedule, the peak procedure has been used in research on the effects of drugs on behavior. Bayley, Bentley, and Dawson (1998) examined the effects of $\underline{\mathrm{d}}$-amphetamine, imipramine, zimeldine, clomipramine, and diazepam on the behavior of rats on a peak procedure. The peak time was not reliably altered following administration of any of these drugs. $\underline{\mathrm{d}}-$ amphetamine produced overall response rate increases at all doses tested; other drugs produced dose-dependent response rate decreases. Shifts in the peak time of responding have been obtained, however. Maricq, Roberts, and Church (1981) examined methamphetamine in rats and 
found leftward shifts in peak time. That is, the time of peak responding occurred earlier following drug administration than following saline administration. Kraemer, Randall, Dose, and Brown (1997) found similar results in their study involving pigeons. Higher doses of $\underline{\mathrm{d}}-$ amphetamine (e.g., 1.0 and $2.0 \mathrm{mg} / \mathrm{kg}$ ) produced leftward shifts (towards earlier points in the interval) in the peak time. Meck and Church (1984) used morphine in a study of peak perfomance in rats. Unlike research involving the amphetamines, they found no alteration in the time of peak responding. Thus, due to mixed findings with $\underline{\mathrm{d}}$-amphetamine in altering behavior and more specifically temporal behavior under a peak procedure and little research using morphine, Experiment 1 made use of that very same procedure in alternation with another timing task, a free-operant psychophysical procedure, which will be referred to as the 'two-key procedure."

The two-key procedure, as used by Bizo and White (1994a; 1994b; 1995), involved pigeons responding to two different keys. When a trial began, the two side keys in a chamber were lit. The keys remained lit for the 50-s duration of the trial. During the first half (25 s) of the trial, reinforcers were arranged for left key responses according to a variable-interval (VI) schedule and there were no scheduled consequences for right key responses. During the second half of the trial, these contingencies were reversed, with no consequences for left key responding and reinforcers arranged for right key responses according to a VI schedule. The pigeons initially responded on the left key and then switched over to the right key near the midpoint of the trial. This switch time is called the point of subjective equality. To determine the point of subjective equality, an experimenter typically collects and groups data from equal segments from within a trial (i.e., all responses within the first $5 \mathrm{~s}$ are aggregated, then all responses within the second $5 \mathrm{~s}$ 
of a trial, etc.). These data are aggregated across all trials from a session. Finally, the experimenter determines the time when the responses are distributed evenly between the keys.

Bizo and White found that they could shift the point of subjective equality by altering the overall reinforcer density of a trial. They showed this by altering the inter-reinforcer intervals (Bizo \& White, 1994a), by manipulating the duration of access to reinforcer (Bizo \& White, 1994b) and by altering the inter-trial interval (Bizo \& White, 1994b). By altering the interreinforcer interval, Bizo and White demonstrated that the hypothetical pacemaker slowed down in lean schedules (i.e., VI 120 s) and sped up in rich schedules (i.e., VI 15 s), producing shifts in the function to the right and left respectively. By increasing the inter-trial interval, they demonstrated a decrease in pacemaker rate, which resulted in functions shifting to the right. Pacemaker rate was increased as reinforcer duration increased. Pacemaker rate was inferred by fitting data to a mathematical model where one variable is said to correspond to pacemaker period. That is, the time between pulses of the hypothetical pacemaker. These changes relate to the extent that functions shift to the left or right. In general, any increase in overall reinforcer density leads to an increase in the hypothetical pacemaker rate. Altering the relative rates of reinforcement for left- and right-key responses also produced changes in the estimate. By reinforcing left-key responses more frequently than right-key responses (but still restricted to the first $25 \mathrm{~s}$ ), for example, the point of subjective equality was shifted to the right. That is, the pigeons pecked on the left key for a longer period of time, on average, before switching to responding on the right key. Conversely, by reinforcing right-key responses more frequently than left-key responses, the point of subjective equality was shifted to the left.

The two-key procedure was not used in studies of the effects of drugs on behavior until recently (Chiang, et al., 2000). When data were averaged across rats, points of subjective 
equality were shifted to the left as a function of increasing dose of $\underline{\mathrm{d}}$-amphetamine. The other major effect on the pattern of behavior was an overall flattening of the function relating response rates to the passage of time. That is, response rates did not differ as much with the passage of time following drug administration as they did following saline. These alterations were shown also in rate-dependency plots where regression lines were steeper as a function of increasing dose of drug. The steeper function was due to both increases of low-rate responding and decreases of high-rate responding.

Although the bulk of timing research with drug administration has been conducted with the peak procedure and with the interval-bisection procedure (Meck, 1983), the two-key procedure has been used to help explore some physiological processes that may be involved in timing behavior. The effects of central 5-hydroxytryptamine (5-HT) depletion in rats were studied using the peak procedure, the interval bisection task, and the two-key procedure (Chiang, Al-Ruwaitea, Ho, Bradshaw, \& Szabadi, 1999; Morrissey, Ho, Wogar, Bradshaw, \& Szabadi, 1994; Morrisey, Wogar, Bradshaw, \& Szabadi, 1993). These experiments all examined the effects of lesions to the ascending 5-hydroxytryptaminergic pathways on behavior. The interval bisection task that was used involved first training rats to respond on one lever (e.g., the left) following a stimulus of short duration and to respond on another lever (e.g., the right) following a stimulus of long duration. After training this discrimination, stimuli of durations between the short and long durations were tested. A point of subjective equality can be found using this procedure by determining at what stimulus duration a rat responds half of the time on the left lever and the other half of the time on the right lever. When behavior in the interval bisection task was used to index timing behavior, the point of subjective equality was found to be lower in the lesioned group than in the sham-lesion control group (Morrisey et al., 1993). However, when 
the two-key procedure and peak-interval procedure were used, no such shifts in timing indexes (i.e., point of subjective equality or peak time) were found. Some differences were found, however. In the two-key procedure, it was shown that switching between levers occurred at higher rates in the lesioned rats. The overall rates of responding also were higher in the lesioned rats. And, although the peak time did not differ between groups in the peak-interval procedure, the peak spread was greater in the lesioned group than in the sham-lesioned group. The peak spread is determined by converting all rates, collected in 2.5-s segments of the trial, into percentages of the maximum rate. The first segment to reach or exceed $70 \%$ of peak rate marks the start of the " $70 \%$ spread" and the first segment to fall below $70 \%$ of peak rate marks the end of the spread. The distance in time, measured in seconds, between those two segments is termed the $70 \%$ spread. So, an increase in spread without a change in peak time indicates an increase in response rates on both sides of the peak relative to control subjects. In summary, reliable alterations in measures of timing have been obtained with both the peak procedure and the free operant psychophysical procedure. A number of drugs, but most commonly $\underline{\mathrm{d}}$-amphetamine, have been shown to alter these indexes of timing.

\section{$\underline{\text { Food Deprivation }}$}

The effects that drugs have on behavior are changed by food deprivation in a number of ways. It has been shown that the rate-suppressing effects of a variety of drugs are found at lower doses when an animal is less food deprived than when the animal is more food deprived (Cole, 1967; Gollub \& Mann, 1969; Kelly \& Thompson, 1988; Schaal \& Branch, 1992; Schaal, Miller, \& Odum, 1995; Odum, Haworth, \& Schaal, 1998). Rate-increasing effects of low doses of cocaine and morphine also have been shown to be enhanced at greater levels of food deprivation (Schaal et al., 1995; Odum et al., 1998). Furthermore, food deprivation has been shown to 
increase drug-reinforced behavior and drug intake (i.e., self-administration) by animals (see Carroll \& Meisch, 1984 for review). Thus, in the current experiments, it was expected that a greater range of drug doses would be testable with increased food deprivation and that some of the drug effects on behavior would be enhanced or made more robust.

\section{Rate-Dependency}

Dews (1955a) presented some of the first data that showed how important the schedule of reinforcement could be in determining the effects of drugs on behavior. He administered pentobarbital to pigeons responding on a multiple FR 50 FI 15-min schedule. The dose-response curves for the two schedules were found to differ. The magnitude of the change in behavior was shown to be dependent not only on the dose administered, but on the schedule under which responding was being reinforced. Even the direction of change that behavior underwent was determined by the combination of dose and schedule. That is, whether response rates increased or decreased at a given dose was dependent on the schedule that was being examined. This experiment on its own did not provide clear evidence to suggest what aspects of the schedules were the important determinants for drug action. Dews followed through with further studies using pentobarbital, methamphetamine, and scopolamine on response patterns maintained by different schedules of reinforcement (Dews, 1955a, 1955b, 1957, 1958a). These studies provided further demonstrations of the importance of schedule in determining the effects of drug on rates of responding. In the last of those studies, Dews demonstrated that a low dose of methamphetamine would increase low rates of responding while not altering high rates of responding. Specifically, low response rates maintained on very lean FI or FR schedules were increased, while high response rates maintained by a rich FR or VI schedule were altered little. On the basis of these and other experiments, Dews (1958b) proposed that an important 
determinant of the effects of amphetamines on behavior was the control rate of responding under a schedule of reinforcement. Specifically, low control rates tend to be increased while high control rates tend to be maintained or decreased. Sanger and Blackman (1976) have referred to this description as the rate-dependency hypothesis.

These rate-dependent effects have been replicated most often with fixed ratio and fixed interval schedules, but the effect can be demonstrated with any schedule that produces appropriately low or high response rates. The generality of the rate-dependency hypothesis has been extended to a variety of drugs through studies similar to those performed by Dews (for a

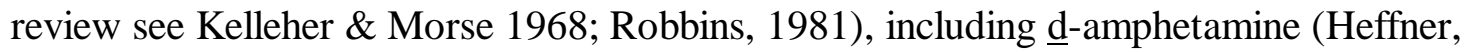
Drawbaugh, \& Zigmond, 1974; Leander \& McMillan, 1974; Katz, 1982; Lucki \& DeLong, 1983) and 1-amphetamine (Katz), pentobarbital (Leander \& McMillan), chlorpromazine (Leander \& McMillan; Leander, 1975), prochlorperazine, perphenazine, chlorprothixene, and tetrabenazine (Leander), phencyclidine and ketamine (Wenger, 1976), cocaine (Howell, Byrd, \& Marr, 1986), and morphine (Thompson, Trombley, Luke, \& Lott, 1970; Heifertz \& McMillan, 1971; McKearney, 1974; Rhodus, Elsmore, \& Manning, 1974; Katz \& Goldberg, 1986; Odum, et al., 1998; Odum \& Schaal, 1999, 2000).

The rate-dependency hypothesis can be taken as a principle, a phenomenon in and of itself and no further explanation is required. Most researchers believe that rate-dependent effects are outcomes of drugs acting on other processes, however. The most general explanation of the rate-dependent effect is that drugs may act as stimuli that alter the controlling context of the environment or that might impair sensory processing of that environment. McKim (1981) has suggested an account that includes Pavlovian "di sinhibition" to explain the rate-increasing effects of drugs and "external inhibition" to describe rate -decreasing effects of drugs. It was 
hypothesized by Pavlov (1927) that in a delayed conditioning procedure using a lengthy (3 min) conditioned stimulus (CS) low levels of responding that occur during the first half of the CS might be increased by the addition of an "extra stimulus" (noise) because the extra stimulus would disrupt active inhibitory processes of the brain. He also hypothesized that high levels of responding that occurred in the latter portion of the CS presentation were decreased by the addition of the extra stimulus by weakening the excitatory processes. Meanwhile, other researchers (Gonzalez \& Byrd, 1977; Ksir, 1981) suggested that drugs might cause responding to be directed towards a constant, intermediate rate as evidence of impaired control by stimuli. Other explanations of the rate-dependent effect have been targeted at stimulants only (see Hill, 1970; Lyon \& Robbins, 1975). Hill suggested that stimulant drugs increase the conditioned reinforcing properties of any stimuli associated with reinforcement, such as feedback from making responses. The suggestion was that feedback from responding may come to act as a conditioned reinforcer and thus an animal might come to behave as if under a continuous reinforcement schedule, which would result in increases in normally low-rate responding. Lyon and Robbins suggested that stimulant drugs may have their effect through behavioral competition. They suggested that any behavior with some minimal tendency would be increased following stimulant administration, including unconditioned responses. Thus low-rate responding will tend to be increased, but high control rate behavior might be decreased because low-rate behavior occurring during that time, such as locomotion, might be increased. For example, responding by pigeons late in an FI may occur at a very high rate, while preening typically occurs at a very low rate, but it does occasionally occur. Lyon and Robbins suggested that low-rate behavior, like preening may be increased. An increase in preening will compete (for time) with key-pecking and produce a reduction in rate of key-pecking. The present studies will 
focus mostly on an account where rate-dependency is an empirical finding that has been replicated in the present study, with exceptions to rate-dependency explained in terms of stimulus control.

\section{Explanatory Frameworks}

A variety of drugs have been shown to have an effect on the behavior of organisms maintained under a variety of temporal schedules of reinforcement. There has been more than one explanation offered for these effects. The explanation that has, arguably, produced the most research is scalar expectancy theory (SET). Stimulus control and its alteration is a behaviorallybased alternative explanation.

According to SET (Church \& Gibbon, 1982; Gibbon, 1977; Gibbon \& Church, 1992), when a subject is exposed to reinforcers that are distributed regularly in time, the behavior comes to reflect control by an underlying timing process. This process includes a memory that contains a distribution of remembered reinforcement times. The subject "draws" one of these times when an interval that is to be timed begins. At that point, a second part of the process, the internal clock, or pacemaker, also begins. The pacemaker generates pulses at a high rate that are sent to an accumulator, which keeps track of the current clock time. A decision to respond or not at any given point is based on the difference between the remembered time and the current clock time. When this difference becomes small enough, a subject will respond. This difference criterion is also subject to variation. Church and Gibbon (1982) have suggested that the timing process depends on subjects attending to the temporal stimulus. A failure to attend to the stimulus will result in a level of responding that is based on the subject's motivation level, reinforcer value, response effort, etc., and not on an underlying timing process. In this conceptualization, drugs can have their effect at any of the points in the process. Most commonly, drugs have been said to 
alter the pacemaker speed. This produces leftward shifts in temporal distributions of behavior if the pacemaker rate increases or rightward shifts if the pacemaker rate decreases. In an FI schedule, this would appear as response rates increasing earlier in the interval following drug administration compared to control conditions. This increase in FI response rates may appear rate-dependent.

Stimulus control accounts suggest that drugs have their effects by increasing or decreasing the stimulus control over an organism's behavior. Such accounts differ from SET accounts mainly in the language used to describe the data. Stimulus control avoids reference to hypothetical constructs, such as memory, a pacemaker, or an accumulator. As a behavioral account, it focuses on describing observable relations in the data. In this account, any sort of gradient of responding produced under control conditions may become more or less sharp following administration of drug. Wilkie (1974) has shown that early portions of FI schedules produce inhibitory gradients of stimulus control. Wilkie trained pigeons to peck a key with a vertical line under an FI schedule of food reinforcement. Following stable performance, the line was tilted to varying degrees from the vertical allowing for generalization gradients to be determined. During the latter parts of the FI, an excitatory gradient (inverted u-shape) was produced. That is, response rates were highest in the presence of the vertical line and decreased as the line's tilt shifted away from the vertical. During the earlier parts of the FI, an inhibitory gradient (u-shape) was produced. That is, response rates were lowest in the presence of the vertical line and increased as the line's tilt shifted away from the vertical. It is possible that these temporally-based stimulus control gradients break down following drug administration, perhaps due to disinhibition by the stimulus effects of drugs (McKim, 1981). A breakdown in the degree 
of temporal stimulus control would then likely produce results such as those that are typically found.

\section{Statement of the Problem}

The present research examined the effects of morphine and $\underline{\mathrm{d}}$-amphetamine on behavior that was temporally organized under several schedule arrangements. Morphine, a mu-opioid receptor agonist, has been shown to have reliable effects on fixed-interval patterning and indexes of timing behavior (Odum \& Schaal, 1999) but is not generally considered to directly act on timing mechanisms. $\underline{\mathrm{d}}$-Amphetamine, an indirectly acting catecholamine agonist, is a classical rate-dependent drug and has been shown to affect measures of timing behavior. That is, morphine is thought to alter behavior through non-timing-specific ways and d-amphetamine in timing-specific ways. Due to reliable effects on schedules involving temporal discrimination, it was expected that both drugs would alter behavior under the schedules used in these experiments. A range of doses was tested with all pigeons to best analyze any effects of the schedule and drug administration on measures of behavior.

Timing indexes and patterns of responding within intervals were compared to determine whether the drugs have similar effects under each of the different schedule arrangements. That is to say, if timing indexes were shifted to the left or right in the peak procedure, were they similarly affected in the free operant psychophysical procedure? This was accomplished within subjects during a single session. To the experimenter's knowledge, such a within-subjects and within-session comparison of timing procedures previously has not been done.

Experiment 1 specifically made use of the peak procedure and the free operant psychophysical procedure. These tasks were chosen for a few reasons. The peak procedure was selected due to its similarity to the FI schedule. Timing is indicated in both schedules by low 
response rates during the early portions of an interval and an increase in response rate as the time of reinforcement approaches. Timing also is indicated in the peak trials by a decrease in response rates in the latter portion of a trial. The time of the peak response rate and the spread of the pattern of response rates across an interval serve as typical indexes of timing under the peak procedure. It was reasoned that any drug that would alter performance under an FI, such as morphine, also would alter performance under a PI, especially during the early portion of an interval. The two-key, free-operant, task is seemingly dissimilar to the FI and PI schedules. Reinforcers can be arranged at any point during a trial and timing is indicated by switching from one response key to the other. This sort of behavior was originally thought to be less subject to rate-dependent effects of drugs (though this was shown not to be the case) and thus be able to focus more clearly on timing-specific alterations due to drug administration.

Experiment 2 used a multiple schedule, with one component being an FI schedule and the other being a concurrent FI VI schedule. This was done to help examine a curious finding from Experiment 1, where pigeons in the two-key procedure switched from the left key to the right much earlier than the contingencies of reinforcement might suggest following drug administration. Specifically, pigeons reliably left a source of reinforcement (the left key) and responded on a key not presently associated with reinforcement (the right key). The multiple schedule of Experiment 2 was arranged to provide another way of examining that phenomenon. In comparing a stand-alone FI schedule with a concurrent VI FI schedule, would FI responding in the concurrent schedule be similarly affected? That is, would response rates on the concurrent FI schedule increase to high rates earlier in the interval than in the stand-alone FI schedule?

To summarize, the present study was designed to assess whether there is any relation between changes in indexes of temporal discrimination and rate-dependent effects following 
administration of morphine and $\underline{\mathrm{d}}$-amphetamine. The generality of changes in indexes of timing were assessed by comparing indexes across multiple timing procedures and schedules of reinforcement. Finally, two levels of food restriction were examined for each combination of drug and procedure (Experiment 1 \& Experiment 2) to assess the empirical generalization that drug administration produces more robust alterations in behavior when an animal is maintained at a lower body weight.

\section{General Method}

\section{$\underline{\text { Subjects }}$}

Eight adult male White Carneau pigeons served as subjects, four in Experiment 1 and four in Experiment 2. The pigeons were maintained at 70 to $90 \%$ of free-feeding body weight (FFW) levels, dependent on experimental condition, through post-session supplementary feeding. Pigeons were housed individually under a 12:12 hr light:dark cycle, with the light cycle starting at 7 a.m., and had free access to water and digestive grit. Sessions were conducted during the light part of the cycle.

\section{$\underline{\text { Apparatus }}$}

Sessions were conducted in four experimental chambers $(33 \mathrm{~cm}$ wide $\mathrm{x} 31 \mathrm{~cm}$ deep $\mathrm{x}$ $37.5 \mathrm{~cm}$ high) constructed of wood with aluminum front panels. The front panels consisted of three $2.1 \mathrm{~cm}$ diameter translucent response keys arranged side-by-side $26 \mathrm{~cm}$ from the floor. Colored lights served as discriminative stimuli and could be lit from behind each key. The response keys required a force of approximately $0.19 \mathrm{~N}$ to record a response. A 28-V 1.1-W lamp, $7 \mathrm{~cm}$ above the center response key served as a houselight. Mixed grain was delivered through a rectangular aperture located $16 \mathrm{~cm}$ below the center response key using a solenoidoperated food hopper. The chambers were sound attenuated and were equipped with fans that 
provided ventilation. A white noise generator, located in the room containing the experimental chambers, was used to further mask extraneous noise. Experimental control and data collection occurred in an adjacent room on MS-DOS-based 80486 microcomputers using the Smart Cumulative Recorder $®$ and Medstate Notation ${ }^{\circledR}$ (MED Associates, Inc. and Tatham, 1991).

\section{Drug Administration}

Morphine sulfate (obtained from the National Institute on Drug Abuse) and $\underline{\mathrm{d}}-$ amphetamine (obtained from Sigma) were dissolved in saline for injection volumes of $1.0 \mathrm{ml} / \mathrm{kg}$ and were administered via intramuscular injection. A minimum of three sessions intervened between injections. The effects of each dose and of saline vehicle were determined 2 or 3 times. Doses of morphine (saline, 1.0, 3.0, 5.6, \& $10.0 \mathrm{mg} / \mathrm{kg}$ ) and $\underline{\mathrm{d}}$-amphetamine (saline, 0.1, 0.3, 1.0, $1.7,3.0, \& 5.6 \mathrm{mg} / \mathrm{kg}$ ) were administered in ascending, descending, then ascending orders. The $0.1 \mathrm{mg} / \mathrm{kg}$ dose of $\underline{\mathrm{d}}$-amphetamine was only used in one experiment due to its lack of effect on behavior. Following injection, pigeons were placed into darkened experimental chambers for 10 minutes prior to the start of the experimental session.

\section{Experiment 1}

This experiment examined the effects of morphine and $\underline{\mathrm{d}}$-amphetamine on key pecking of pigeons maintained under a multiple schedule made up of two timing procedures. One procedure was the two-key free operant psychophysical procedure; the second procedure was the peak procedure. The effects of the two drugs on behavior maintained by these two procedures were assessed at both high and low body weights. The assessment included overall response rates, response patterns and rates within intervals, indexes assessing aspects of the timing behavior measured by the procedures, and rate-dependent plotting of the data. 
$\underline{\text { Subjects }}$

\section{$\underline{\text { Method }}$}

Four adult male White Carneau pigeons $(2219,4244,2238, \& 4571)$ were used as subjects. Pigeon 2219 died prior to the start of $\underline{\mathrm{d}}$-amphetamine administration. These pigeons had previous exposure to the behavioral procedures used in this experiment and the drug, atropine. Eighty-eight sessions intervened between the last administration of atropine in the previous experiment and the first administration of morphine in this experiment.

\section{Procedure}

The pigeons had been trained on this procedure and therefore required no special training prior to the start of the experimental conditions. Each 50-min session began with a 10-min blackout. A session consisted of a multiple schedule of fixed-interval (FI)/peak-interval (PI) trials and two-key trials. The trial types alternated strictly and were separated by 10 -s inter-trial intervals during which the chamber was dark. There were 20 trials of the FI/PI type and 20 trials of the two-key type. Reinforcement, in all cases, consisted of 2.75-s access to grain.

Of the 20 FI/PI trials, 6 trials were PI 100-s and 14 trials were FI 25-s. The PI trials occurred semi-randomly during the session, with 3 PI trials occurring during the first 10-trial block and 3 occurring in the second 10-trial block. At the beginning of an FI/PI trial, the center key stimulus was lit from behind by a red lamp. If the FI 25-s schedule was in effect, grain was presented following the first peck after $25 \mathrm{~s}$ had elapsed. During the PI 100-s trials, the key remained lit for $100 \mathrm{~s}$ and the trial ended without a reinforcer.

Two-key trials were $50 \mathrm{~s}$ in duration. At the beginning of a 50-s trial, the two sideresponse keys were lit green. Responses to the left key during the first $25 \mathrm{~s}$ of the trial were reinforced according to a variable-interval (VI) 67.86-s schedule (Fleshler \& Hoffman, 1962) 
while responses to the right key were not reinforced. Responses to the right key during the second $25 \mathrm{~s}$ of the trial were reinforced according to a second, independent VI 67.86-s schedule while responses to the left key were not reinforced. A VI 67.86-s schedule arranged an equal rate of reinforcement for the two-key procedure and the peak procedure (fixed-interval and peakinterval trials combined). The schedule associated with the left key only timed during the first half of a trial, and the schedule associated with the right key only timed during the second half of the trial. Reinforcers that were scheduled but not delivered during a trial were held over until the next two-key trial. A changeover delay (COD) of $2 \mathrm{~s}$ was used in the two-key procedure. That is, following a change from one response key (e.g., left) to the other (e.g., right), a 2-s timer started. A response on the right key could not be reinforced until those 2 seconds had passed. If the pigeon switched back to the left key, the 2-s timer started over. This meant that it was impossible for a reinforcer to be presented more quickly than $2 \mathrm{~s}$ following a switch in response keys and it prevented the immediate reinforcement of switching behavior.

The pigeons were exposed first to these procedures while maintained at $80 \%$ of their freefeeding weights. Testing of morphine began for individual pigeons when overall response rates and trial response patterns were stable, based on visual inspection of the data. Following drug testing, the pigeons' body weights were decreased to $70 \%$ of their free-feeding weights (FFW). The transition between body weights required between 11 and 20 sessions to complete. Fortyfive to fifty sessions were conducted at the new body weight prior to drug testing following the same procedures used previously. Following all determinations of morphine, the experiment was repeated with $\underline{\mathrm{d}}$-amphetamine as the drug used. Food restriction levels were counterbalanced across subjects during the $\underline{\mathrm{d}}$-amphetamine testing. Pigeon 2238 was maintained at $90 \% \mathrm{FFW}$, 4244 and 4571 were maintained at 85\% FFW for the higher body weights, and all pigeons were 
maintained at $70 \%$ FFW for the lower body weight comparison. The difference of $85 \%$ and $90 \%$ was due to extreme disruption and/or cessation of responding of the other two pigeons when attempts were made to maintain them at $90 \%$ FFW.

\section{Data Analysis}

Overall response rates were computed separately for FI/PI trials, left two-key, and right two-key responding. All means and standard deviations presented are based on 2 or 3 determinations of each drug dose or saline administration. Means and standard deviations for control sessions are based on the data points for each day preceding saline or drug administration.

Response patterns were examined by collecting data in 2.5-s segments for each trial type within a session. Responses within a segment were aggregated across an entire session. Response rates presented in the figures were computed by averaging the response rates within each segment for each dose and subject.

In FI trials, indexes of curvature (Fry, Kelleher, \& Cook, 1960) were determined. The index of curvature (I) was calculated for each session using the following formula:

$$
\underline{I}=\left[9 \underline{\mathrm{R}}_{10}-2\left(\underline{\mathrm{R}}_{1}+\underline{\mathrm{R}}_{2}+\ldots+\underline{\mathrm{R}}_{8}+\underline{\mathrm{R}}_{9}\right)\right] / 10 \underline{\mathrm{R}}_{10}
$$

where $\underline{R}_{1}$ is the total number of responses in the first segment, $\underline{R}_{2}$ is the total number of responses in the first and second segments, up through $\underline{\mathrm{R}}_{10}$ which is the total number of responses in all ten segments.

Peak-interval response patterns, peak time, and 70\% spread were derived for most determinations. However, at a dose of $5.6 \mathrm{mg} / \mathrm{kg}$, responding was greatly suppressed during one session for pigeon 4244 and one session for pigeon 4571. This rate suppression prevented the derivation of indexes for peak time and peak spread during those sessions. In these cases, 
analyses were based on the remaining determinations. Peak time was determined by finding the 2.5-s segment containing the greatest number of pecks (e.g., if the greatest number of pecks occurred in the sixth segment, then the peak time would be $15 \mathrm{~s}$ ). The peak spread was determined by finding the difference (in seconds) between the first time that response rates rose above $70 \%$ of the maximum response rate and the last time that response rates fell below $70 \%$ of the maximum response rate. A process of linear interpolation estimated the two $70 \%$ points of the peak spread. Linear interpolation was accomplished by converting responses into proportions of maximum responding and then determining proportionally where $70 \%$ of that maximal rate was reached.

In two-key trials, the times at which $50 \%$ of responses occurred on the right key (T-50) were assessed through a process of linear interpolation, just as $70 \%$ spread points for PI trials were derived. Difference limens were calculated to give an indication of the amount of variability around the T-50. Difference limens were determined by finding the times at which $25 \%$ (T25) and 75\% (T75) of the responses had occurred on the right key, finding the difference between those times and taking half of that value $($ limen $=(\mathrm{T} 75-\mathrm{T} 25) / 2)$.

Data from each trial type also were analyzed in rate-dependency plots. Mean response rates following the administration of morphine and $\underline{\mathrm{d}}$-amphetamine within each 2.5 -s segment were divided by mean response rates from the corresponding segment following saline administration and plotted on a logarithmic axis. This ratio was plotted as a function of the mean saline response rate of the corresponding segment also on a logarithmic axis. A linear regression line was fitted to each set of data using the method of least squares. 


\section{Results}

Morphine

Response rates changed in a dose-dependent manner following morphine administration at both levels of food deprivation across each of the experimental conditions (Figure 1). Control and saline response rates did not systematically differ from one another when pigeons were maintained at either $80 \%$ or $70 \%$ FFW. Relative to saline response rates at both levels of food deprivation, response rates following morphine administration tended to increase or be maintained following low to moderate doses (i.e., $1.0 \& 3.0 \mathrm{mg} / \mathrm{kg}$ ) and to decrease following higher doses (i.e., $5.6 \& 10.0 \mathrm{mg} / \mathrm{kg}$ ). The extent of rate suppression was, however, attenuated by a lower body weight. That is, response rates following higher doses of morphine tended to be higher when pigeons were maintained at a lower body weight than when they had been maintained at a higher body weight. For example, both the 5.6 and $10.0 \mathrm{mg} / \mathrm{kg}$ dose of morphine suppressed nearly all behavior when pigeons were maintained at $80 \%$ FFW but only the 10.0 $\mathrm{mg} / \mathrm{kg}$ dose suppressed all behavior for some pigeons when maintained at $70 \% \mathrm{FFW}$. Data for doses that reliably suppressed all, or nearly all, behavior are not presented in the other figures.

In FI trials (Figure 2), response rates following saline administration began at a very low level and increased throughout the latter part of each interval at both levels of food deprivation. Morphine increased rates of responding during the early part of each interval relative to the response rates maintained following saline. These rate increases early in the interval appear to be somewhat dose-dependent, with higher doses of morphine producing greater rate increases early in the interval. When pigeons were maintained at $80 \% \mathrm{FFW}$, the dose-dependent relation (see 2219) was not readily apparent (cf., 4244, 2238, \& 4571), but was apparent in 3 of 4 pigeons when maintained at 70\% FFW. Indexes of curvature (Figure 3) following saline administration 


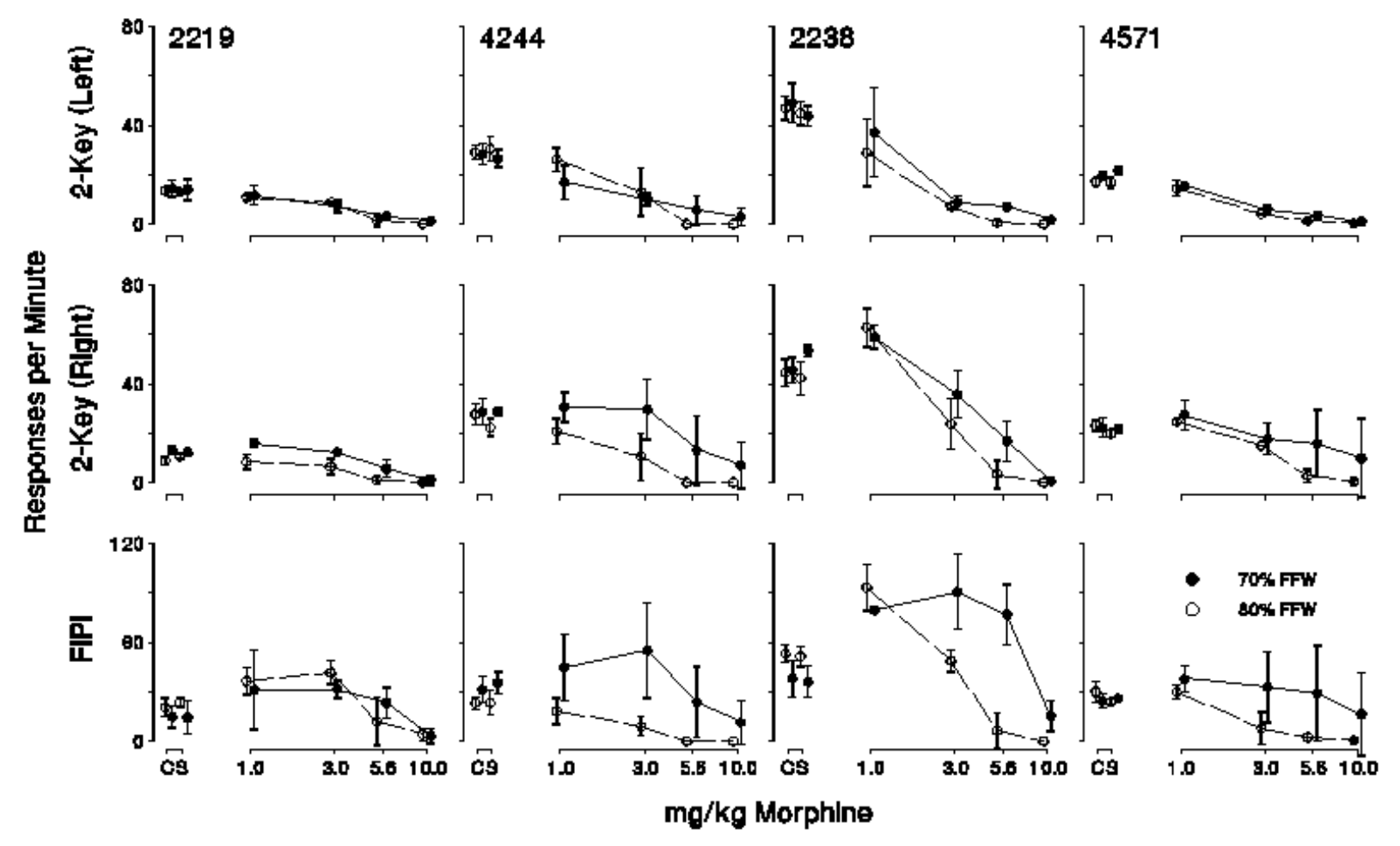

Figure 1. Response rates as a function of dose of morphine for each pigeon responding on each procedure under both levels of food deprivation. Points represent means of determinations of each dose. Error bars represent standard deviations. 


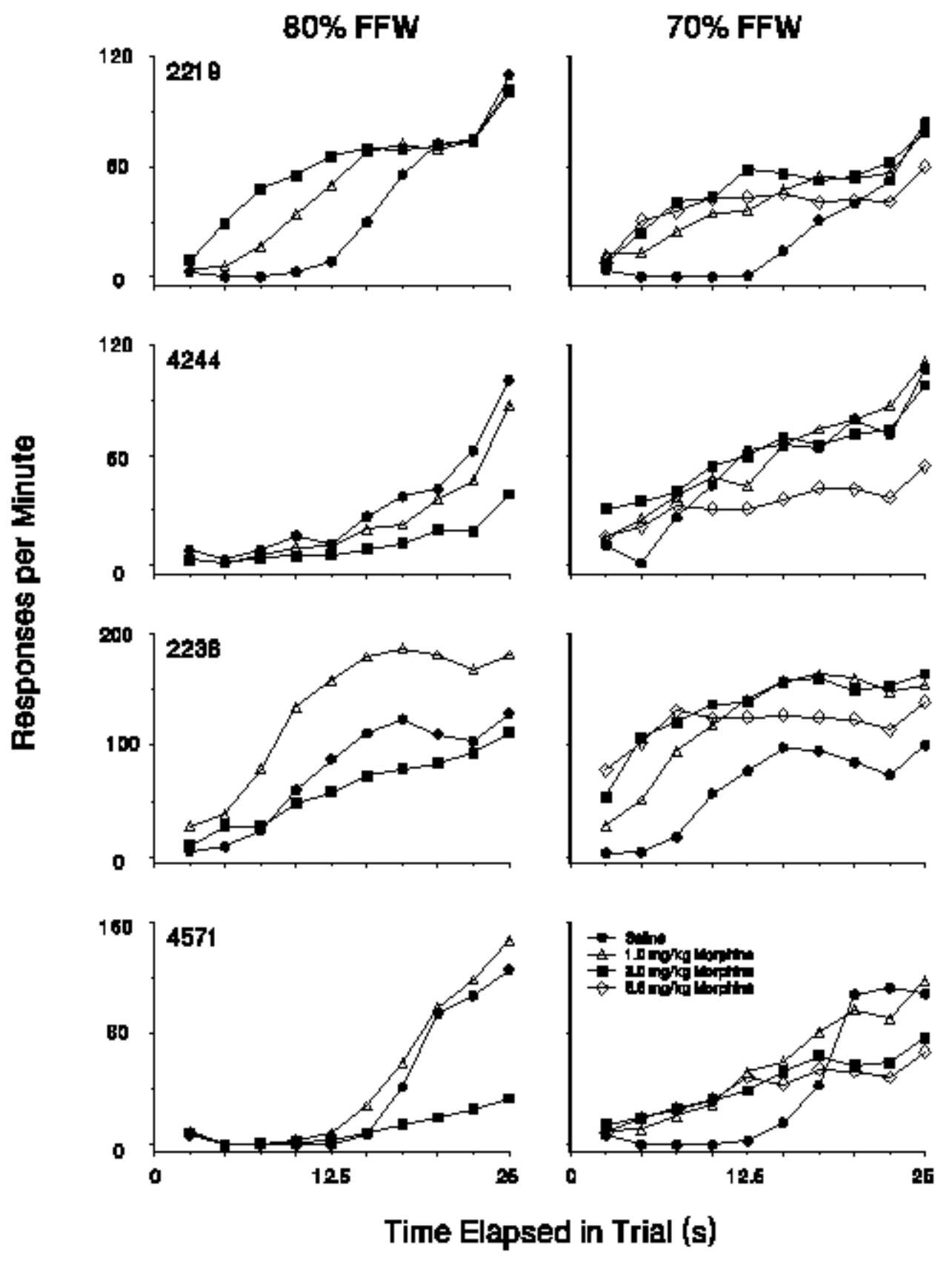

Figure 2. Response rates in consecutive 2.5-s bins of FI 25-s trials for saline and morphine conditions for each pigeon. Points represent means of determinations of each dose. 

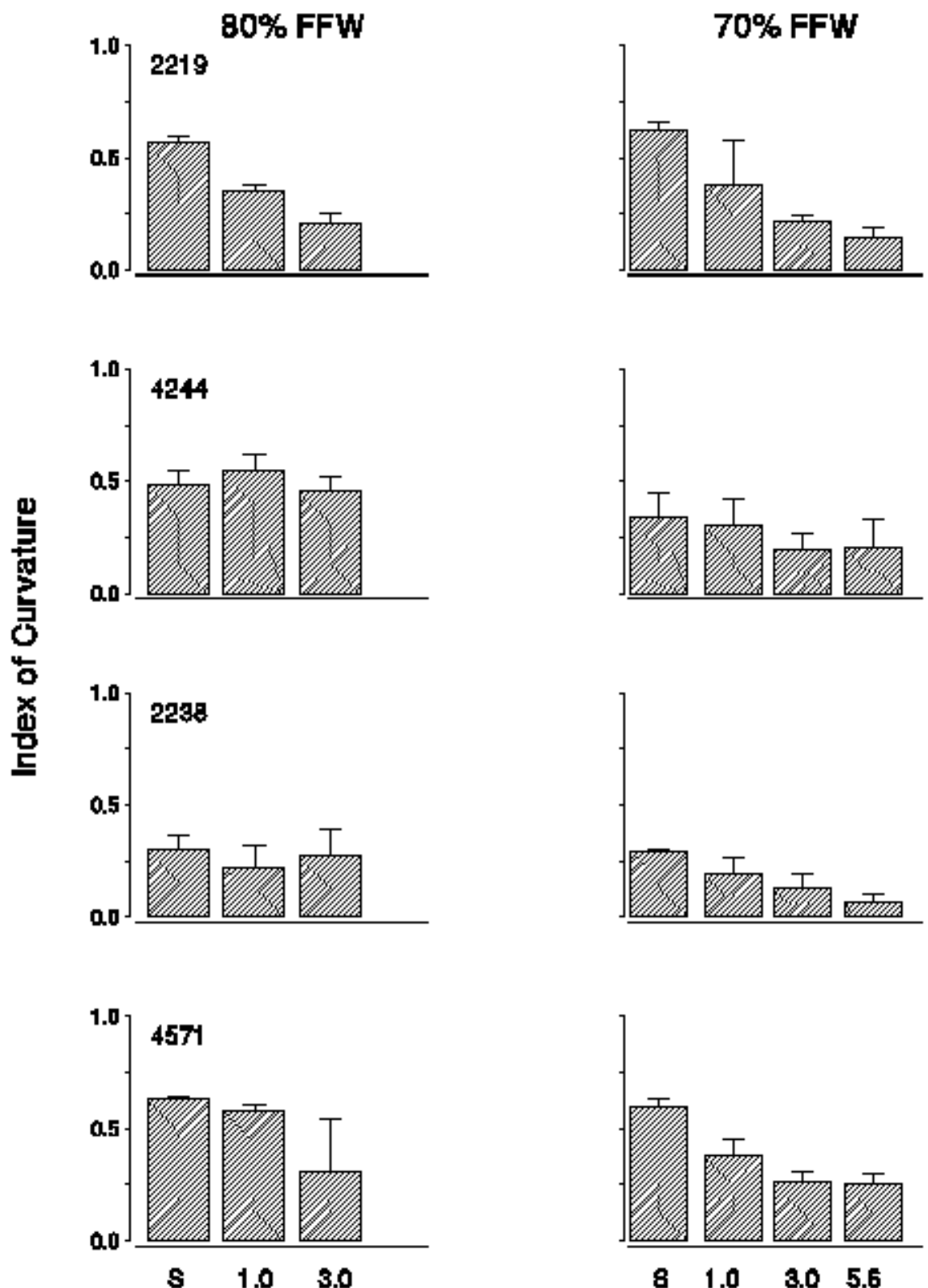

$\mathrm{mg} / \mathrm{kg}$ Morphine

Figure 3. Indexes of curvature in FI 25-s trials for saline and morphine conditions for each pigeon. Large bars represent means. Error bars represent standard deviations. 
were comparable across body weight conditions, ranging from 0.30 to 0.63 in the $80 \% \mathrm{FFW}$ condition and from 0.30 to 0.62 in the $70 \%$ FFW condition. These values indicate acceleration of response rates across the interval, typical of the response patterns generated by FI schedules of reinforcement. Morphine administration in the $80 \%$ FFW condition showed dose-dependent decreases in the index of curvature for 2 pigeons $(2219 \& 4571)$, while 3 pigeons $(2219,2238, \&$ 4571) showed dose-dependent decreases when maintained at $70 \% \mathrm{FFW}$. The decreases in the index of curvature as a function of dose primarily reflect the rate increases occurring early in the interval.

In PI trials (Figure 4), following saline administration, response rates began at a low or zero level and increased through the interval roughly up until the time in which a peck would produce a reinforcer in an FI trial (25 s into the trial). Response rates then decreased, eventually reaching a low or zero level where they remained until the end of a trial. During the early portion of peak interval trials, response rates were affected by morphine in a manner similar to the effect seen in FI trials. That is, response rates towards the start of the interval were increased, with higher doses of morphine producing greater rate increases. The dose-dependent effect of increasing low rates at the beginning of PI trials was more clearly shown in the $70 \%$ FFW condition than in the $80 \% \mathrm{FFW}$ condition. Following the peak rate of responding, response rates following morphine tended to decrease at about the same time they had following saline. Some doses, however, produced more erratic behavior where this did not hold true (i.e., $3.0 \mathrm{mg} / \mathrm{kg}$ for 4244 at $70 \%$ FFW). Following morphine administration, response rates in the latter part of intervals rarely fell to zero levels of responding. Secondary rises at the end of the interval and/or maintenance of moderate response rates were more prevalent following drug administration than following saline administration. This was true for both levels of food deprivation. The indexes of 

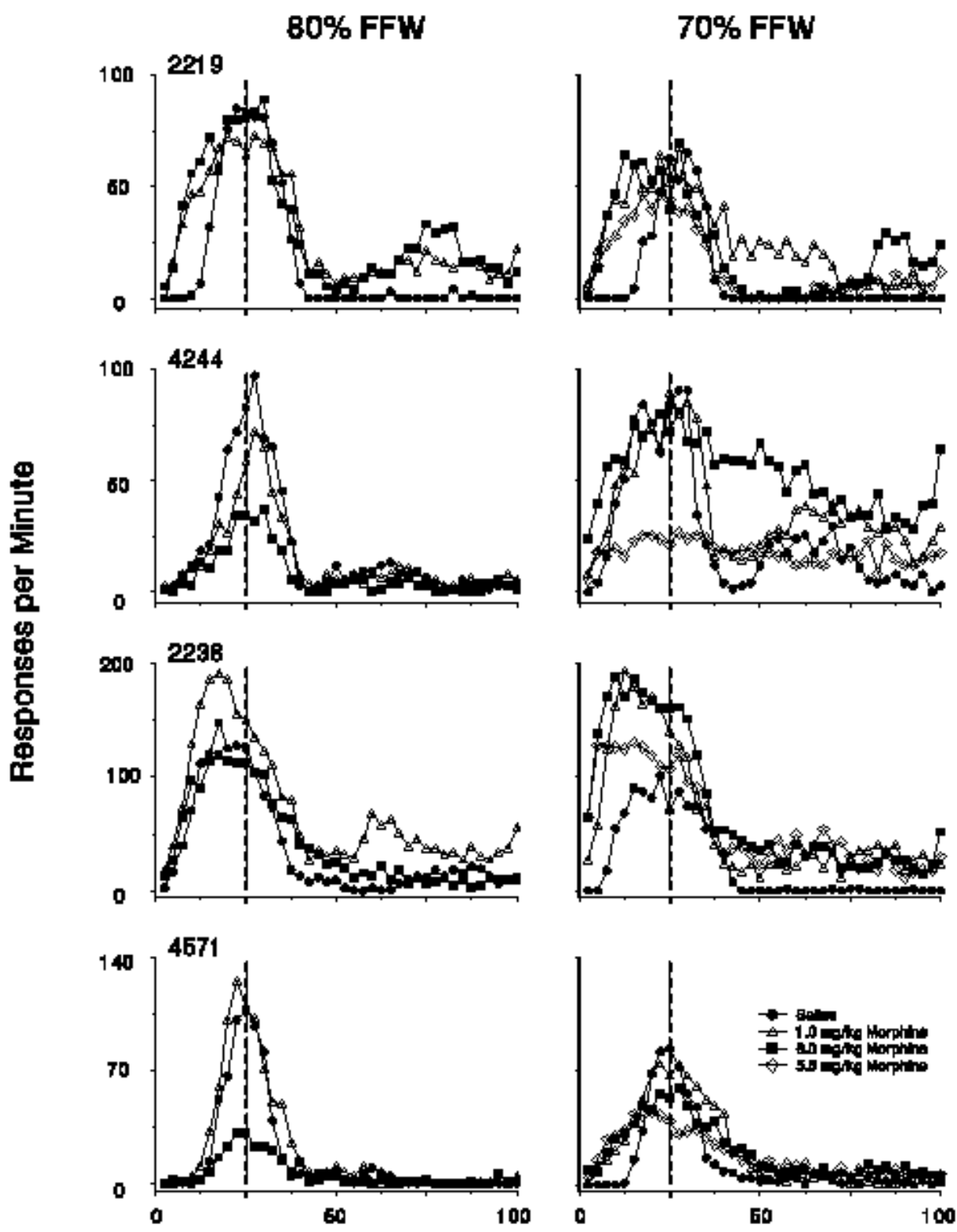

Time Elapsed in Trial (s)

Figure 4. Response rates in consecutive 2.5-s bins of PI trials for saline and morphine conditions for each pigeon. Points represent means of determinations of each dose. The dashed line indicates the point $25 \mathrm{~s}$ into a trial. 
timing behavior for PI trials (Figure 5) in the $80 \%$ FFW condition did not change systematically as a function of dose. That is, the time of peak responding and the spread of the peak function remained relatively constant in comparisons of doses of morphine and saline. However, there were dose-dependent changes in these indexes in the $70 \%$ FFW condition. The time of peak responding showed a decreasing trend as drug dose increased in 3 pigeons $(2219,2238, \& 4571)$. The spread around the peak function showed a general increasing trend with increases in drug dose for all subjects, although 2219 showed a decrease at the highest dose administered. The dose-dependent changes in PI indexes that were readily apparent in the $70 \%$ FFW condition and not the $80 \%$ FFW condition occurred despite a lack of systematic differences in saline performance between the two body weight conditions.

Responding in two-key trials is shown as a percentage of right-key responses (Figure 6). Following saline administration, the percentage of right-key pecks occurred at a low level until roughly the mid-point of each 50-s trial, at which point responding was almost equally distributed between the left and right keys. The percentage of right-key pecks continued to increase from that point until pigeons responded almost exclusively to the right key for the remainder of a trial. Examination of response patterns for trials both with and without reinforcers revealed no systematic differences. For this reason, all two-key trial data were included in the present analysis. Following morphine administration at $80 \%$ FFW, the percentage of right-key pecks early in trials increased in 2 of 4 pigeons, and showed slight changes in the other 2 pigeons. In the 2 pigeons that showed the greatest changes, the increase in responding occurred in a dose-dependent manner. That is, increasing doses of morphine produced greater increases in the percentage of right-key pecks relative to saline. The percentage of right-key pecks remained high during the second half of each trial following morphine although it was more erratic than 

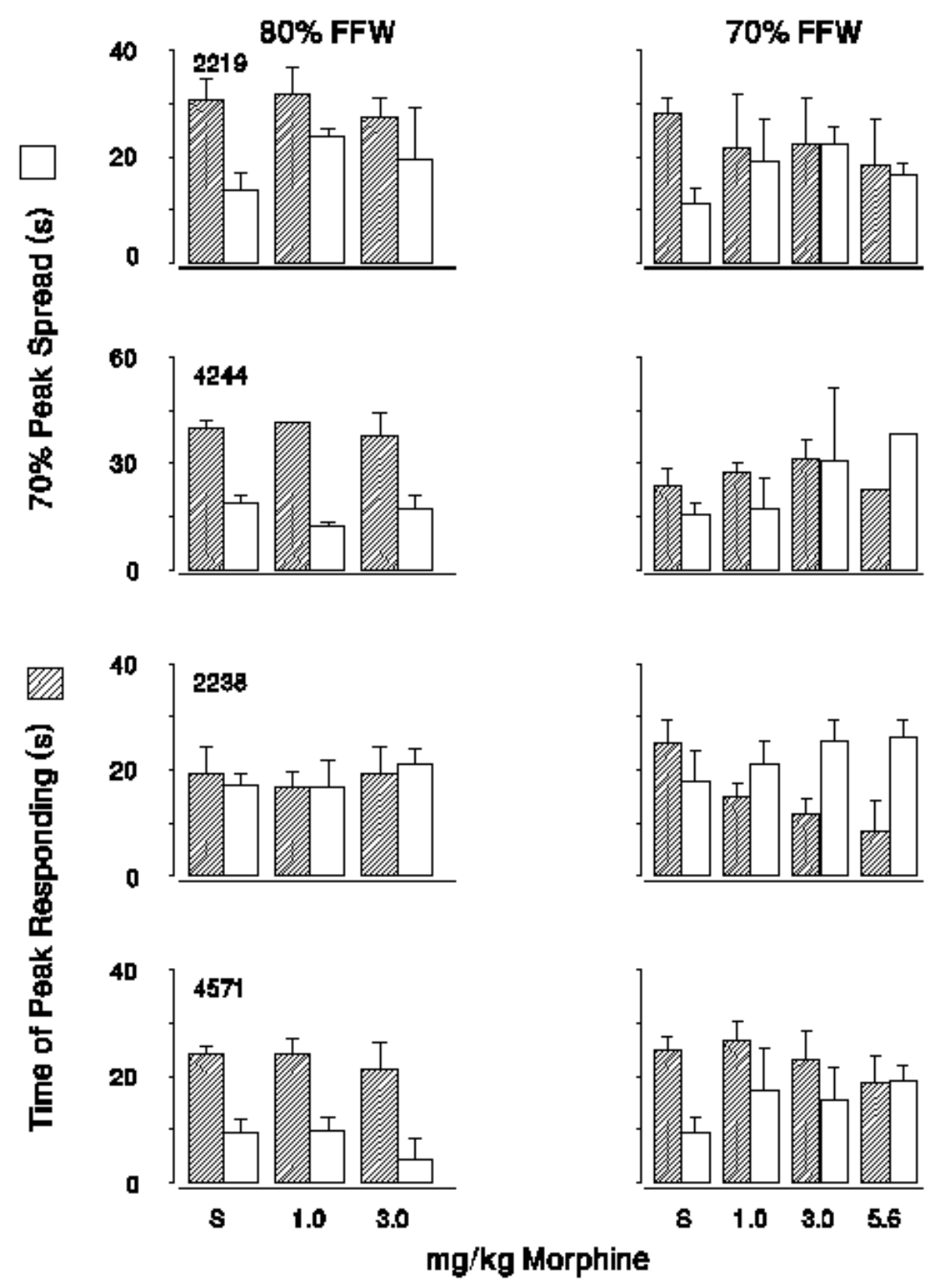

Figure 5. Times of peak response rates and the 70\% spread around that peak in PI trials for saline and morphine conditions for each pigeon. Filled bars represent mean times (in seconds) of peak rate responding. Open bars represent the distance between the two points on the function where $70 \%$ of the peak rate of responding occurs. Error bars represent standard deviations. No error bars are present for P4244 at the $5.6 \mathrm{mg} / \mathrm{kg}$ dose of morphine as the indexes from the determinations did not differ. 


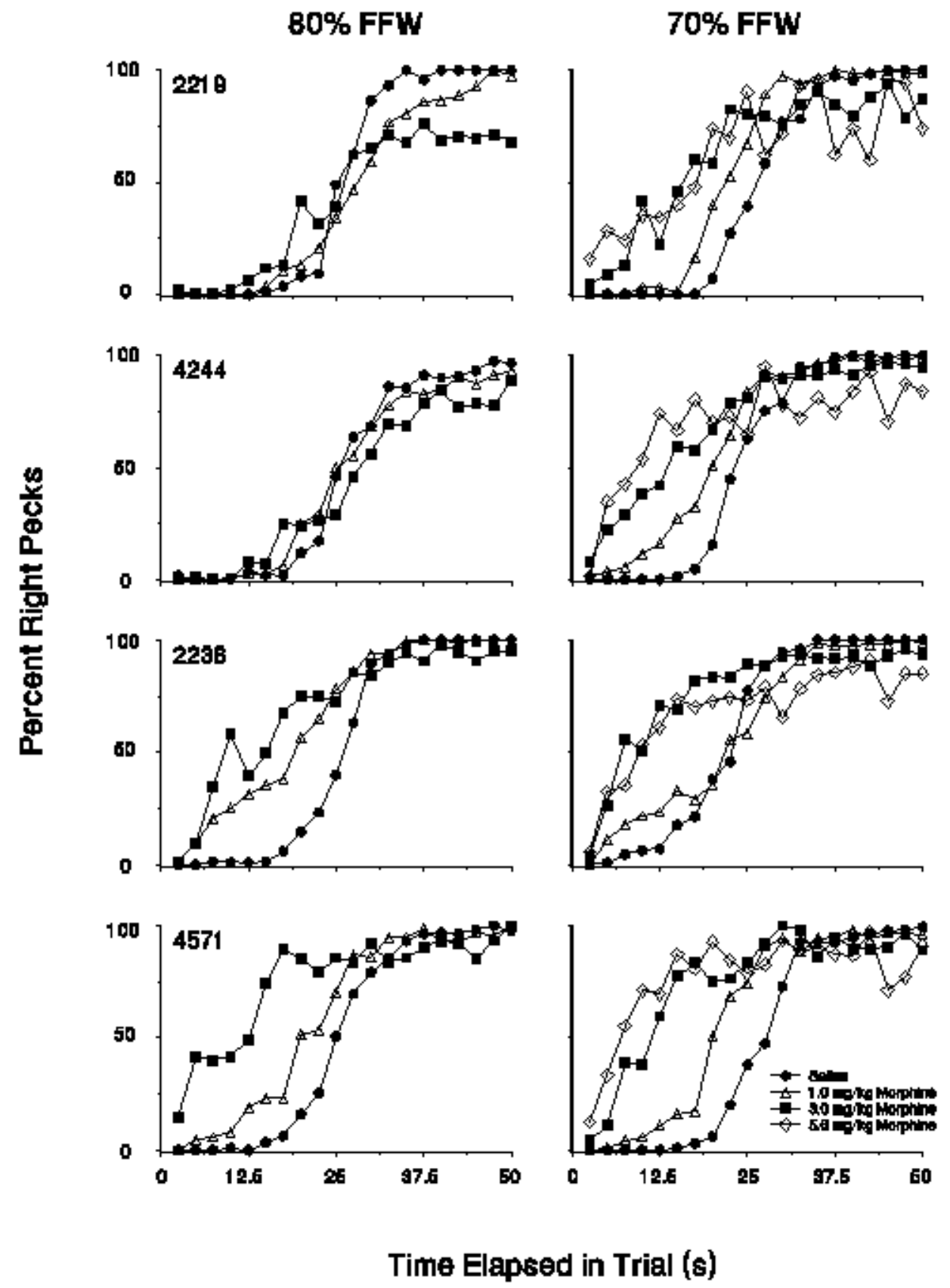

Figure 6. Percent of right-key pecks per 2.5-s bin of two-key trials for saline and morphine conditions for each pigeon. Points represent means of three determinations of each dose. 
the percentage of responding following saline. In the 70\% FFW condition, a similar increase in the percentage of right-key pecks early in trials occurred, but it occurred in all 4 pigeons. The percentage of right-key pecks systematically increased as a function of increasing dose of morphine for all pigeons. Similar to the $80 \%$ FFW condition, the percentage of right-key pecks remained high at the end of the interval, but following the highest dose of morphine that did not suppress behavior $(5.6 \mathrm{mg} / \mathrm{kg})$ the percentage maintained was more erratic than that maintained following saline. The increases observed in the percentage of right-key pecks early in the trials are clearly shown in the time at $50 \%$ of responding (T-50; Figure 7 ). In the $80 \%$ FFW condition, the T-50 showed decreases with increasing doses of morphine for 2 of 4 pigeons and showed increases in the limen (a measure of the slope of the functions shown in Figure 6) for 2 of 4 pigeons. All 4 pigeons in the $70 \%$ FFW condition showed changes in the T-50 as a function of dose of morphine, although only 3 show systematic changes with each dose. The limen is also shown to increase following higher doses of morphine relative to saline. Comparisons between saline performances at the two body weights do not reveal any systematic differences. Rates of reinforcment obtained following saline and following morphine were also compared. Following saline, the number of reinforcers obtained in a session varied between 3 and 14. Following administration of morphine, obtained reinforcers were not found to reliably differ from these values and they did not change in any consistent manner.

In the rate-dependency plots (Figures $8 \& 9$ ), points falling above the dashed line indicate rate increases and points falling below the line indicate rate decreases following morphine administration relative to rates following saline. The rate-dependency plots only present data from the $70 \%$ FFW condition, as it was that condition that produced the most reliable and systematic alterations in behavior when morphine was administered. Low saline response rates in 

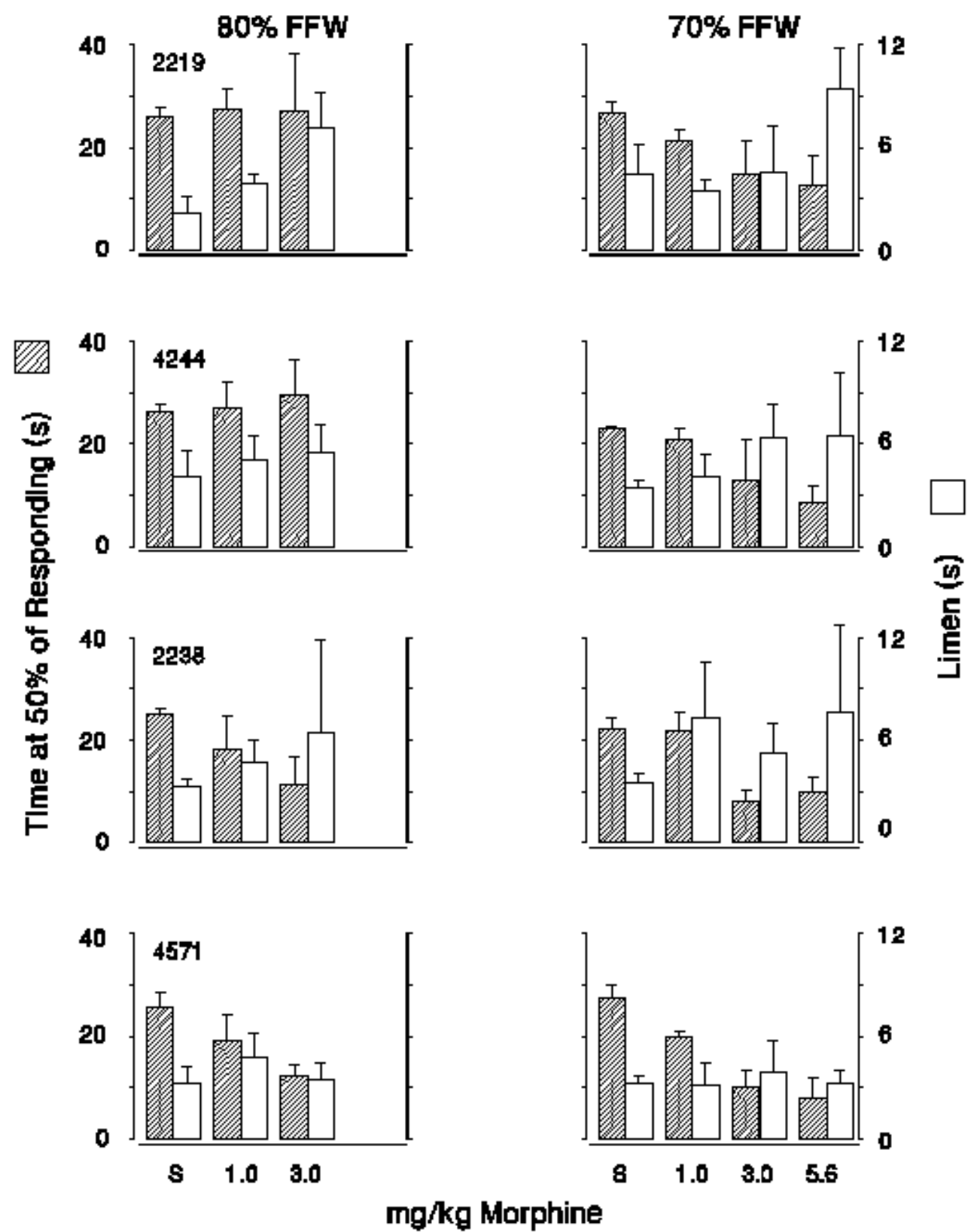

Figure 7. Times of 50\% right-key responding and difference limens in two-key trials for saline and morphine conditions for each pigeon. Filled bars represent mean times (in seconds) of 50\% right-key responding. Open bars represent mean difference limens (half the distance between $25 \%$ and $75 \%$ right-key responding). Error bars represent standard deviations. 


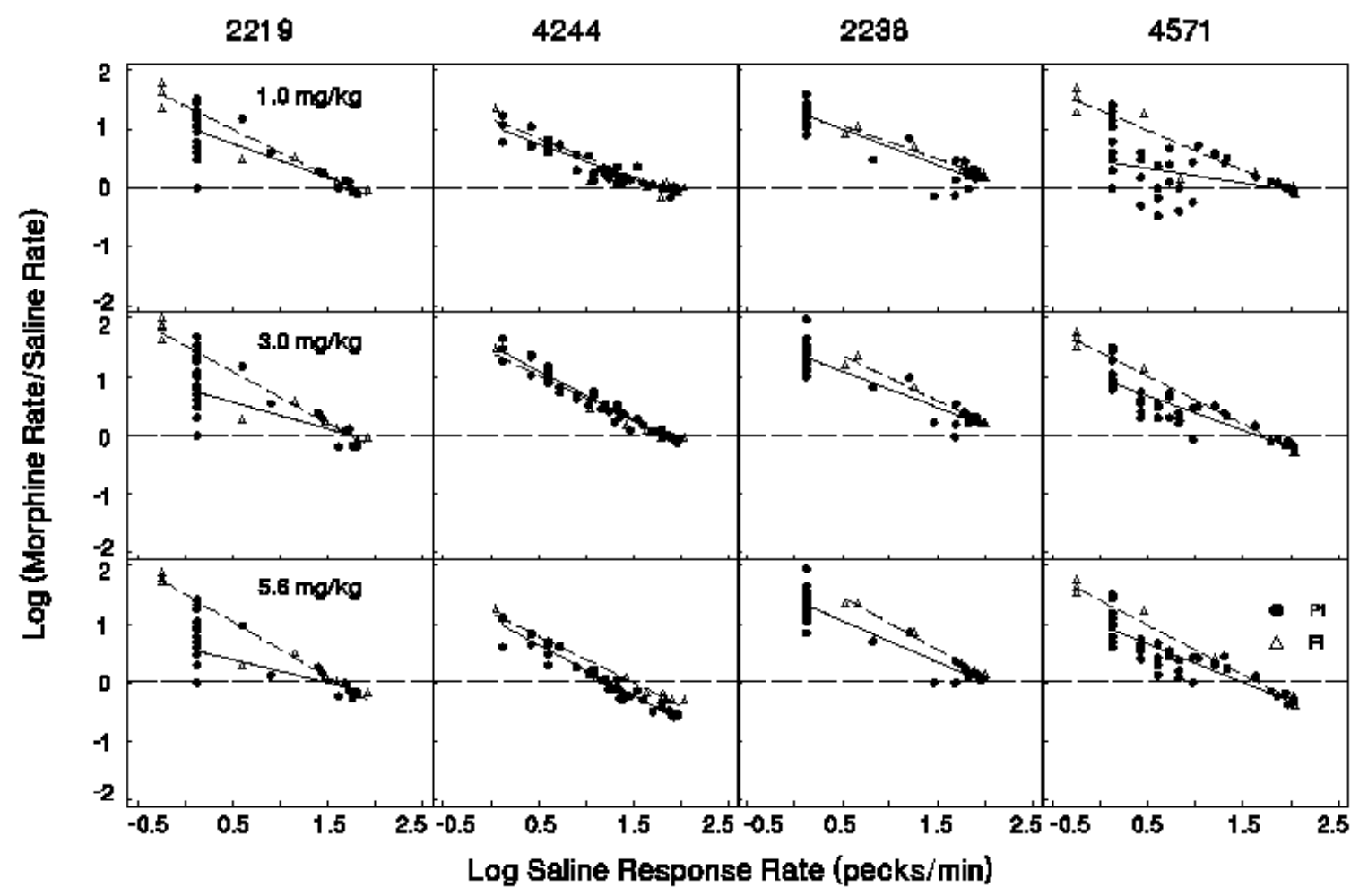

Figure 8. Rate-dependency plots for fixed-interval and peak-interval trials for each pigeon following morphine administration. Dashed lines indicate saline response rates. Points falling above the dashed line indicate rate increases, points falling below the dashed line represent rate decreases relative to saline response rates. 


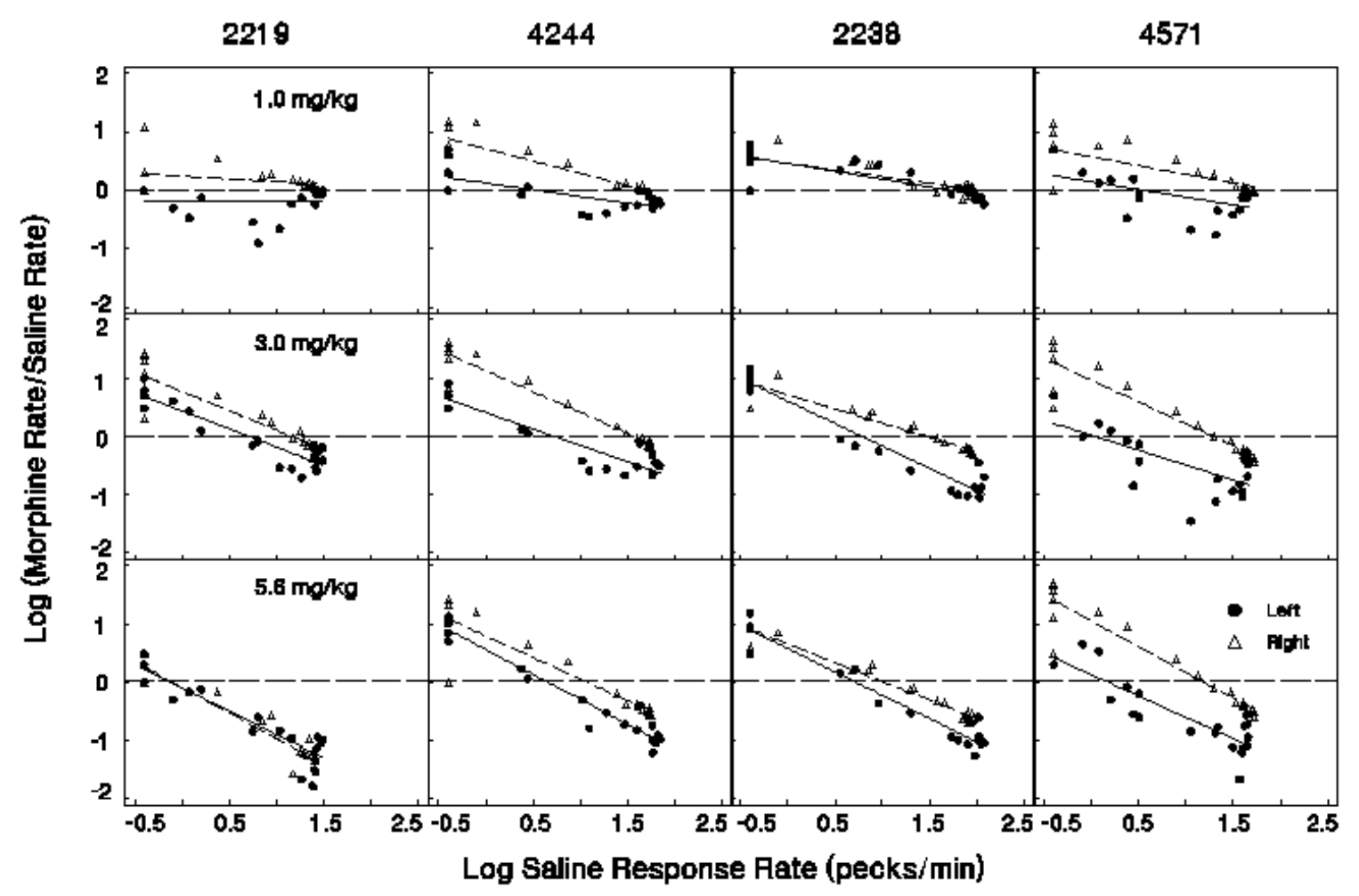

Figure 9. Rate-dependency plots for two-key trials for each pigeon following morphine administration. Dashed lines indicate saline response rates. Points falling above the dashed line indicate rate increases, points falling below the dashed line represent rate decreases relative to saline response rates. 
FI trials (open triangles, Figure 8) were increased and high saline response rates were maintained or slightly decreased following morphine administration at all doses. The highest dose of morphine shown $(5.6 \mathrm{mg} / \mathrm{kg})$ appeared to have had a greater rate-decreasing effect on high-rate responding than did the lower doses of morphine. There were no other systematic differences among the pigeons' FI behavior across morphine doses. A similar effect is shown in PI trials (filled circles, Figure 8), with low saline response rates being increased and high saline response rates being maintained or slightly decreased following morphine administration at all doses. The rate-increasing effect of morphine on low-rate saline responding is, however, much more variable in comparison to FI trials. This can be seen in the "tail" of data points starting near the dashed line representing control rates of responding and extending straight upwards at the lowest saline response rates (on the left side of each panel). This 'tail'" of data points is responsible for the slope of the PI regression being less steep than that of the FI function. An examination of Figure 4, showing the PI response patterns suggests that a fair portion of the "tail" seen in the rate-dependency plot is due to the relatively smaller rate increases obtained in the latter portion of PI trials.

Data from two-key trials were also analyzed using rate-dependency plots separately for left- and right-key responses (Figure 9, closed circles and open triangles respectively). For both the left and right keys, low response rates following saline administration were increased following morphine administration. Overall, the right-key plots tended to fall higher on the yaxis than did the left-key plots. In 8 of 12 comparisons between right- and left-key data, increases in low-rate responding were greater for right-key pecks than for left-key pecks. For both left and right keys, high rates of responding following saline administration remained unchanged or decreased following morphine administration. In 10 of 12 comparisons between 
right- and left-key data, decreases in high-rate responding were greater for left-key responding than for right-key responding. The rate decreases were clear and consistent at both the 3.0 and $5.6 \mathrm{mg} / \mathrm{kg}$ doses of morphine for the left key, but only for the $5.6 \mathrm{mg} / \mathrm{kg}$ dose of morphine for the right key. Both differential rate increases and decreases reflect the earlier switching from left to right keys (Figures $6 \& 7$ ). That is, response rates generally increased early in trials on right keys with corresponding decreases early in trials of response rates on the left key. These two changes contributed to an average earlier switch from left-key to right-key responding as depicted in Figures 6 and 7.

\section{$\underline{\text { d-Amphetamine }}$}

Response rates changed as a function of dose following $\underline{\mathrm{d}}$-amphetamine administration at both levels of food deprivation across each of the experimental conditions (Figure 10). Control and saline response rates at $70 \%$ FFW were higher in 6 of 9 comparisons with $85 / 90 \%$ FFW. The lowest dose of $\underline{\mathrm{d}}$-amphetamine $(0.1 \mathrm{mg} / \mathrm{kg})$ was only administered in the first body weight condition for each pigeon and then dropped due to a lack of observed changes in behavior. Leftkey response rates in two-key trials were maintained at low doses of $\underline{\mathrm{d}}$-amphetamine, but decreased with increasing dose. These changes were observed at both $70 \%$ and $85 / 90 \%$ FFW. Slightly higher response rates were maintained at 70\% FFW condition. Right-key response rates in two-key trials were maintained across a larger range of doses $(0.1-1.7 \mathrm{mg} / \mathrm{kg})$, with rates decreasing at the highest two doses. In 2 of 3 pigeons, response rates were maintained at higher levels at $70 \%$ FFW. Fixed-interval and peak-interval response rates were maintained by the lowest dose and decreased at higher doses for 2 of 3 pigeons at 85/90\% FFW. In the remaining pigeon, and in all 3 pigeons at $70 \% \mathrm{FFW}$, response rates increased at low doses of $\underline{\mathrm{d}}-$ amphetamine and then decreased at the highest two doses of $\underline{\mathrm{d}}$-amphetamine. Response rates 

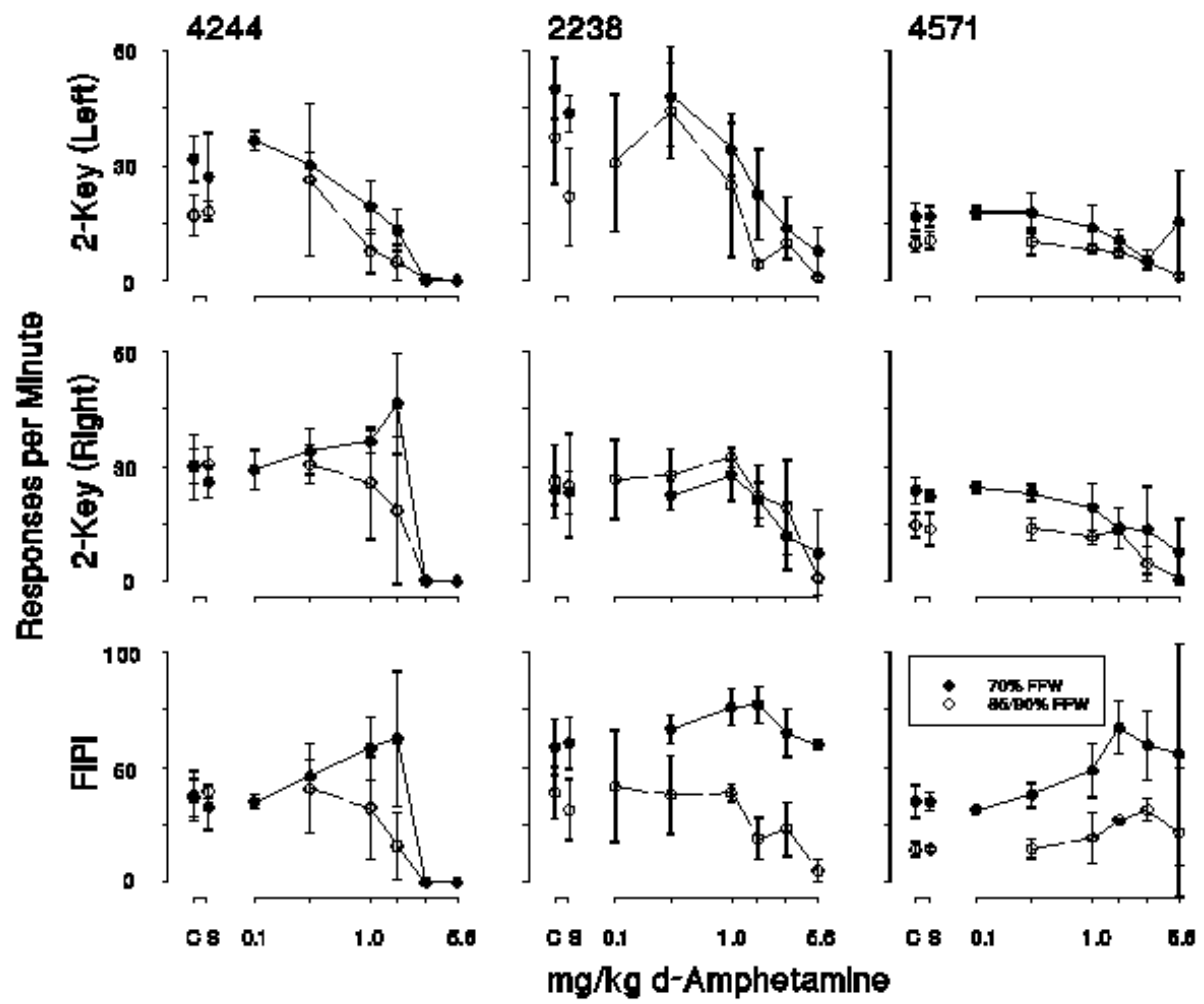

Figure 10. Response rates as a function of dose of $\underline{d}$-amphetamine for each pigeon responding on each procedure under both levels of food deprivation. Points represent means of determinations of each dose. Error bars represent standard deviations. 
were higher at $70 \%$ FFW for each of the 3 pigeons during trials of these types. Data for doses that reliably suppressed all, or nearly all, behavior are not presented in the figures showing quantitative indexes of behavior.

In FI trials (Figures $11 \& 12$ ), response rates following saline administration began at a very low level and increased throughout the latter part of each interval at both levels of food deprivation. To make it easier to observe the effects of each dose, Figure 11 shows the effects of the lower doses of $\underline{\mathrm{d}}$-amphetamine $(0.1,0.3, \& 1.0 \mathrm{mg} / \mathrm{kg})$ and saline and Figure 12 shows the effects of the higher doses of $\underline{\mathrm{d}}$-amphetamine $(1.7,3.0, \& 5.6 \mathrm{mg} / \mathrm{kg})$ and saline. At 85/90\% FFW, response rates decreased late in the interval relative to saline as a function of increasing $\underline{\mathrm{d}}-$

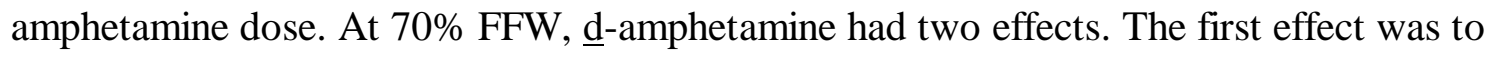
decrease response rates relative to saline late in the interval as a function of increasing drug dose. The second effect was to increase response rates relative to saline early in the interval as a function of increasing drug dose. These changes in response rates at both body weights are shown in the indexes of curvature (Figure 13). All pigeons, at both body weights, show systematic decreases in the index of curvature as a function of increasing dose of $\underline{\mathrm{d}}-$ amphetamine. The highest dose of $\underline{\mathrm{d}}$-amphetamine $(5.6 \mathrm{mg} / \mathrm{kg})$ at $70 \% \mathrm{FFW}$, however, had no further decreasing effect on the index of curvature relative to the index derived at $3.0 \mathrm{mg} / \mathrm{kg} \underline{\mathrm{d}}-$ amphetamine.

In PI trials (Figures $14 \& 15$ ), following saline administration, response rates began at a low level and increased through the interval roughly until the time at which a peck would produce a reinforcer in an FI trial (25 s into the trial). Response rates then decreased, eventually reaching a low level where they remained until the end of a trial. During the early portion of peak interval trials, response rates were affected by $\underline{\mathrm{d}}$-amphetamine in a manner similar to that 

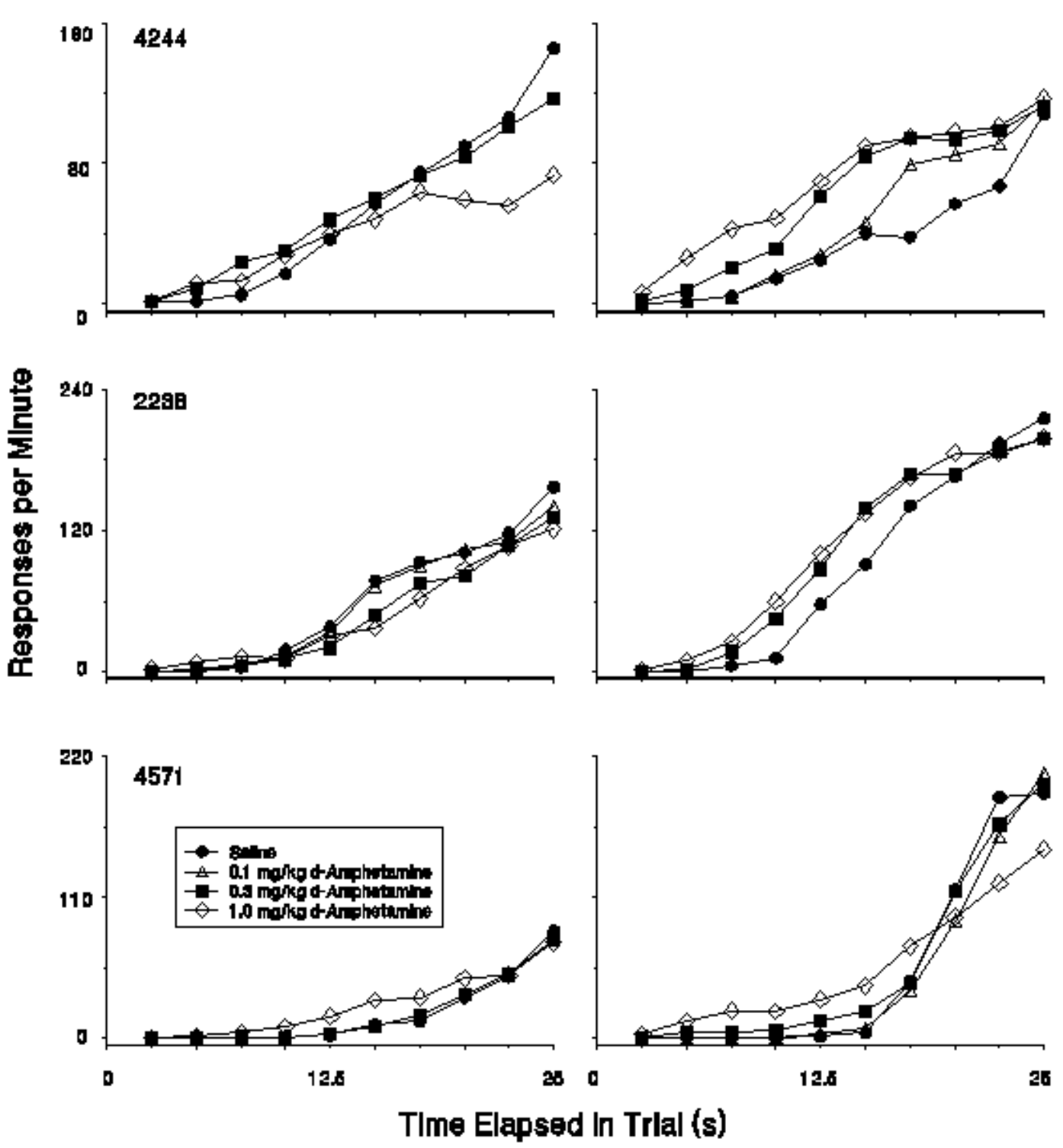

Figure 11. Response rates in consecutive 2.5-s bins of FI 25-s trials for saline and low doses of $\underline{\mathrm{d}}$ amphetamine for each pigeon. Points represent means of determinations of each dose. 
B5/90\% FPW
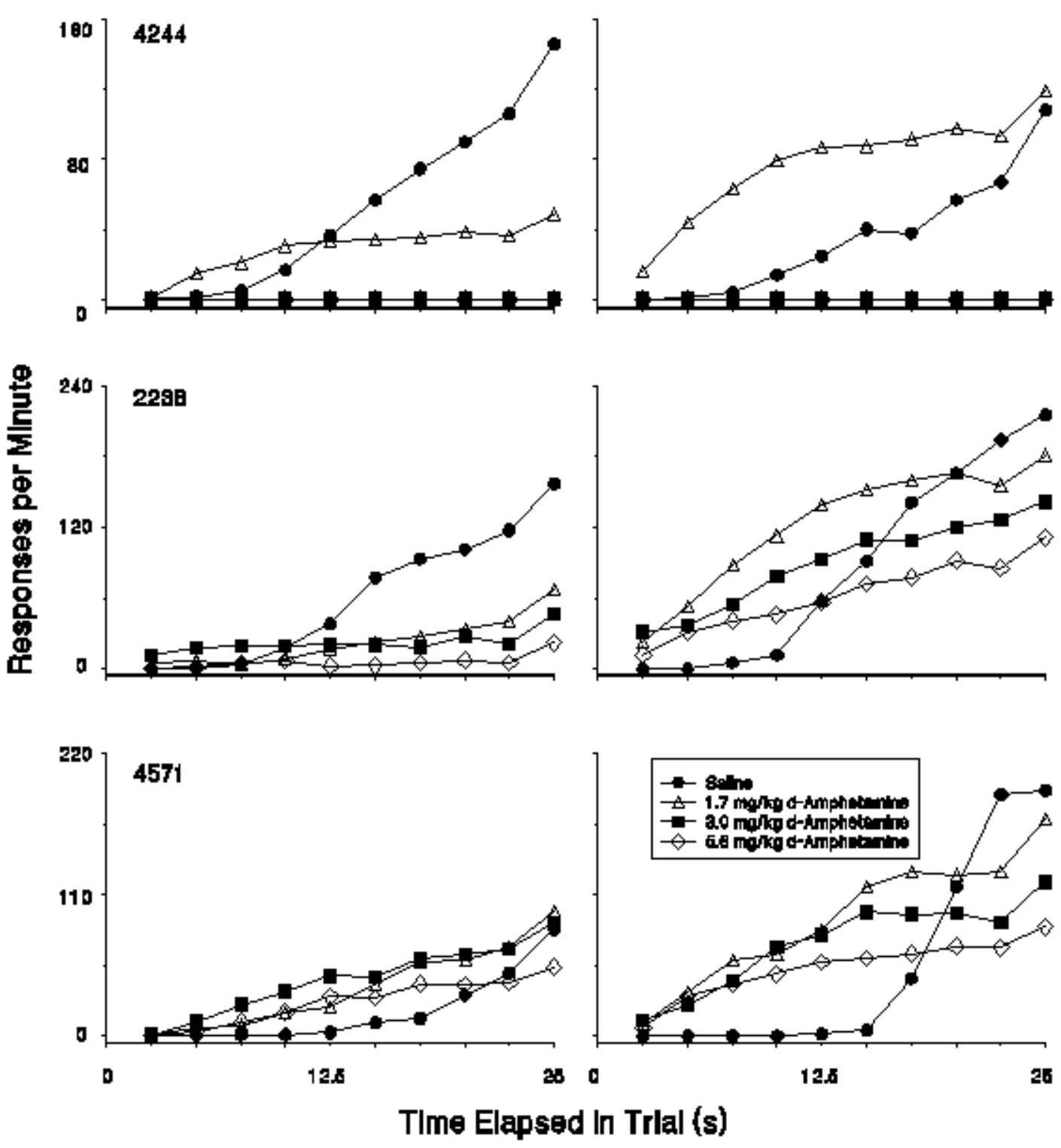

Figure 12. Response rates in consecutive 2.5-s bins of FI 25-s trials for saline and high doses of d-amphetamine for each pigeon. Points represent means of determinations of each dose 
$85 / 90 \%$ FFW
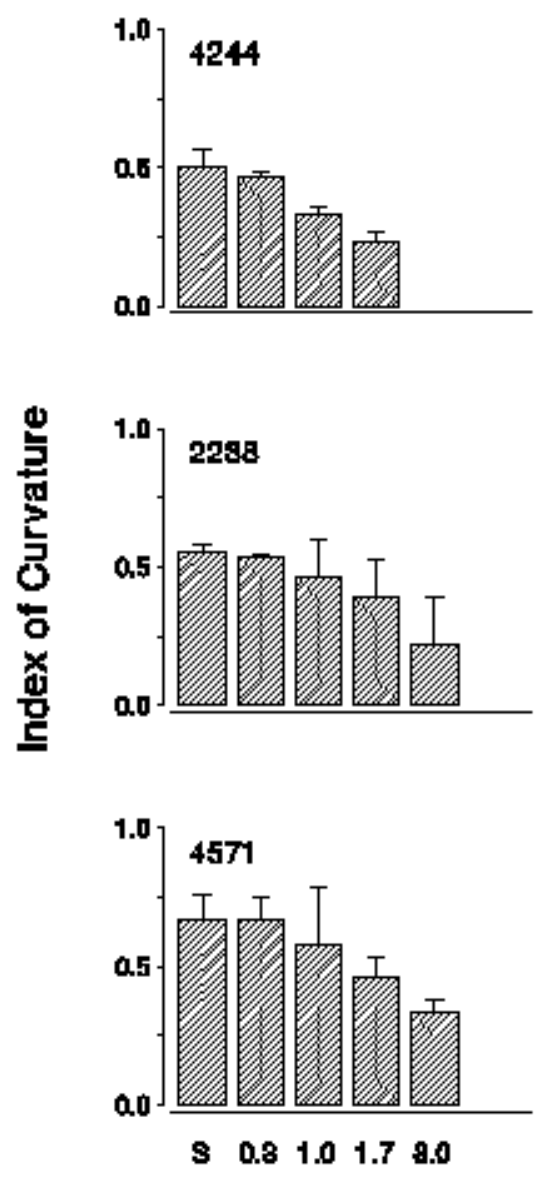

$70 \%$ FFW
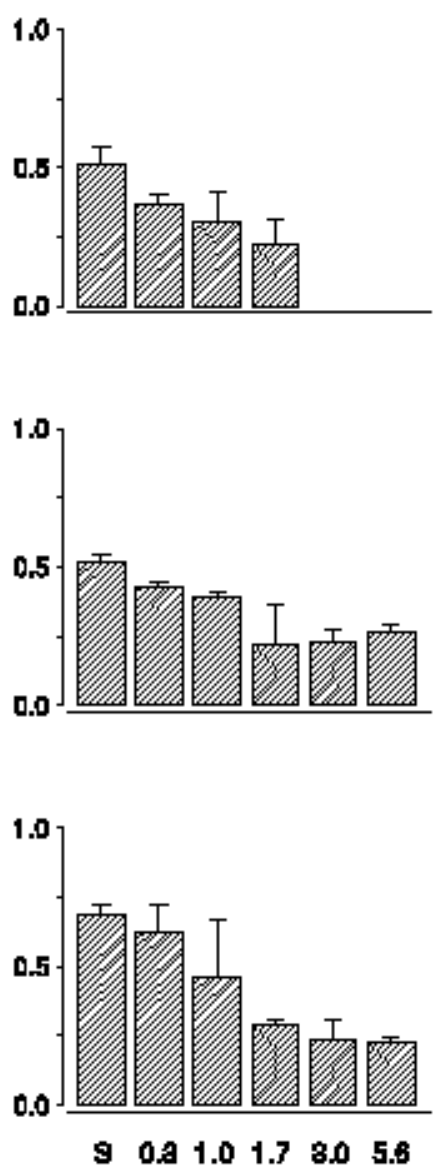

$\mathrm{mg} / \mathrm{kg} \mathrm{d}$-Amphetamlne

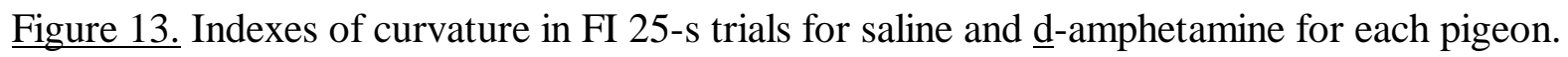
Large bars represent means. Error bars represent standard deviations. 
85/90\% FFW
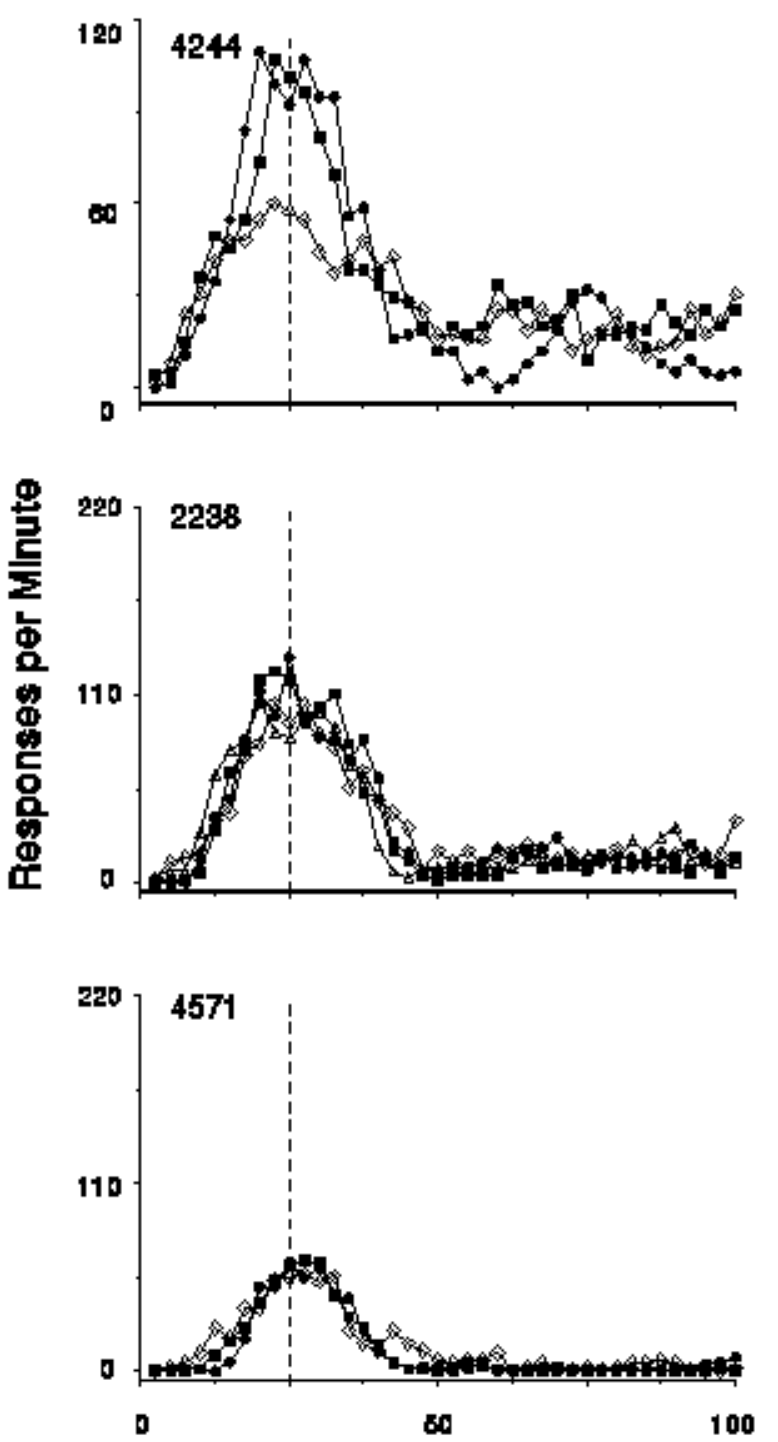

$70 \%$ FFW
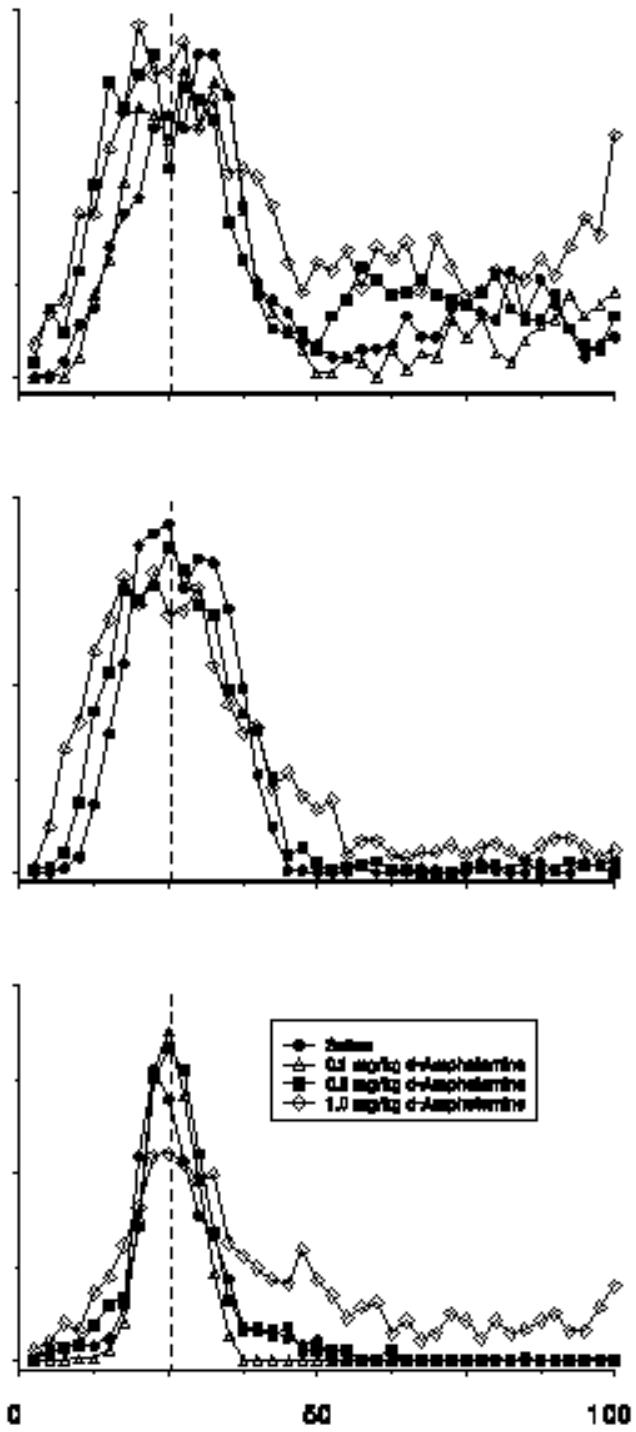

TIme Elapsed In Trlal (s)

Figure 14. Response rates in consecutive 2.5-s bins of PI trials for saline and low doses of $\underline{\mathrm{d}}$ amphetamine for each pigeon. Points represent means of determinations of each dose. The dashed line indicates the point $25 \mathrm{~s}$ into a trial. 
85/90\% FFW
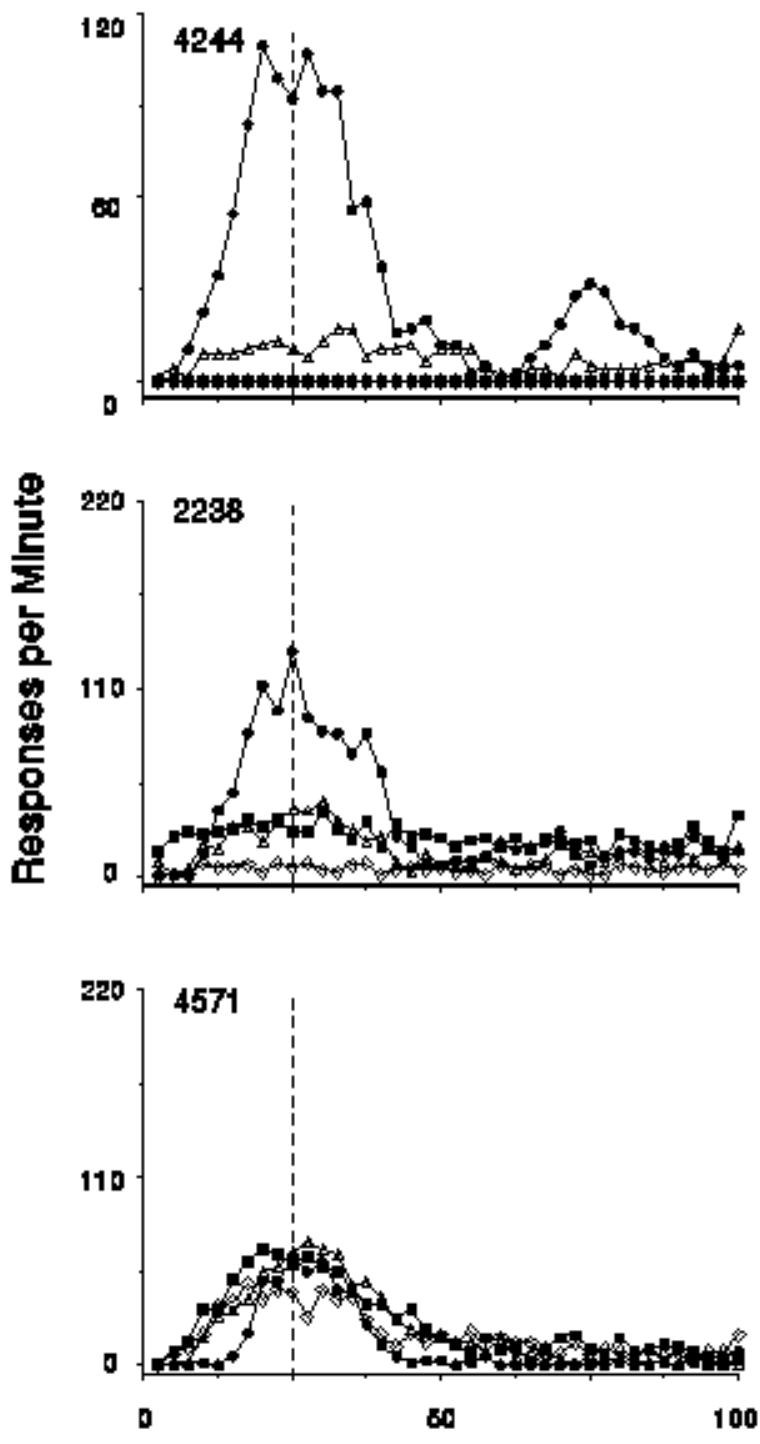

$70 \%$ FFW
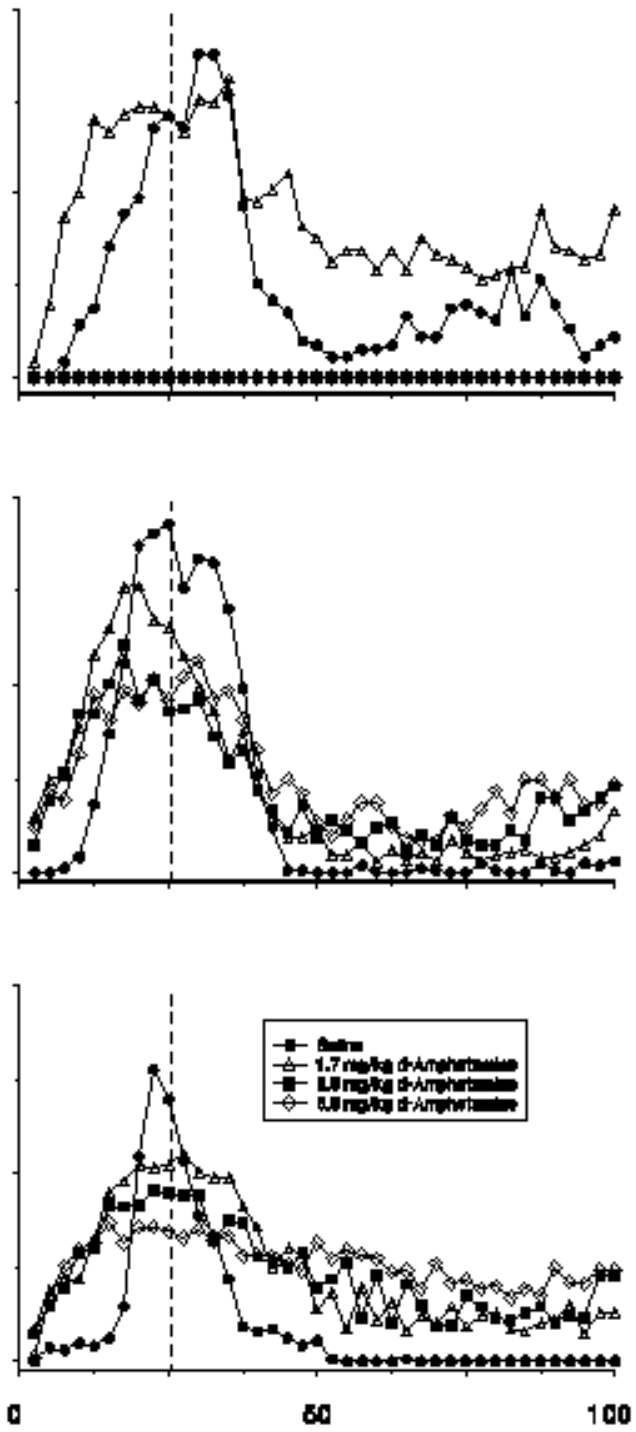

Tlme Elepsed In Trlal (s)

Figure 15. Response rates in consecutive 2.5-s bins of PI trials for saline and high doses of $\underline{\mathrm{d}}$ amphetamine for each pigeon. Points represent means of determinations of each dose. The dashed line indicates the point $25 \mathrm{~s}$ into a trial. 
seen in FI trials. That is, response rates near the start of the interval were increased, with higher doses of $\underline{\mathrm{d}}$-amphetamine producing greater rate increases than lower doses. At $70 \%$ FFW, early interval rate-increases were more reliable and robust than at 85/90\% FFW. Furthermore, there were greater differences in response rates between drug doses at $70 \% \mathrm{FFW}$. Rate increases were also observed in the latter portion of each interval at both $70 \%$ and $85 / 90 \%$ FFW, though higher rates or secondary rises were more likely to be observed in the $70 \%$ FFW condition. The peak time for PI trials (Figure 16) did not show systematically change at 85/90\% FFW, though there were some indications of increased spread of the peak function with the $3.0 \mathrm{mg} / \mathrm{kg}$ dose of $\underline{\mathrm{d}}-$ amphetamine. Similarly, at $70 \%$ FFW, the measure of peak time did not reliably change as a function of drug dose, but higher doses of drug did produce increases in the spread of the peak function relative to following saline.

Responding in two-key trials is shown as a percentage of right-key responses (Figures 17 \& 18). Performance following saline administration was nearly identical to that obtained under saline conditions when morphine was being tested. At 85/90\% FFW there were mixed effects of low doses of $\underline{\mathrm{d}}$-amphetamine. The percentage of right-key responding increased early in the interval in some pigeons, whereas a low percentage was maintained longer than following saline administration in other pigeons. At higher doses, $1.7 \mathrm{mg} / \mathrm{kg}$ reliably produced earlier changes in the proportion of responses away from the left key and towards the right key. At higher doses this was less prevalent and in many cases behavior became much more variable (see $5.6 \mathrm{mg} / \mathrm{kg}$ for pigeons $2238 \& 4571$, Figure 18). The percentage of right-key pecks was more reliably affected at $70 \%$ FFW, with the tendency being for the percentage of right-key pecks to increase earlier in the interval with increasing doses of $\underline{\mathrm{d}}$-amphetamine. Responding in the second half of trials was also not exclusively to the right key at $70 \% \mathrm{FFW}$ as indicated by the response patterns 


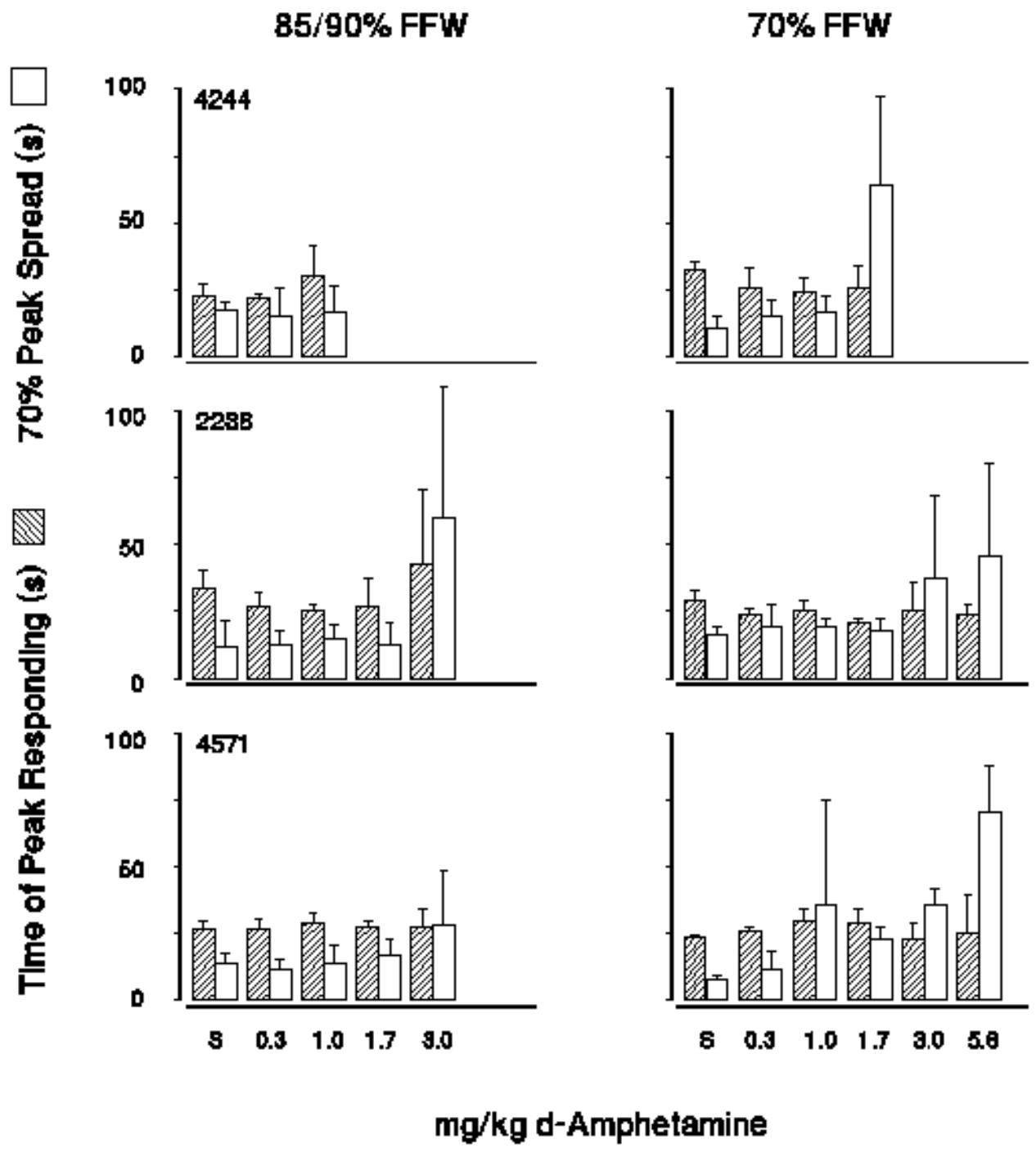

Figure 16. Times of peak response rates and the 70\% spread around that peak in PI trials for saline and $\underline{d}$-amphetamine conditions for each pigeon. Filled bars represent mean times (in seconds) of peak rate responding. Open bars represent the distance between the two points on the function where $70 \%$ of the peak rate of responding occurs. Error bars represent standard deviations. 
65/90\% FFW
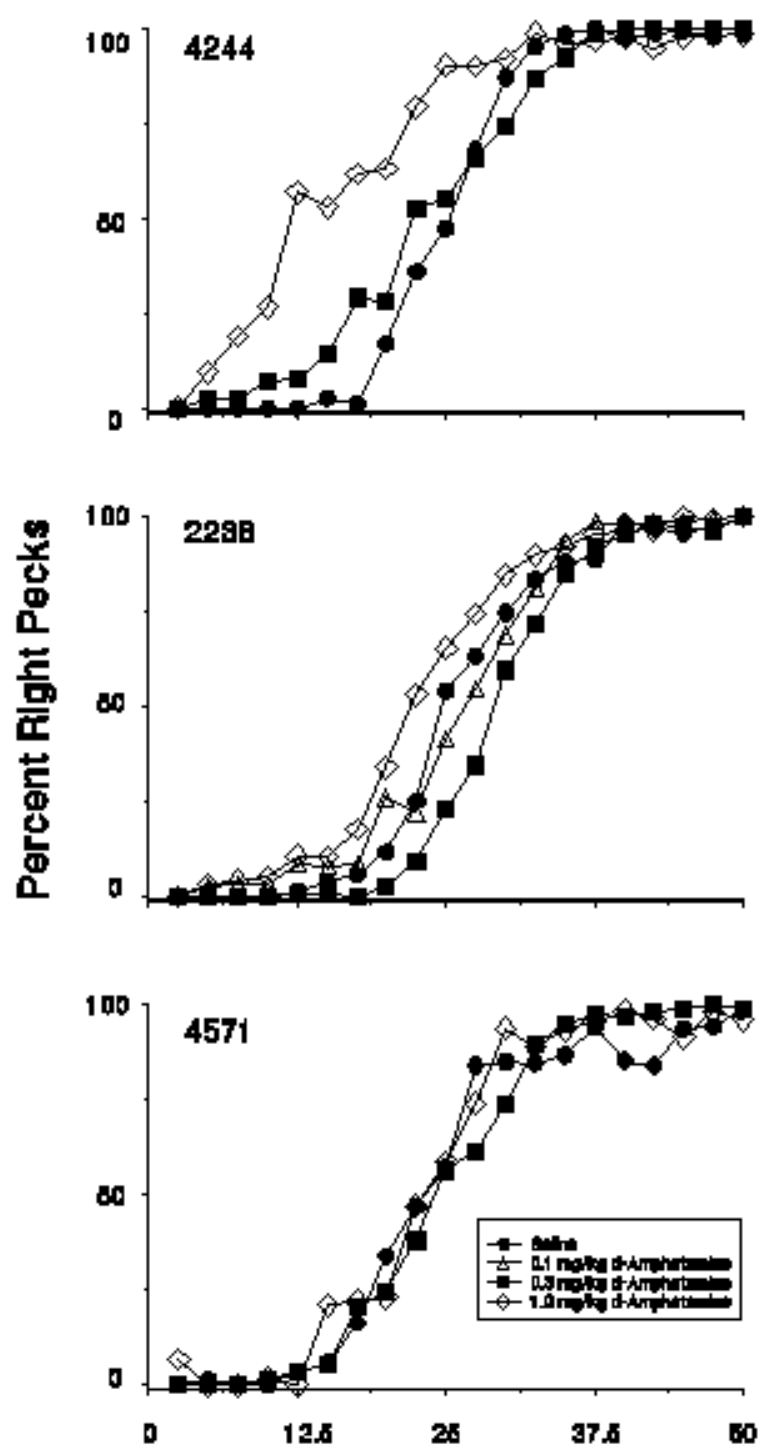

$70 \% \mathrm{FFW}$
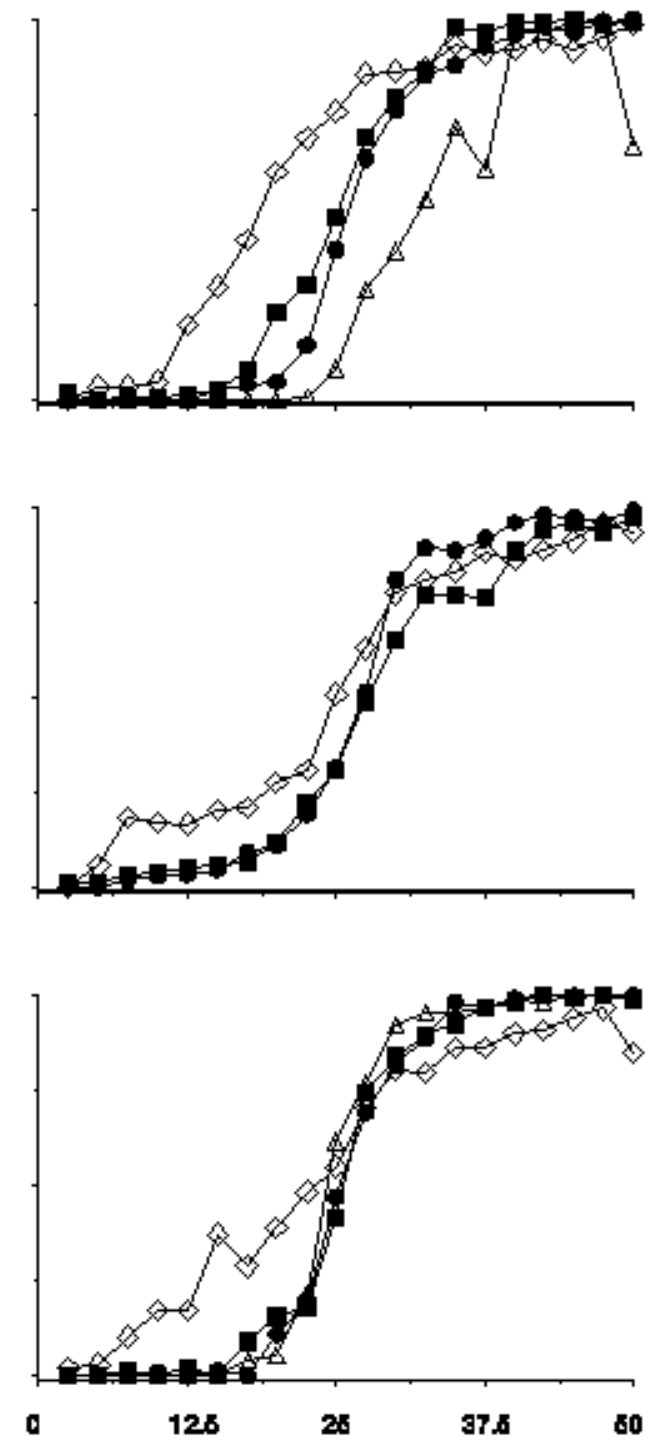

Time Elapsed in Trial (s)

Figure 17. Percent of right-key pecks per 2.5-s bin of two-key trials for saline and low doses of d-amphetamine conditions for each pigeon. Points represent means of three determinations of each dose. 
65/90\% FFW
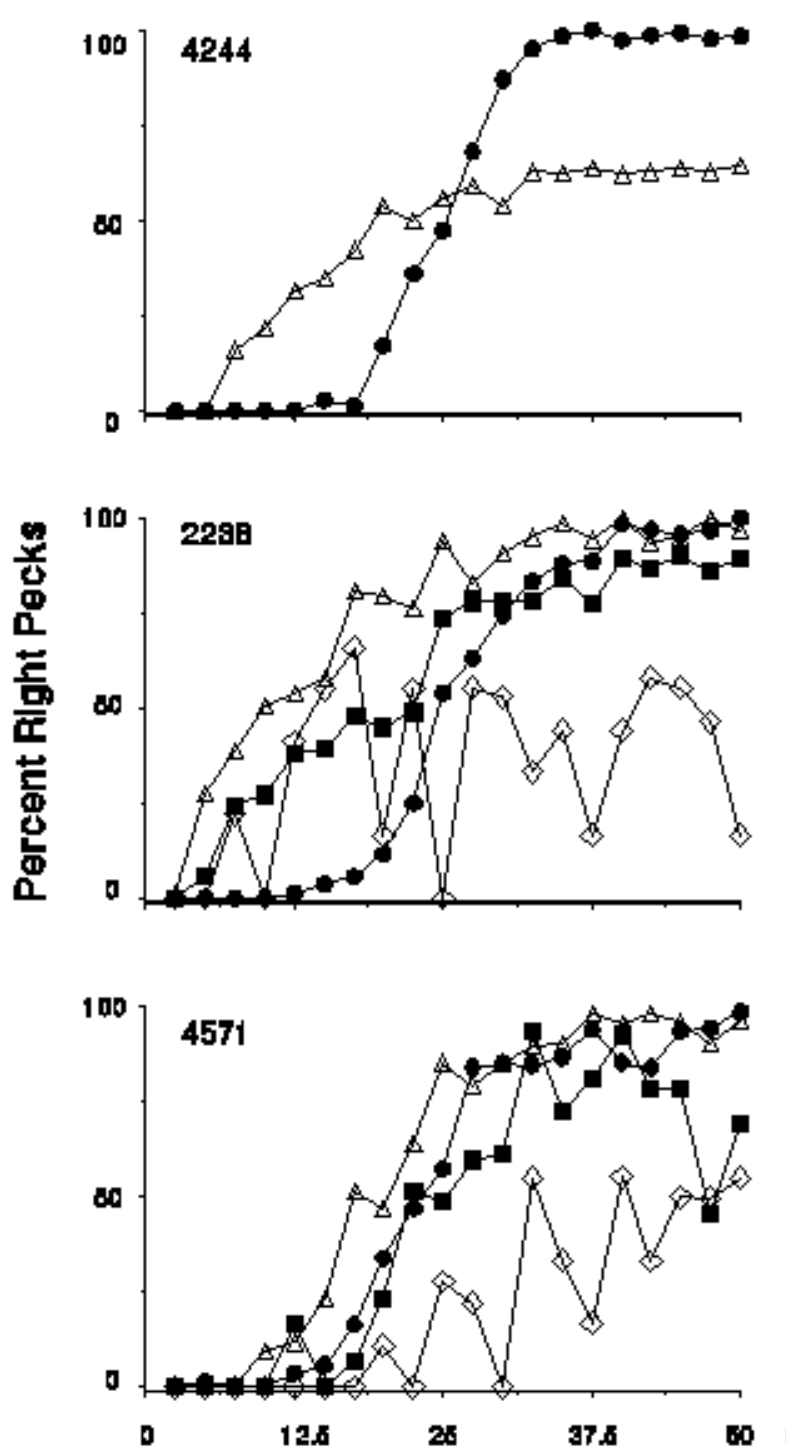

$70 \% \mathrm{FFW}$
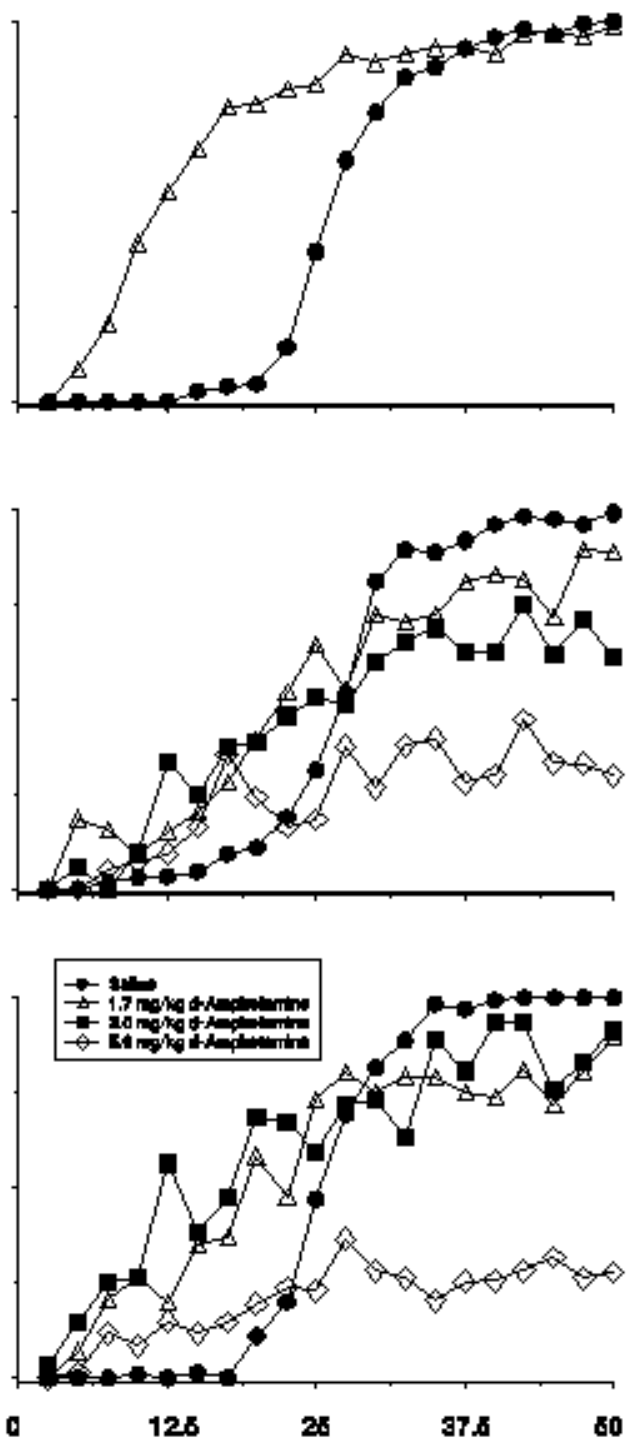

Time Elapsed in Trial (s)

Figure 18. Percent of right-key pecks per 2.5-s bin of two-key trials for saline and high doses of d-amphetamine conditions for each pigeon. Points represent means of three determinations of each dose. 
not all reaching 100 percent. This effect was more pronounced following administration of the higher doses of $\underline{\mathrm{d}}$-amphetamine (Figure 18). Some of these trends are made more apparent in the quantitative indexes of the time at 50\% right key responding and the difference limen (Figure 19). At $85 / 90 \% \mathrm{FFW}$, the T-50 decreased for some pigeons while remaining unchanged for other pigeons. Similarly, the limen increased for one pigeon, while mixed results were obtained with the other pigeons. Results were more consistent across pigeons at 70\% FFW. The T-50 decreased with increasing doses of $\underline{\mathrm{d}}$-amphetamine and the limen generally increased relative to saline conditions. Rates of reinforcment obtained following saline and following $\underline{\mathrm{d}}$-amphetamine were compared and results were similar to those obtained with morphine. Following saline, the number of obtained reinforcers varied considerably from session to session and the number of reinforcers obtained following drug administration did not differ from the baseline values.

The rate-dependency plots (Figures $20 \& 21$ ) only present data from the $70 \%$ FFW condition, which produced the most reliable and systematic alterations in behavior when $\underline{\mathrm{d}}-$ amphetamine was administered. In FI trials, there was a tendency for low saline response rates to be increased following $\underline{\mathrm{d}}$-amphetamine administration, with the higher drug doses producing a larger increase in rate. Moderate saline response rates were increased less and high response rates were not increased or were decreased. In PI trials, low saline response rates increased following $\underline{\mathrm{d}}$-amphetamine. Similar low response rates were not all similarly affected, however. This is evident in the "tail" of the function, similar to the "tail" in the rate -dependency plot for morphine (Figure 8). The same differential rate increases following drug were observed at very low rates of responding following saline. Moderate response rates following saline were less affected by $\underline{\mathrm{d}}$-amphetamine administration and low response rates following saline were either maintained or decreased. PI trials and FI trials differed, in general, in that PI trials produced 

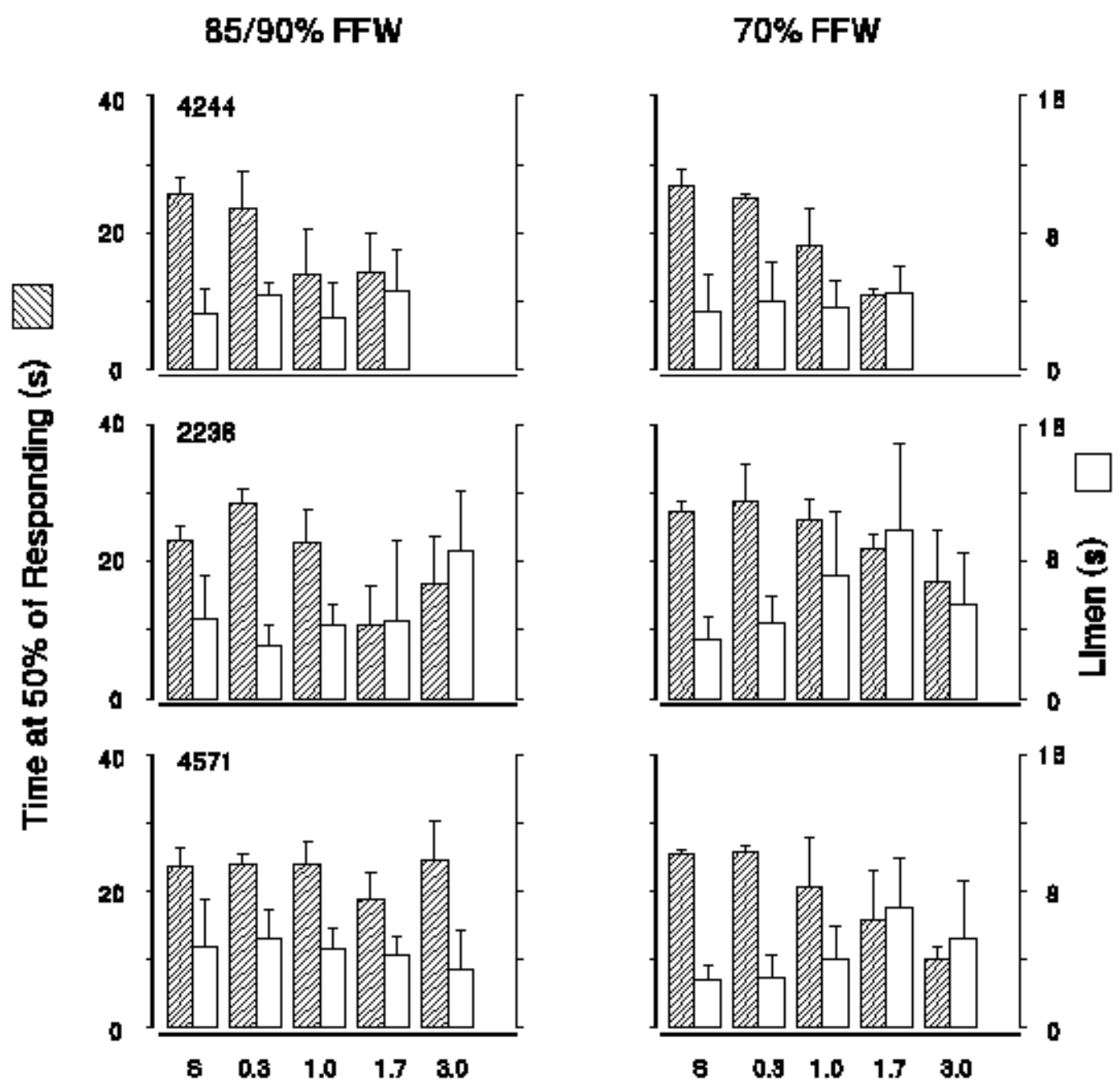

\section{$\mathrm{mg} / \mathrm{kg}$ d-Amphetamine}

Figure 19. Times of 50\% right-key responding and difference limens in two-key trials for saline and d-amphetamine conditions for each pigeon. Filled bars represent mean times (in seconds) of $50 \%$ right-key responding. Open bars represent mean difference limens (half the distance between $25 \%$ and $75 \%$ right-key responding). Error bars represent standard deviations. 


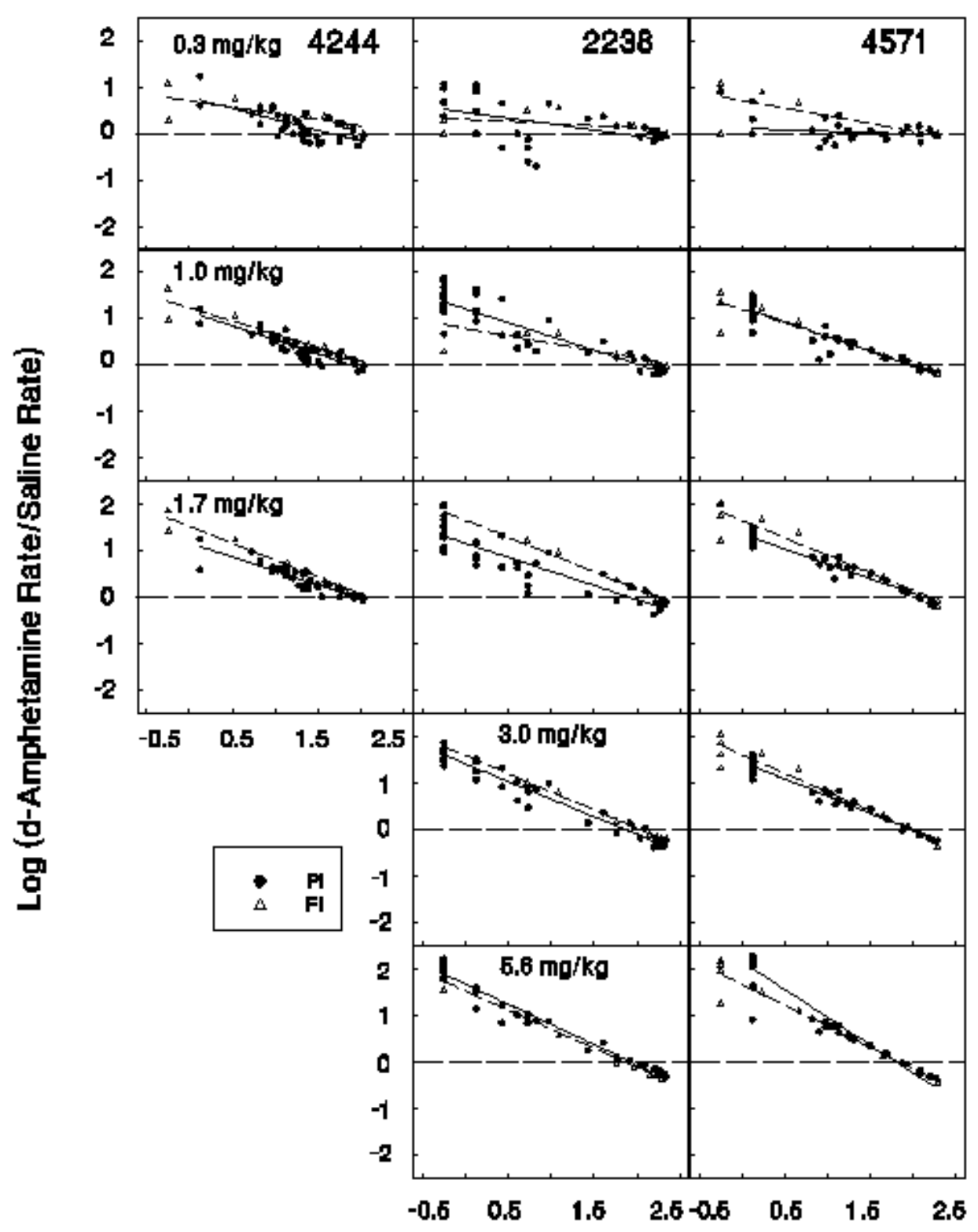

Log Saline Response Rate (pecks/min)

Figure 20. Rate-dependency plots for fixed-interval and peak-interval trials for each pigeon following $\mathrm{d}$-amphetamine administration. Dashed lines indicate saline response rates. Points falling above the dashed line indicate rate increases, points falling below the dashed line represent rate decreases relative to saline response rates. 


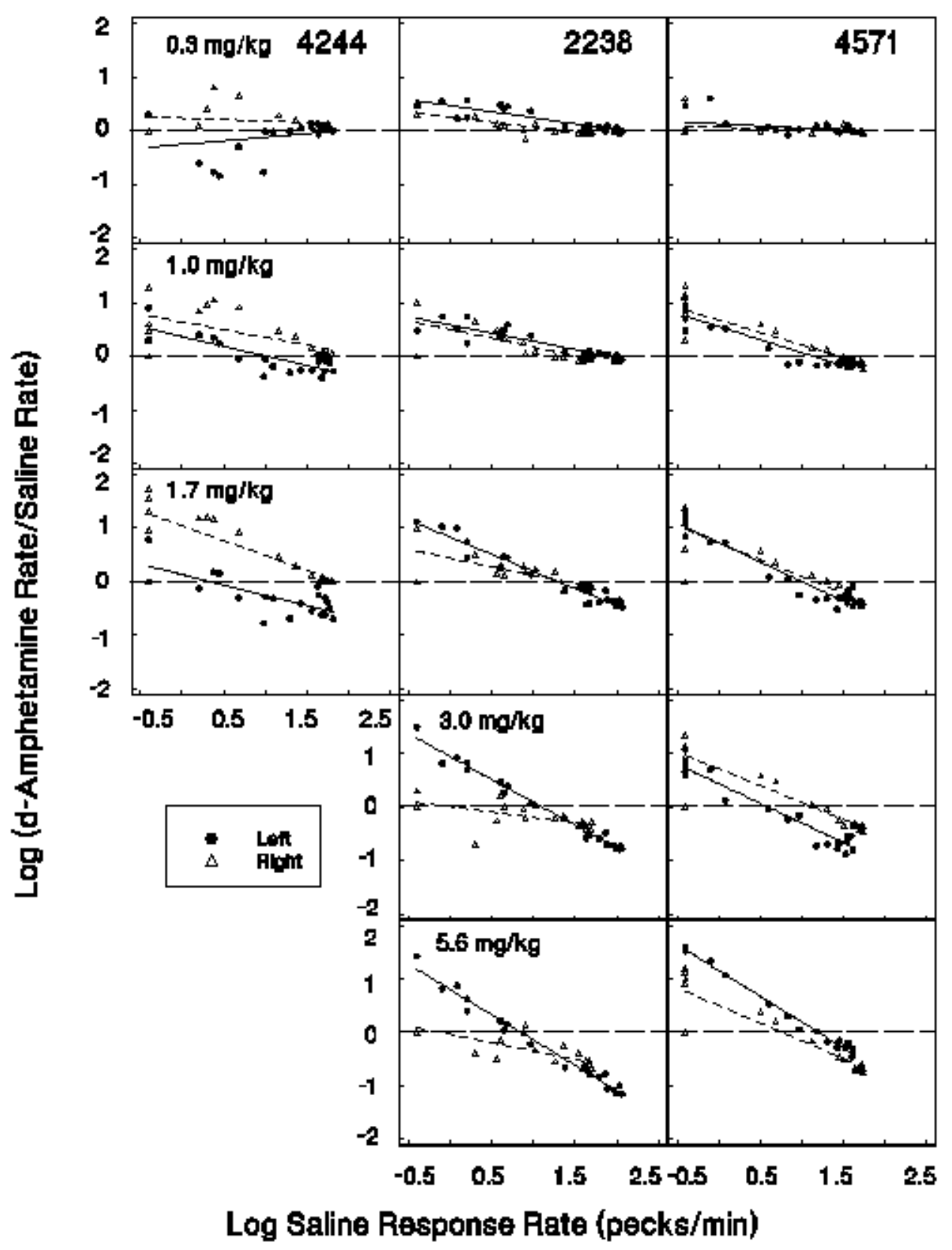

Figure 21. Rate-dependency plots for two-key trials for each pigeon following $\underline{\mathrm{d}}$-amphetamine administration. Dashed lines indicate saline response rates. Points falling above the dashed line indicate rate increases, points falling below the dashed line represent rate decreases relative to saline response rates. 
more variability in rate changes, with points falling further from the regression line. The slope of all functions, both FI and PI, tended to become steeper with increasing dose of drug. This change was largely due to increases of low-rate responding following drug administration.

Data from two-key trials were also analyzed in rate-dependency plots (Figure 21). Low rate responding on the right key following saline tended to increase following $\underline{\mathrm{d}}$-amphetamine administration, with the increase being greatest at moderate doses $(1.0 \& 1.7 \mathrm{mg} / \mathrm{kg})$ compared to both lower $(0.3 \mathrm{mg} / \mathrm{kg})$ and higher $(3.0 \& 5.6 \mathrm{mg} / \mathrm{kg})$ doses. Moderate response rates following saline administration tended to increase, but to a lesser extent than did low response rates, and high response rates were maintained or decreased. Decreases were more substantial at higher doses of drug. In contrast, low-rate left-key responding tended to increase across all doses of $\underline{\mathrm{d}}$-amphetamine. Moderate left-key response rates tended to be maintained following $\underline{\mathrm{d}}-$ amphetamine, and high response rates decreased as a function of increasing doses of $\underline{\mathrm{d}}-$ amphetamine.

\section{Discussion}

Morphine and $\underline{\mathrm{d}}$-amphetamine altered the patterns of responding established by the twokey trials and by the peak procedure. Low rates of responding early in FI trials were increased following drug administration and high rates of responding late in FI trials were decreased. This was reflected in decreases in the index of curvature. Rates of responding were similarly affected during the initial part of peak trials. Later in peak trials, low rates of responding continued to be elevated following drug administration. The peak time did not reliably change except for one pigeon following morphine at 70\% FFW (2238, Figure 5). The spread about the peak functions increased at higher doses of both drugs. In two-key trials, pigeons tended to start responding on the right key earlier following drug administration than following saline, producing leftward 
shifts in the timing index. This shift was more robust at the 70\% FFW. The effects of both drugs were largely rate-dependent; low baseline rates were increased and higher baseline rates were less affected or were reduced by low to moderate doses.

Two primary comparisons will be considered in evaluating the data from this experiment. A comparison of the indexes of timing behavior across the different procedures will be followed by a comparison of the effects of the drugs at different body weights. Any differences between the two drugs will be considered and noted at each stage. Both drugs decreased the index of curvature and the T-50 measure of the two-key procedure. This result was similar to that obtained by Chiang and colleagues (Chiang et al., 2000). They studied the effects of $\underline{\mathrm{d}}-$ amphetamine in rats responding on a 2-lever procedure similar to the 2-key procedure used in the present study. When data were plotted as a percent of second lever responses following drug administration, the percentage increased early in intervals and decreased slightly late in the interval relative to responding following saline. Rate-dependency plots became steeper with increased doses, and did so more reliably than the rate-dependency plots obtained in the present study.

The peak time in the present study did not decrease reliably, although previous studies have shown small decreases in peak time in both rats (Bayley, Bentley, \& Dawson, 1998) and

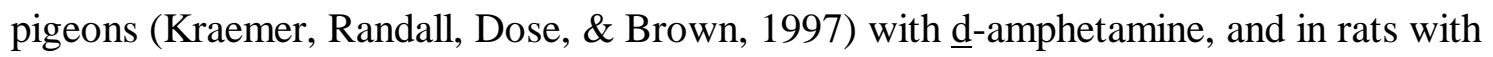
methamphetamine (Maricq, Roberts, \& Church, 1981). Bayley et al. used an FI 72-s schedule and occasional peak trials to assess peak time and peak spread. The peak time was difficult to visually assess in the Bayley et al. study due to a flattening of the function once a peak rate of responding was obtained. The authors reported no statistically significant change in the peak time with any dose tested $(0.5,0.75,1.5 \mathrm{mg} / \mathrm{kg})$. Kramer et al. used an FI 30 -s schedule with 
peak trials interspersed. They demonstrated decreases in peak time in pigeons at doses of both 1.0 and $2.0 \mathrm{mg} / \mathrm{kg}$, with a larger decrease occurring at the higher dose. Maricq et al. demonstrated this same finding with methamphetamine in rats trained on FI 40-s schedules and tested with occasional peak trials. That is, peak time reliably decreased following drug administration. The method all of these authors used to derive peak time was dissimilar to the present methods (to use the segment of the trial with the highest response rate). The authors assessed the two points at which $70 \%$ of maximal responding occurred (points used to calculate the $70 \%$ peak spread) and took the value halfway between those two points as the peak. Their peak time, then, might be interpreted as a mathematically-derived peak time as opposed to an actual, obtained peak time. In the present study, it was observed that, at times, the spread of the function increased to a greater extent to the left of the actual peak, compared to the right.

The peak spread in the present study reliably increased at high doses of drug much as the two-key measure, the limen, increased. This replicates data obtained describing changes in the limen (Chiang et al., 2000) and the peak spread (Bayley et al., 1998; Maricq et al., 1981). The peak spread, however, was unchanged in another study (Kraemer et al., 1997). The data presented by Kramer et al., however, provide the clearest indication of a decrease in peak time (with no alteration in the peak spread) that would support a pacemaker with an increased speed. Changes in timing indexes are not always reliable. At times they are observed, and at other times they are not.

The T-50 and peak time are the primary measures of temporal discrimination in these procedures. In previous studies, decreases in these indexes have been taken as evidence that the speed of a hypothetical pacemaker has increased. This result was obtained with the two-key procedure, in the present study, but not with the peak procedure. If the findings in the present 
study were accepted as evidence that the drugs altered performance differently in the two procedures, it would suggest that different behavioral processes (established as different by the differential effects of a third variable, the drug) were responsible for the temporal organization of behavior under the two tasks.

Two observations, however, suggest that the drugs had the same effect on behavior in the two procedures. The first involves similarities in the contingencies of the two procedures. In both procedures, pecking a single key can be reinforced after $25 \mathrm{~s}$ of the trial has elapsed; the center key in FI/PI trials and the right key in two-key trials. In FI/PI trials, no other explicitly reinforced behavior is available during that period; in the two-key task pigeons can peck the left key for food. In both cases, the drugs increased rates of these responses (center key or right key) early in the trials. In the case of the two-key trials, increases in right-key pecking produced a leftward shift in the T-50. In the FI/PI trials, early-trial rate increases were not necessarily accompanied by left-shifts in the time of peak responding, but did produce changes in the index of curvature. By this view, the same kind of effect was observed in both procedures, and behavior under the two procedures may still reflect control by a common mechanism.

The second observation is the similarity in the rate-dependency plots. Such ratedependent effects of morphine (Thompson, Trombley, Luke, \& Lott, 1970; Odum, Haworth, \& Schaal, 1998) and $\underline{d}$-amphetamine (Heffner, Drawbaugh, \& Zigmond, 1974; Leander \& McMillan, 1974; Katz, 1982; Lucki \& DeLong, 1983) have been shown before. Slopes between plots were often similar, although relative differences in the extent of rate changes varied between schedule types in a manner similar to previous research examining rate-dependent effects on performance under schedules of different types and values (Thompson et al., 1970). An example of such a relative difference is that rates were much more prone to increases in the 
FI and PI schedules (Figures $8 \& 20$ ) than in the two-key procedure (Figures $9 \& 21$ ), so the FI and PI plots typically fall higher on the y-axis. What is new is that early-trial right-key rate increases occurred even though pigeons had to leave a source of reinforcement, the left-key, to respond early on the right key. That explicit source of reinforcement may have been responsible for the graded effects of the two-key procedure relative to the more all-or-none effects on the FI/PI task. Nevertheless, the similar effects revealed by the rate-dependency plots suggest that the drugs had comparable effects on behavior under the two tasks.

A careful examination of the rate-dependency plots for peak and two-key tasks (Figures $8,9,20, \& 21)$ reveals two clear exceptions to the rate-dependency effect, however. In peakinterval trials, a 'tail" was obtained at the lowest response rates, which means that the lowest rates were not all equally increased by the drugs. It can be seen in Figures 3, 14, and 15 that low response rates during the beginning of an interval were reliably increased by drug. Equivalent response rates occurring later, toward the end of the peak interval, were not increased as robustly. The second exception can be seen in the two-key rate-dependency plots following morphine (Figure 9). Low response rates on the right key (which occurred early in the trial) were usually increased more robustly than low response rates on the left key (which occurred late in the trial). This effect was not prevalent following $\underline{\mathrm{d}}$-amphetamine. It can be seen in pigeon 4244 , but not in either of the other 2 pigeons. It bears noting that pigeon 4244 is the only one of those three to maintain consistent right-key only responding towards the end of an interval following high $\underline{\mathrm{d}}$-amphetamine doses (Figure 18). Responding in the other 2 pigeons indicates relatively equal responding to both keys and perhaps a breakdown in discrimination. In both the peak- and two-key procedures (following morphine), low response rates toward the beginning of a trial were more subject to rate-increasing effects than similarly low rates toward the end of a trial. For 
PI trials, this can be seen by examining Figure 4 and attending to response rates following drug at times where saline responding does not occur (the very start of an interval and the latter portion of an interval). Response rates tend to increase more early in the interval. For two-key trials, this effect is most clear by looking at the rate-dependency plot (Figure 9). Low saline response rates are on the leftmost side of each panel. The proportion of saline response rates is higher for the right key than the left key in 8 of 12 instances, and is equal in the other 4 instances. Low-rate right-key responding following saline occurs only during the first half of a trial, while low-rate left-key responding occurs only during the second half of a trial.

The effects of the drugs might, therefore, be considered both rate-dependent and timedependent. They were time-dependent insofar as the time in a trial appeared to have altered the extent of the rate-increasing and rate-decreasing effects of the drugs. These relations between indexes of timing and rate-dependency plots are important to note due to a lack of such comparisons in previous timing experiments. Rate-dependency has been neglected as a possible mechanism through which timing indexes might be altered. It might be that alterations to some central timing process produce rate-dependent changes in responding, but it is also possible that rate-dependent changes in behavior can produce changes in indexes of timing. Of course, some other variable might be responsible for both of these changes in behavior. These possibilities will be considered in the General Discussion.

The second important comparison is between body weights. First and foremost, the overall response rate data (Figures $1 \& 10$ ) indicate that the $70 \%$ FFW maintained higher response rates following drug administration than did the $85 / 90 \% \mathrm{FFW}$ in a manner consistent with previous research (Cole, 1967; Gollub \& Mann, 1969; Kelly \& Thompson, 1988; Schaal \& Branch, 1992; Schaal, Miller, \& Odum, 1995; Odum, Haworth, \& Schaal, 1998). This occurred 
despite a lack of systematic differences in control or saline response rates. This allowed a broader range of doses to be studied when the subject was maintained at $70 \%$ FFW. More reliable and robust changes in response patterns can be seen when the pigeons were maintained at $70 \%$ FFW. This is, generally, more easily seen in looking at the quantitative indexes of behavior. The changes in performance, as indicated by the indexes, also appeared more graded when pigeons were maintained at $70 \% \mathrm{FFW}$. That is changes in indexes were observed to consistently increase or decrease with increases in drug dose, as opposed to an all-or-none effect where an index would be maintained at a given level across multiple doses and only change to a new level once a certain dose had been reached. The drug effect is related to the size of the dose administered. The observed differences, of an enhancement of the rate-increasing effects of low doses of drug and an attenuation of rate-suppressive effects of drugs were both born out by the present experiment.

The results of this experiment suggest that procedures that provide measures of timing may be influenced similarly by a third variable, a drug (morphine and $\underline{\mathrm{d}}$-amphetamine in this case). Rate-dependent effects were shown in all procedures and with both drugs. When shifts in functions, such as the two-key functions, were observed rate-dependent effects were always present.

\section{Experiment 2}

This experiment examined the effects of morphine and $\underline{\mathrm{d}}$-amphetamine on key pecking of pigeons maintained under a multiple schedule. The first part of the multiple schedule was a simple FI schedule; the second part was a concurrent FI VI schedule (which can also be construed as a mixed VI FI schedule, similar to the two-key procedure of Experiment 1). This schedule arrangement was devised to examine a result of Experiment 1, in which pigeons left a 
source of reinforcement (the left key) in the two-key task to respond to an alternative that was not yet a source of reinforcement (the right key). Would pigeons similarly leave a VI schedule to respond early to an FI schedule of reinforcement? The effects of the two drugs on behavior maintained by these two procedures were assessed at both a high and low body weight to help answer this question. The assessment included overall response rates, response patterns and rates within intervals, indexes of curvature to assess the shape of FI response patterns, and ratedependent plotting of the data.

$\underline{\text { Subjects }}$

\section{Method}

Four adult male White Carneau pigeons (740, 241, 273, and 726) were used in Experiment 2. Pigeon 726 died a couple of weeks following the morphine administration condition and so no data appear for 726 in the presentation of $\underline{\mathrm{d}}$-amphetamine data. The pigeons had previous exposure to various schedules of reinforcement. Other details are provided in the general Subjects section.

\section{$\underline{\text { Procedure }}$}

Each session lasted for approximately $55 \mathrm{~min}$ and was preceded by a 10-min blackout. The pigeons were initially exposed to a concurrent FI 2-min (amber center key) VI 2-min (white right key) schedule of reinforcement. Following reliable responding under this arrangement, the FI value was increased to $5 \mathrm{~min}$ and the VI value was increased to $150 \mathrm{~s}$. Reliable responding on the FI portion of this concurrent schedule was difficult to maintain because pigeons pecked the VI key so often. Therefore, the VI schedule was made to operate only during the first 4 min of the trial. Reliable responding followed this change. Thus, the terminal procedures included a VI 150-s schedule on the white right key available during the first 4 min of the FI 5-min schedule. The right key remained lit during the last minute of the FI, but pecks had no scheduled 
consequences. This can be construed as a mixed VI 150-s FI 1-min schedule, with the VI component lasting for 4 minutes. In this manner, the schedule is related to the two-key procedure of Experiment 1, but with a switch point $80 \%$ of the way through a given trial.

The concurrent VI FI schedule alternated with an FI 5-min schedule (amber center key). The trial types were separated by 10-s inter-trial intervals during which the chamber was dark. There were 4 trials of the FI type and 4 trials of the concurrent FI VI type. Reinforcement, in all cases, consisted of 4-s access to grain. Fixed-interval trials were terminated by a key-peck or if a limited hold of $2 \mathrm{~min}$ was reached. That is, there was a limited period of time ( $2 \mathrm{~min}$ ) following the end of the 5-min interval in which a response could be reinforced. The limited hold was included to eliminate the possibility of a trial or session never reaching completion (due to a drug-induced cessation of responding, for example). The same limited hold applied to the concurrent schedule. A 3-s COD was in effect during the concurrent schedule. All VI schedules were arranged according to a Fleshler and Hoffman (1962) progression.

Determinations of each dose of morphine were conducted under this procedure while the pigeons were maintained at $80 \%$ of their FFW following 54 sessions of baseline. The body weights were then lowered to $70 \%$ of FFW and morphine was tested again. The experiment was then repeated, using $\underline{\mathrm{d}}$-amphetamine instead of morphine. Food restriction levels were counterbalanced across subjects for $\underline{\mathrm{d}}$-amphetamine determinations. The lower body weight used was $70 \%$ FFW for all pigeons. The upper body weight used was $82.5 \%$ FFW for 740 , and $85 \%$ FFW for 241 and 273. The slightly lower upper FFW used for 740 was due to disruptions in patterns of responding when attempts were made to maintain responding at the higher body weight. 


\section{Data Analysis}

Overall response rates were computed separately for FI, Concurrent FI, and VI schedules. All means and standard deviations presented are based on 2 or 3 determinations of each drug dose or saline administration. Means and standard deviations for control sessions are based on the data points for each day preceding saline or drug administration.

Response patterns were examined by collecting data in 30-s segments for each schedule within a session. Responses within a segment were aggregated across an entire session. Response rates presented in the figures were computed by averaging the response rates within each segment for each dose and subject.

In FI and Concurrent FI trials, indexes of curvature (Fry, Kelleher, \& Cook, 1960) were determined. The index of curvature (I) was calculated for each session using the following formula:

$$
\underline{I}=\left[9 \underline{R}_{10}-2\left(\underline{R}_{1}+\underline{R}_{2}+\ldots+\underline{R}_{8}+\underline{R}_{9}\right)\right] / 10 \underline{R}_{10}
$$

where $\underline{R}_{1}$ is the total number of responses in the first segment, $\underline{R}_{2}$ is the total number of responses in the first and second segments, up through $\underline{\mathrm{R}}_{10}$ which is the total number of responses in all ten segments.

Data from each schedule were also analyzed in rate-dependency plots. Mean response rates following the administration of morphine and $\underline{\mathrm{d}}$-amphetamine within each 30 -s segment were divided by mean response rates from the corresponding segment following saline administration and plotted on a logarithmic axis. This ratio was plotted as a function of the mean saline response rate of the corresponding segment also on a logarithmic axis. A linear regression line was fitted to each set of data using the method of least squares. 
$\underline{\text { Results }}$

Morphine

Response rates decreased as a function of dose following morphine administration at both levels of food deprivation across each of the experimental conditions (Figure 22). Comparisons of control versus saline response rates did not differ systematically from one another at any given body weight. Similarly, comparisons across body weights did not reveal systematic differences (i.e., control rates at $70 \%$ vs. $80 \%)$. At $80 \%$ FFW, the lowest dose of morphine $(1.0 \mathrm{mg} / \mathrm{kg})$ increased slightly or did not affect response rates compared to saline, but higher doses of morphine decreased response rates. At 70\% FFW, the lowest dose functioned in a similar fashion and did not alter most response rates. However, increases in response rates occurred more frequently than at the $80 \%$ FFW. Higher doses of morphine decreased response rates. Response rates for subjects 740 and 726 were clearly higher at $70 \%$ FFW than at $80 \%$ FFW, response rates had a tendency to be higher at $70 \%$ FFW in subject 241, and results were mixed with subject 273. In general, a 70\% FFW attenuated the rate suppressing effects of high doses of morphine. Data for the highest doses of morphine that reliably suppressed nearly all behavior were omitted from the remaining figures.

In the FI schedule (Figure 23), response rates following saline administration began at a very low level and increased throughout the interval, ending at a high terminal rate at both levels of food deprivation. At $80 \% \mathrm{FFW}$, rates increased earlier in the interval for 3 of 4 pigeons following morphine than following saline administration. High, terminal response rates were decreased for 3 of 4 pigeons following morphine. At 70\% FFW, rates increased earlier in the interval for all pigeons following morphine than following saline administration. High rates of behavior late in the interval were only reliably suppressed by the highest doses of morphine (5.6 


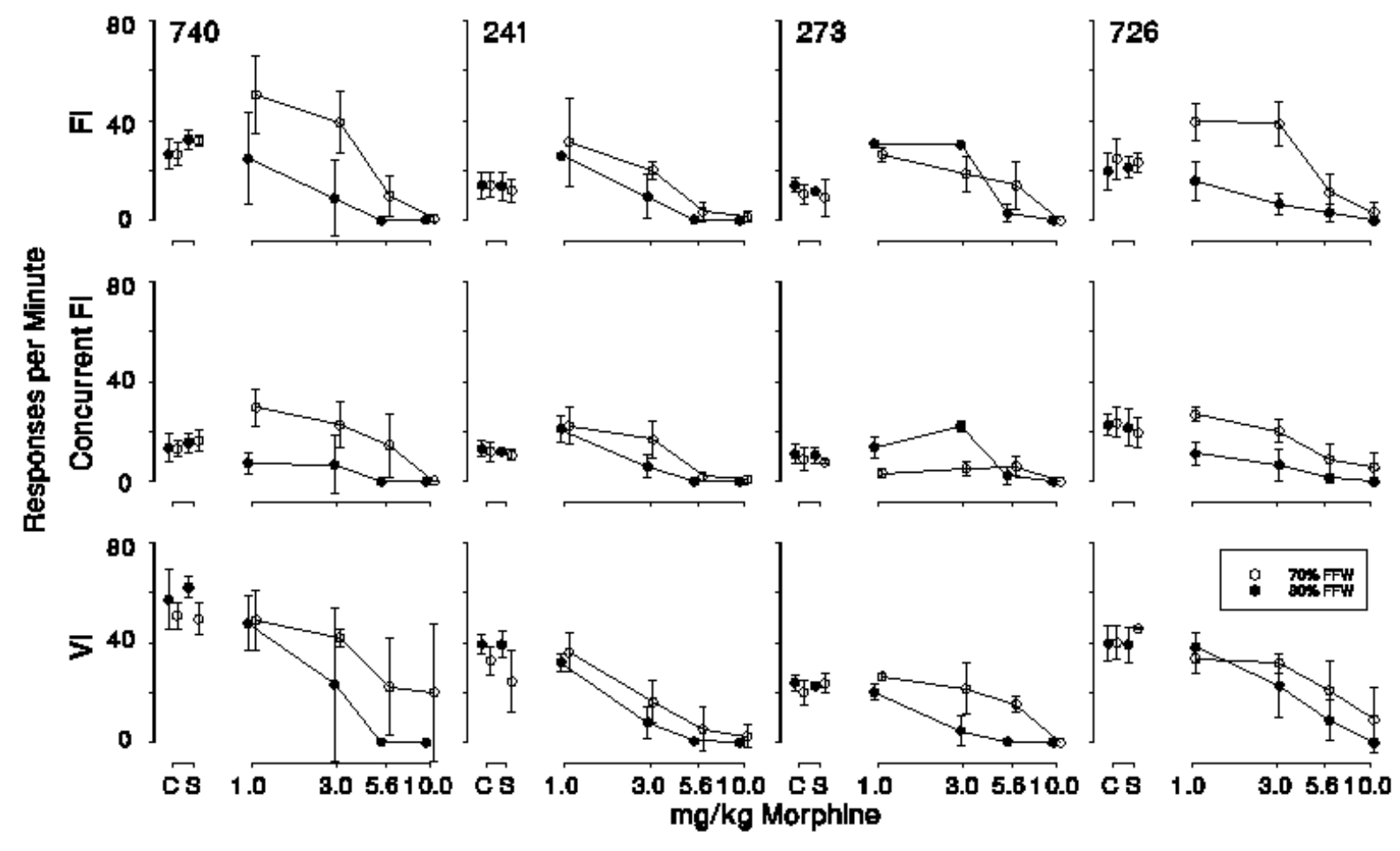

Figure 22. Response rates as a function of dose of morphine for each pigeon responding on each schedule under both levels of food deprivation. Points represent means of determinations of each dose. Error bars represent standard deviations. 


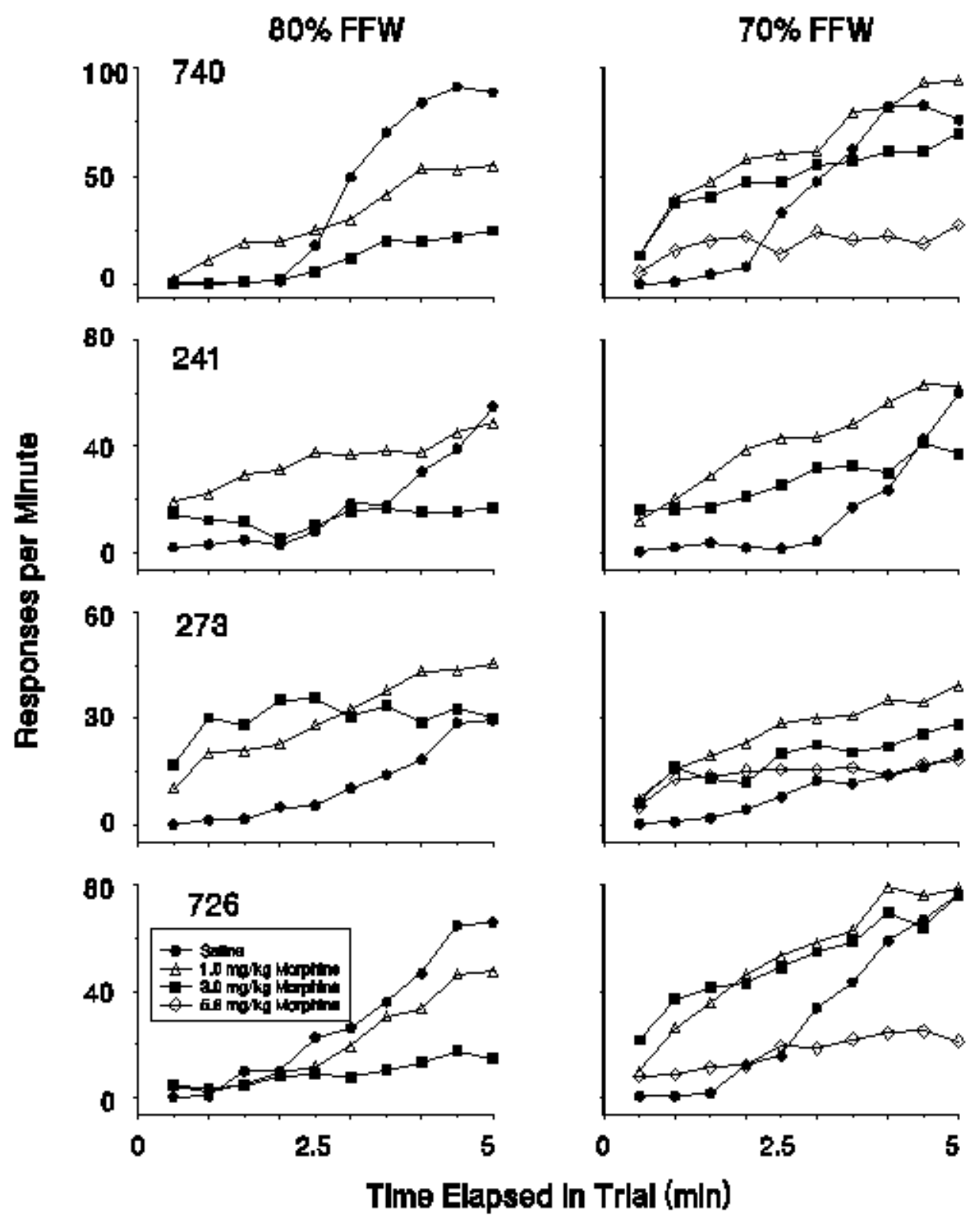

Figure 23. Response rates in consecutive 30-s bins of FI 5-min intervals for saline and morphine conditions for each pigeon. Points represent means of determinations of each dose. 
$\mathrm{mg} / \mathrm{kg}$ ). Although saline response rates were comparable between body weights, there was a tendency for less rate-suppression following morphine at 70\% FFW.

In the concurrent FI schedule (Figure 24), response rates following saline administration began at a very low level and increased throughout the interval, ending at a high terminal rate at both levels of food deprivation. At $80 \%$ FFW, rates increased earlier in the interval for 2 of 4 pigeons following morphine than following saline administration. Terminal rates of responding decreased as a function of dose of morphine for 3 of 4 pigeons. At $70 \% \mathrm{FFW}$, rates increased earlier in the interval for all pigeons following morphine than following saline. Terminal response rates were suppressed in all pigeons as a function of increasing dose of morphine. Indexes of curvature are presented for both the FI and Concurrent FI schedules at both body weights (Figure 25). The index of curvature was not systematically higher across pigeons for either of the two schedules at $80 \% \mathrm{FFW}$. The index of curvature was higher in the concurrent FI schedule for pigeons 740 and 241 following saline and higher in the FI schedule for pigeons 273 and 726. Similar, mixed results were obtained at 70\% FFW. These differences were sometimes maintained following morphine administration (i.e., pigeon 740 at $70 \% \mathrm{FFW}$ ), however standard deviations tended to be large relative to mean differences for all pigeons.

In the VI schedule (Figure 26), response rates following saline administration began at a high level and decreased throughout the interval, ending at a moderate, terminal rate at both levels of food deprivation. Response rates decreased as a function of morphine dose at $80 \%$ FFW. Moderate response rates at the end of the schedule increased slightly in 3 of 4 pigeons at the $1.0 \mathrm{mg} / \mathrm{kg}$ dose of morphine, but not at $3.0 \mathrm{mg} / \mathrm{kg}$. Response rates also decreased as a function of morphine dose at $70 \% \mathrm{FFW}$. Pigeon 241 was the exception, where $1.0 \mathrm{mg} / \mathrm{kg}$ of 


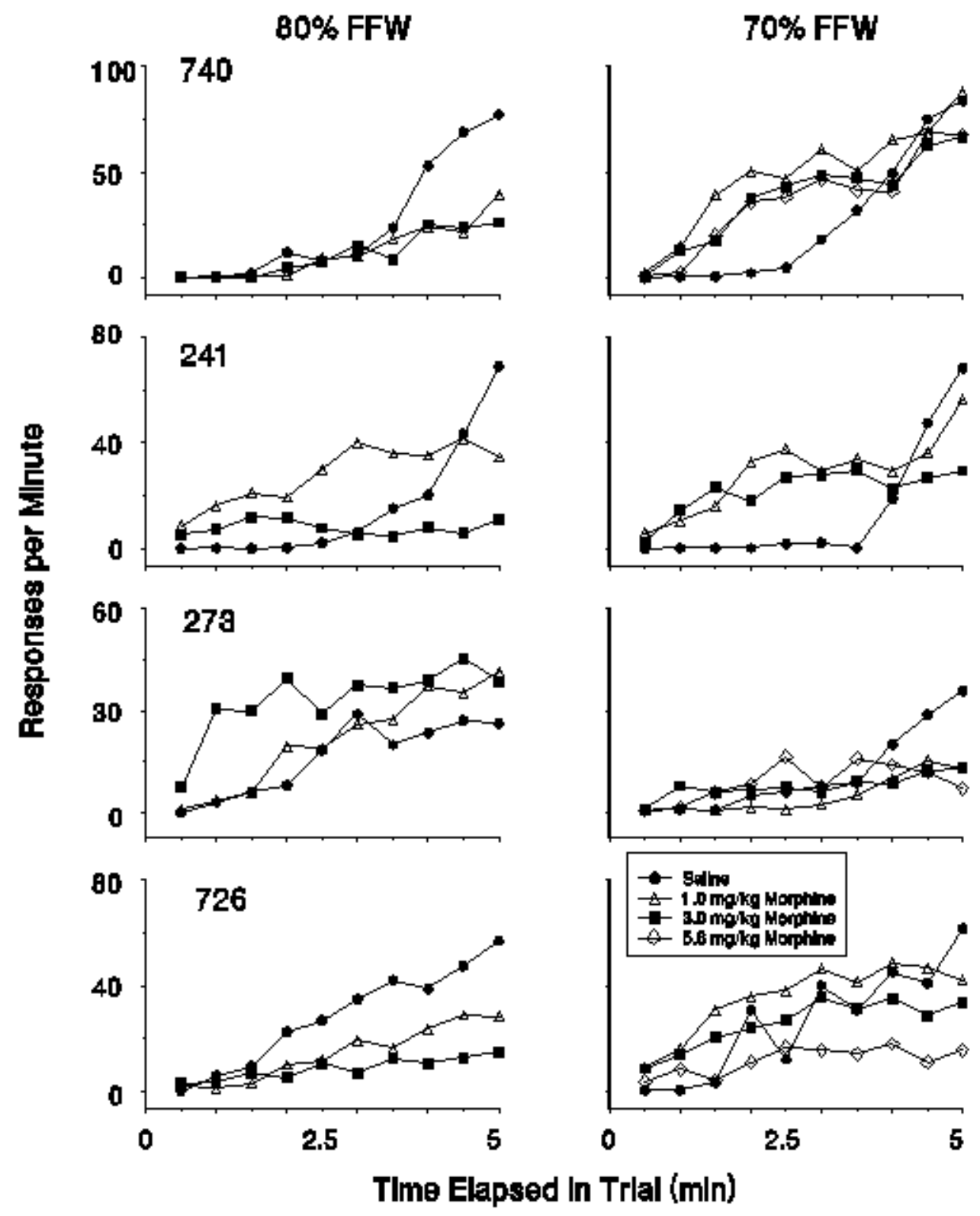

Figure 24. Response rates in consecutive 30-s bins of concurrent FI 5-min intervals for saline and morphine conditions for each pigeon. Points represent means of determinations of each dose. 


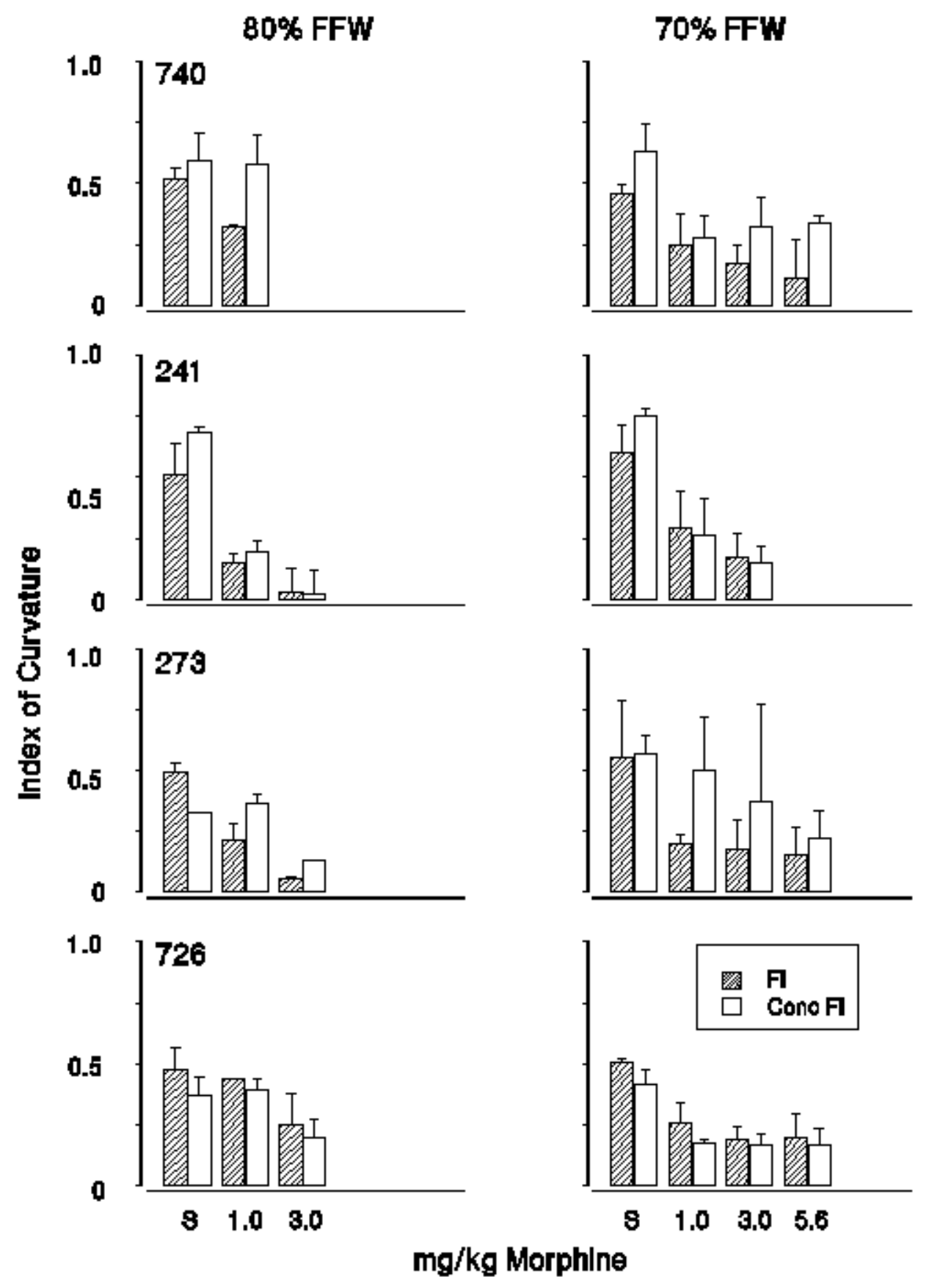

Figure 25. Indexes of curvature in FI 5-min and concurrent FI 5-min intervals for saline and morphine conditions for each pigeon. Large bars represent means. Error bars represent standard deviations. 


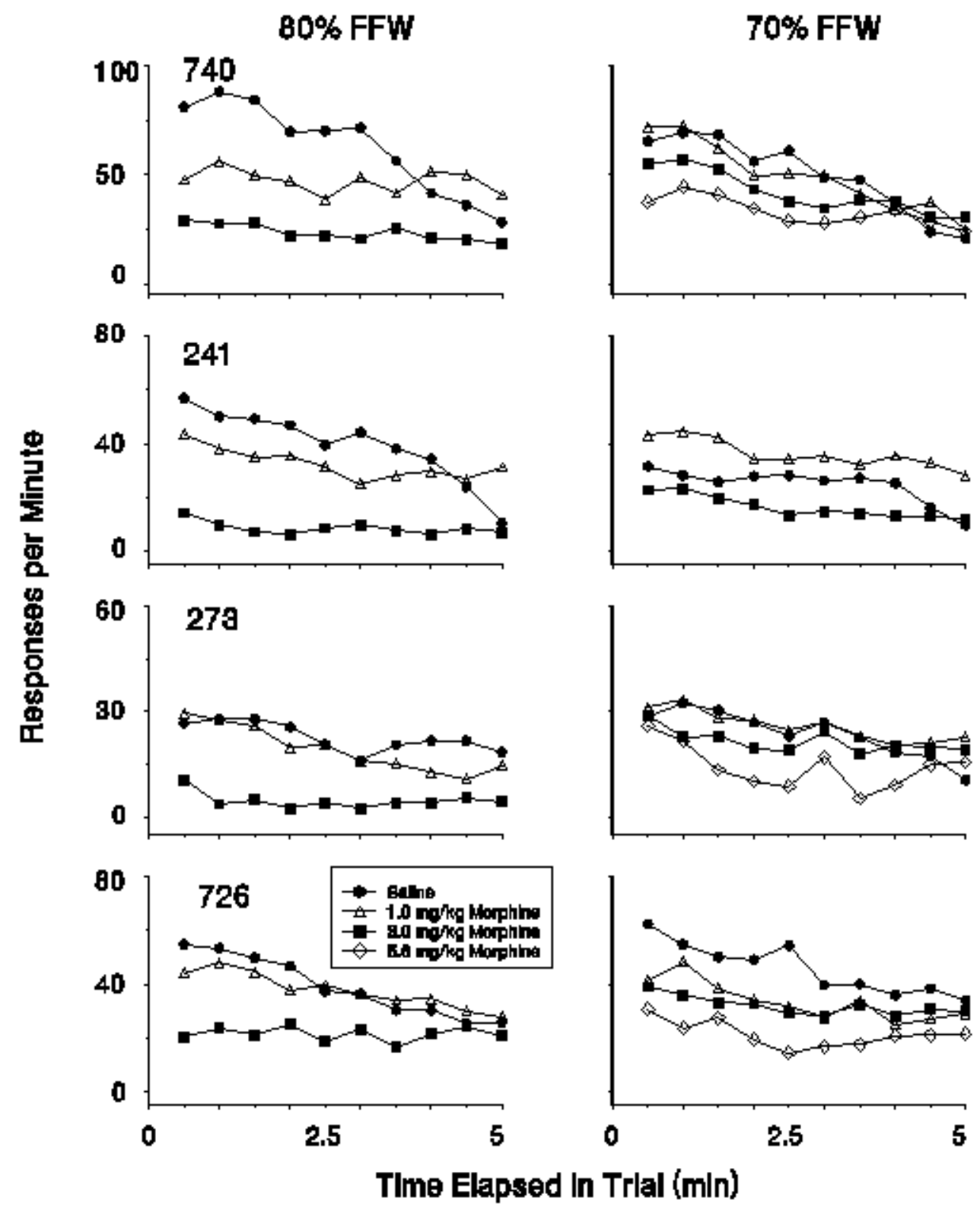

Figure 26. Response rates in consecutive 30-s bins of concurrent VI 150-s intervals for saline and morphine conditions for each pigeon. Points represent means of determinations of each dose. 
morphine produced response rate increases throughout the interval. Reliable differences, aside from those noted, were not observed between body weights.

The rate-dependency plots (Figure 27) only present data from the $70 \%$ FFW condition, similar to Experiment 1. In the FI schedule, low saline response rates were increased following morphine. Moderate saline response rates were also increased, but not to the same relative extent as those obtained at low saline response rates. High saline response rates decreased slightly or were not altered following morphine. Rate decreases were most prominent following high doses of morphine. In the Concurrent FI schedule, low saline response rates were increased following morphine and moderate saline response rates were also increased, but not as greatly. High saline response rates decreased following morphine. In the VI schedule, saline response rates, all high, were similarly affected by morphine: response rates decreased slightly or were not altered in a manner comparable to high rates in either of the other two schedules.

\section{d-Amphetamine}

Response rates decreased as a function of dose following $\underline{\mathrm{d}}$-amphetamine administration at both levels of food deprivation across each of the experimental conditions (Figure 28). At 82.5/85\% FFW, control and saline response rates did not differ from one another. Response rates following low to moderate $\underline{\mathrm{d}}$-amphetamine doses $(0.3 \& 1.0 \mathrm{mg} / \mathrm{kg})$ increased slightly or were not altered relative to saline. Response rates decreased as a function of higher doses of $\underline{\mathrm{d}}-$ amphetamine, with the highest dose $(5.6 \mathrm{mg} / \mathrm{kg})$ reliably suppressing behavior under all schedules. At the $70 \%$ FFW, control and saline response rates did not differ from one another.

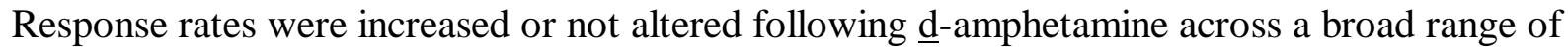
doses $(0.3-1.7$ and sometimes $3.0 \mathrm{mg} / \mathrm{kg})$. Response rates were suppressed by the highest doses. Response rates were higher at $70 \%$ FFW in some instances (pigeon 241, VI), but more 


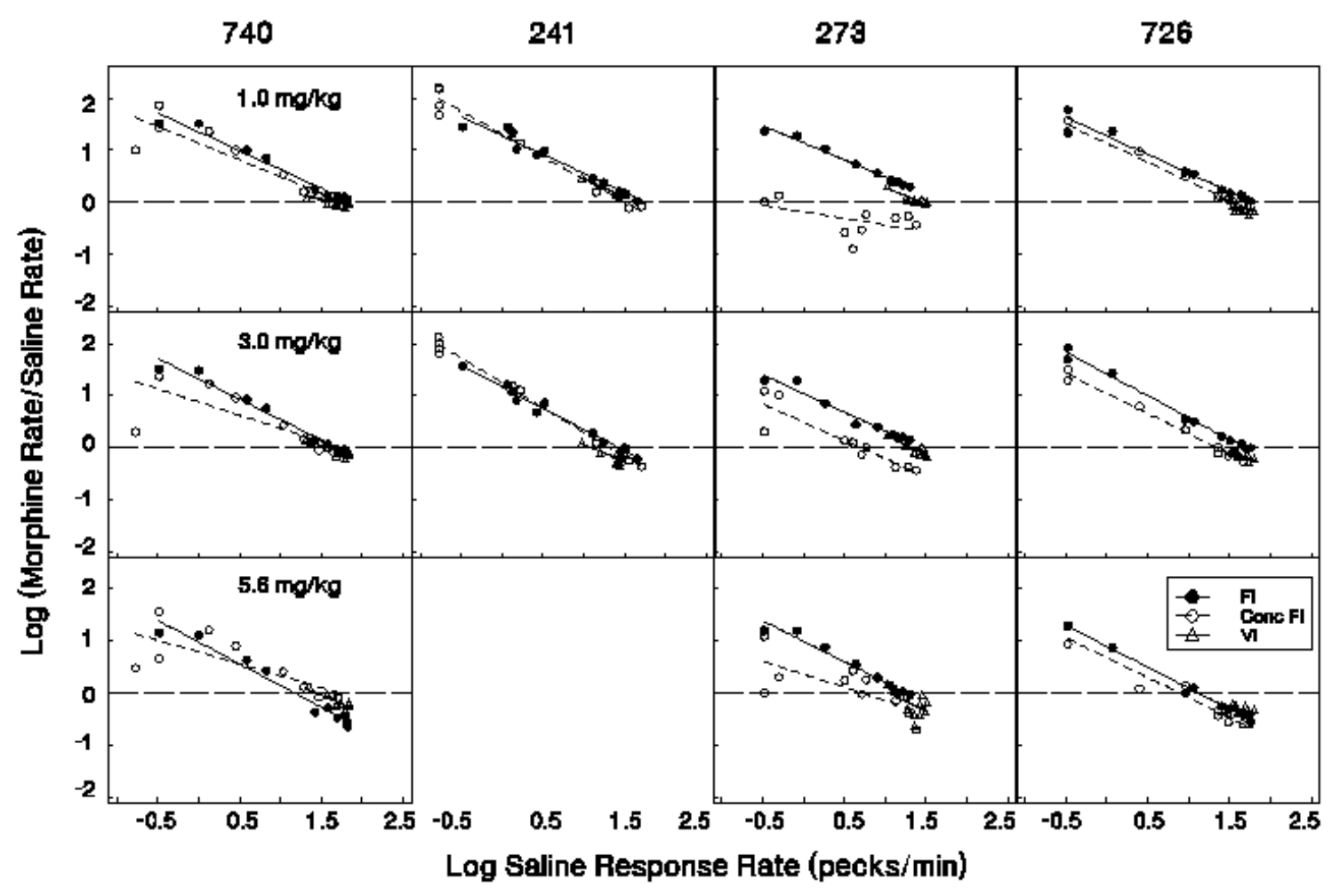

Figure 27. Rate-dependency plots for fixed-interval, concurrent fixed-interval, and concurrent variable-interval schedules for each pigeon following morphine administration. Dashed lines indicate saline response rates. Points falling above the dashed line indicate rate increases, points falling below the dashed line represent rate decreases relative to saline response rates. 


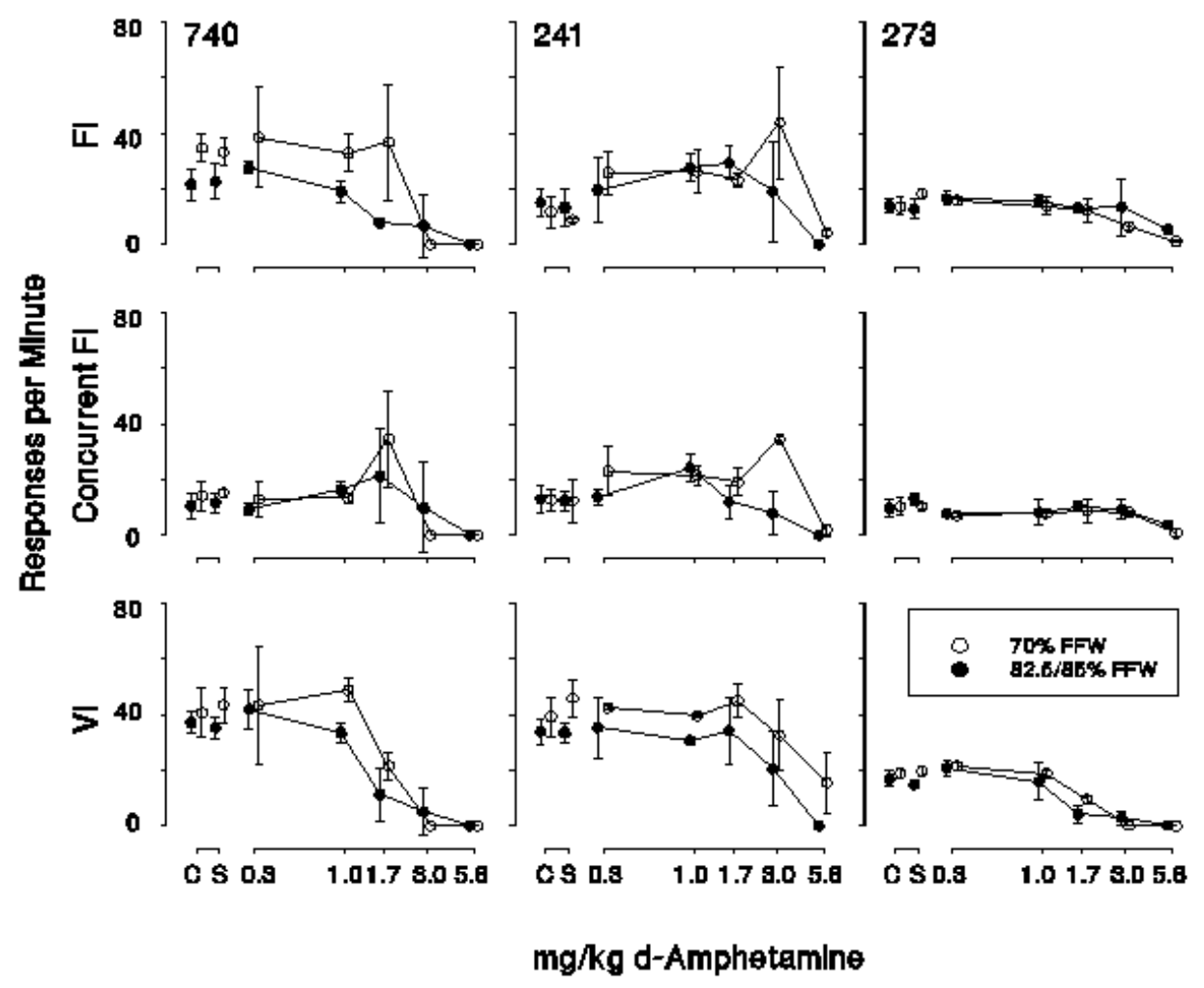

Figure 28. Response rates as a function of dose of $\underline{\mathrm{d}}$-amphetamine for each pigeon responding on each schedule under both levels of food deprivation. Points represent means of determinations of each dose. Error bars represent standard deviations. 
often there was no reliable difference between response rates maintained by the different body weights (pigeon 273).

In the FI schedule (Figures $29 \& 30$ ), response rates following saline administration began at a very low level and increased throughout the interval, ending at a high terminal rate at both levels of food deprivation. A comparison of saline response rates across body weights revealed no systematic difference in terminal response rates. At $82.5 / 85 \% \mathrm{FFW}$, response rates increased earlier in the interval following $\underline{\mathrm{d}}$-amphetamine than following saline administration across all doses save for the highest drug doses for pigeon 740. Although rate increases were the

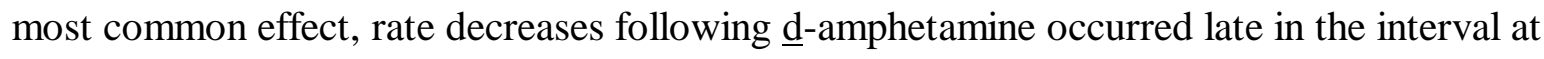
high doses (Figure 30) in pigeons 241 and 273 (and throughout the entire interval for 740). Rate decreases were most reliable at the highest dose of $\underline{\mathrm{d}}$-amphetamine. At $70 \% \mathrm{FFW}$, response rates increased slightly or were not altered (Figure 29, pigeon 273) by low doses of $\underline{\mathrm{d}}$-amphetamine early in the interval in comparison to response rates following saline. At higher doses, response rates relative to those following saline either decreased (pigeon 273) or increased (pigeons $740 \&$ 241). In general, following $\underline{\mathrm{d}}$-amphetamine, rates tended to increase for pigeons 740 and 241 regardless of body weight and rates decreased or were not altered for pigeon 273.

In the concurrent FI schedule (Figures $31 \& 32$ ), response rates following saline administration began at a very low level and increased throughout the interval, ending at a high terminal rate at both levels of food deprivation. At $82.5 / 85 \% \mathrm{FFW}$, response rates increased earlier in the interval for 2 of 3 pigeons ( $740 \& 241)$ following $\underline{\mathrm{d}}$-amphetamine than following saline. The response rates for the remaining pigeon (273) decreased slightly across the entire interval following $\underline{\mathrm{d}}$-amphetamine. Terminal response rates at the higher doses (Figure 32) decreased for 2 of 3 pigeons (241 \& 273). At 70\% FFW, a similar effect was found. At all doses, 

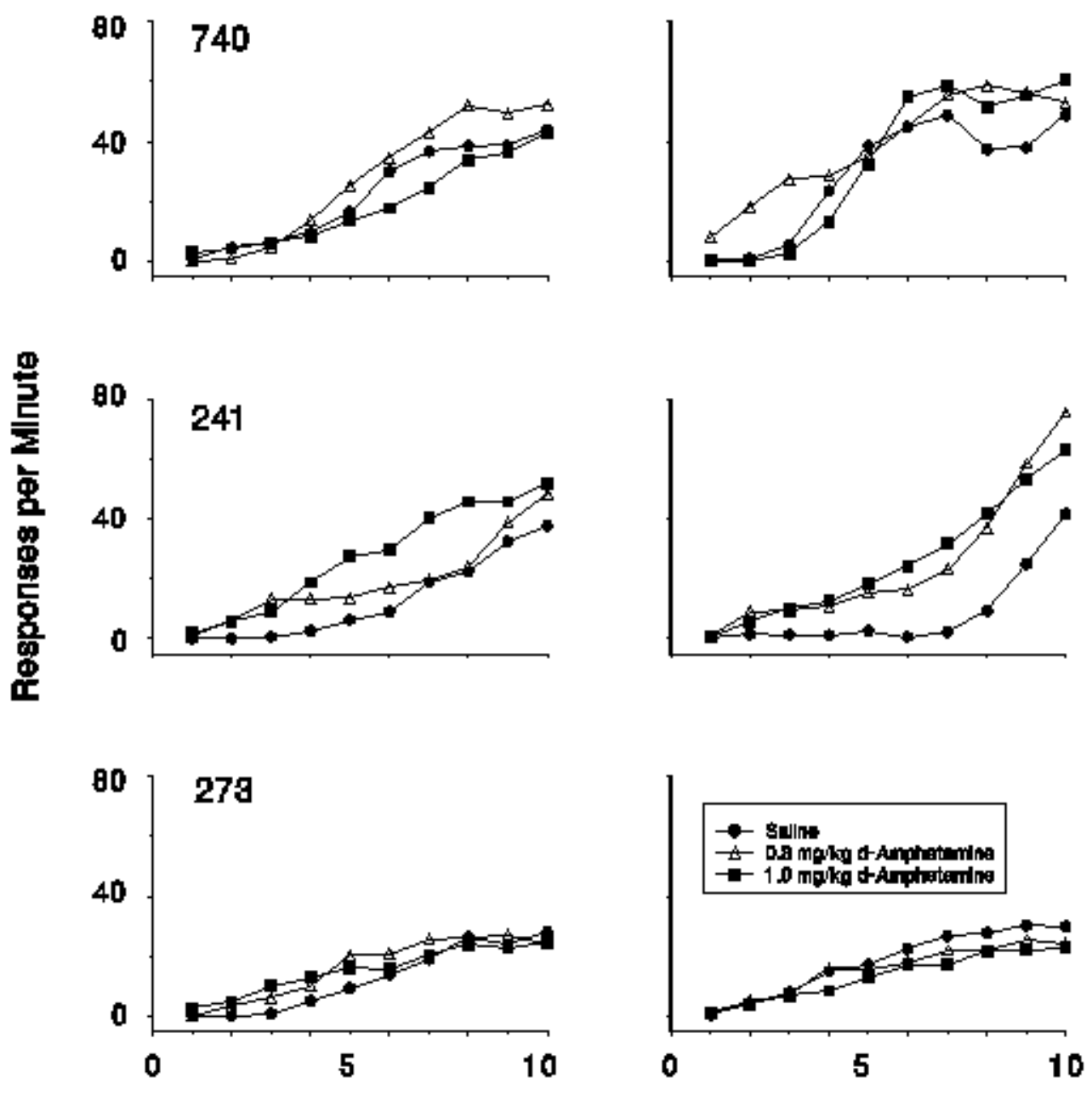

30-s segment of trlal

Figure 29. Response rates in consecutive 30-s bins of FI 5-min intervals for saline and low doses of $\underline{\mathrm{d}}$-amphetamine for each pigeon. Points represent means of determinations of each dose. 

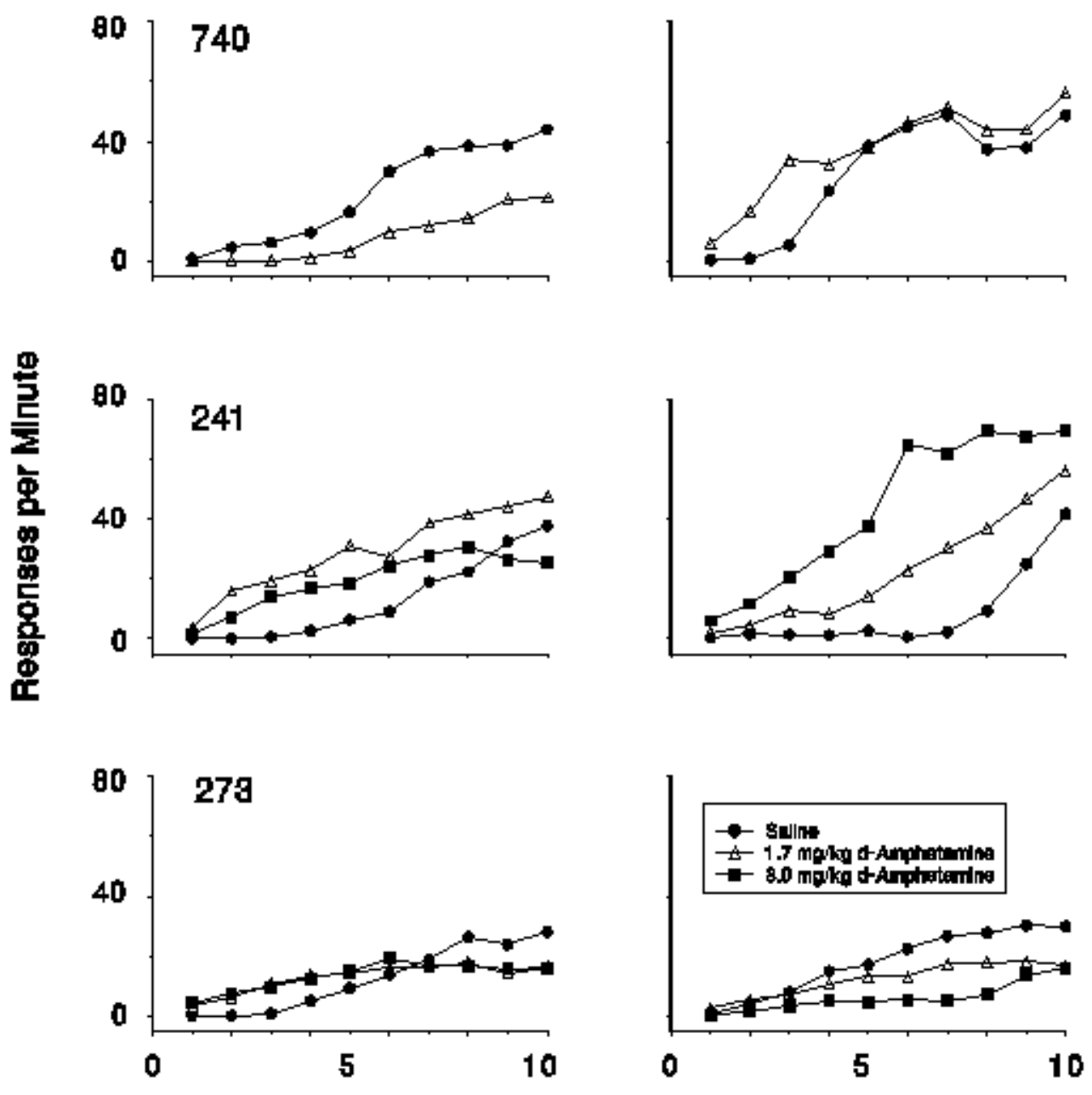

30-s segment of trlal

Figure 30. Response rates in consecutive 30-s bins of FI 5-min intervals for saline and high doses of $\underline{d}$-amphetamine for each pigeon. Points represent means of determinations of each dose. 

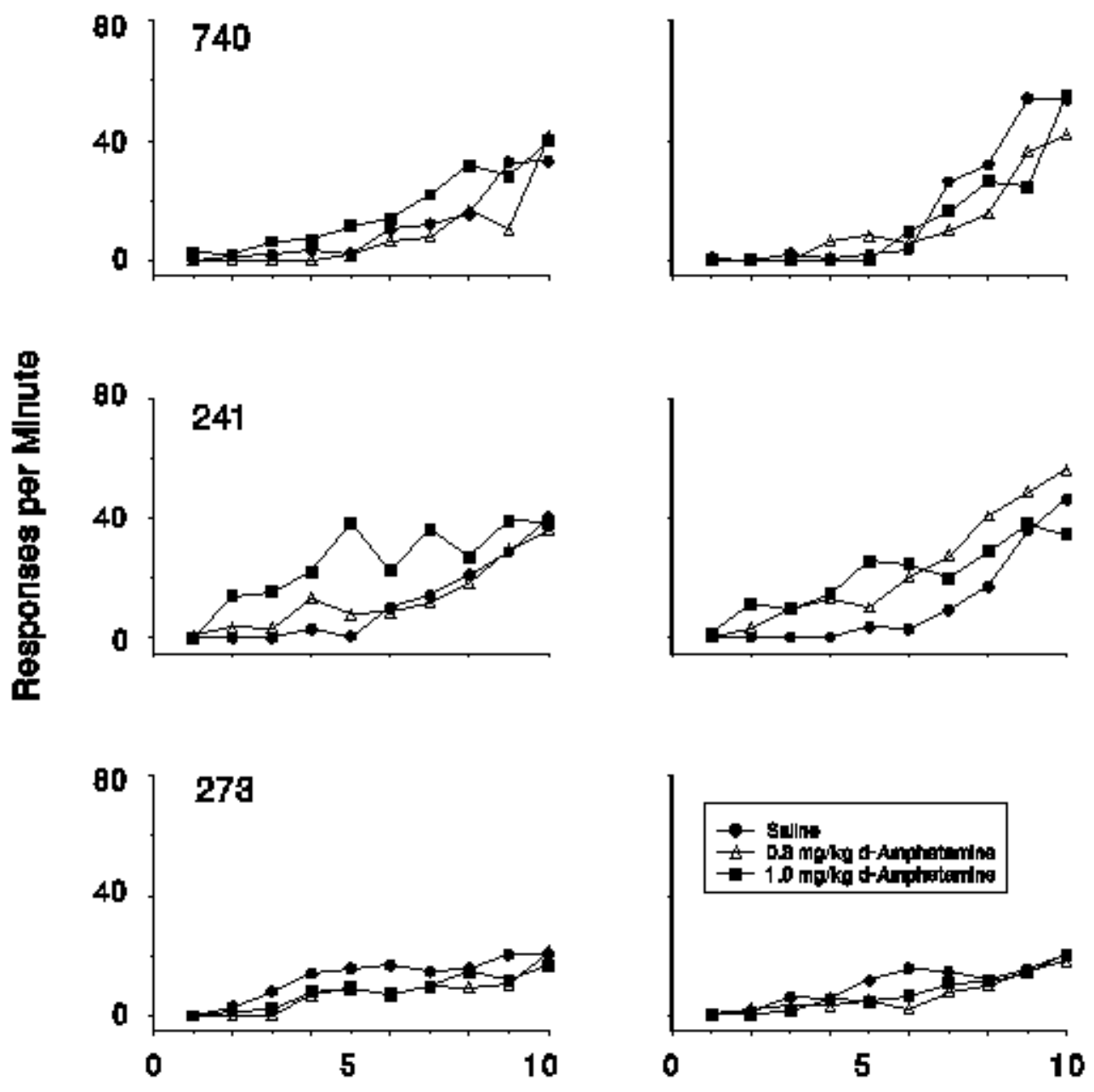

30-s segment of trlal

Figure 31. Response rates in consecutive 30-s bins of concurrent FI 5-min intervals for saline and low doses of $\underline{d}$-amphetamine for each pigeon. Points represent means of determinations of each dose. 

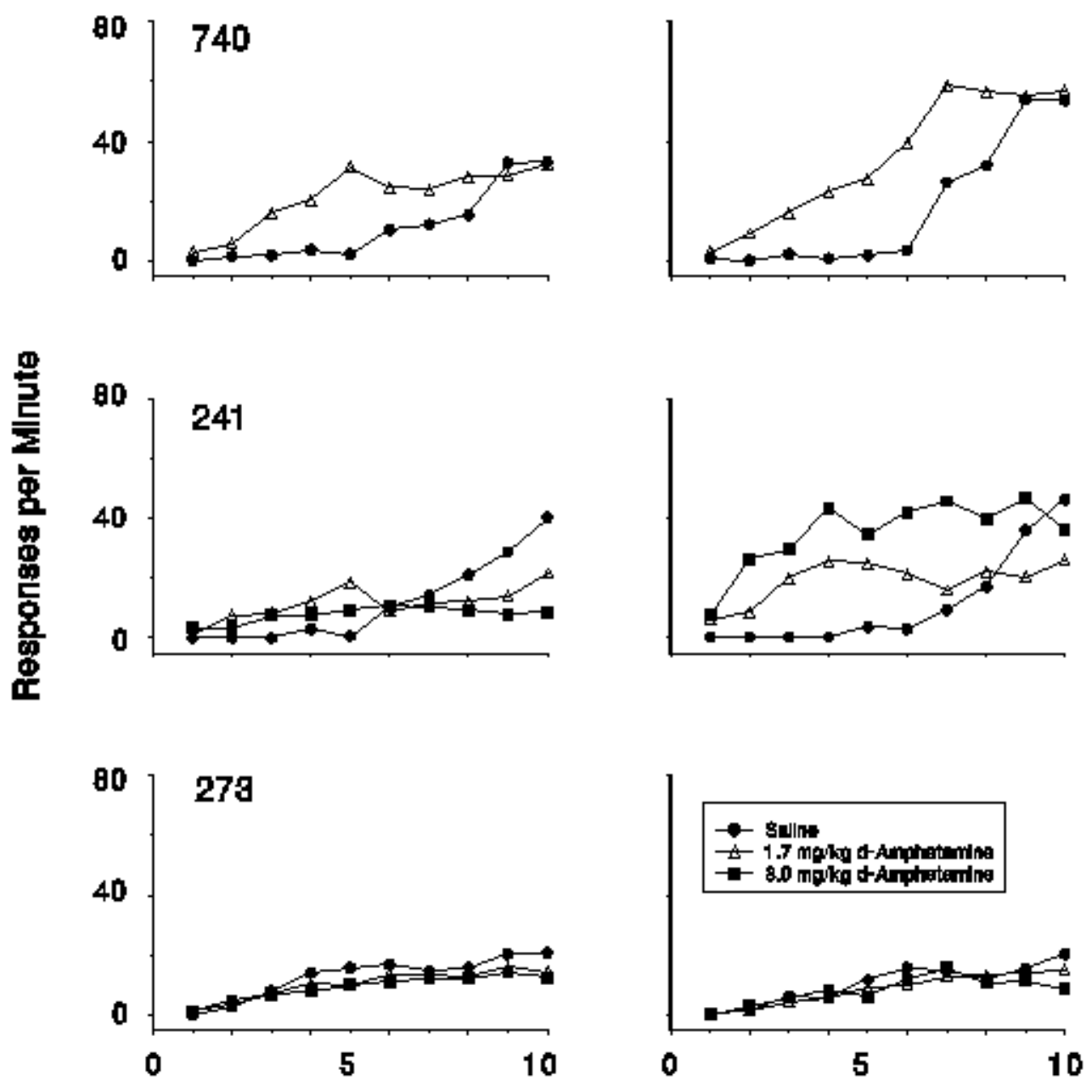

30-s segment of trlal

Figure 32. Response rates in consecutive 30-s bins of FI 5-min intervals for saline and high doses of $\underline{\mathrm{d}}$-amphetamine for each pigeon. Points represent means of determinations of each dose. 
response rates were increased early in the interval for pigeons 740 and 241, while rates were not altered for pigeon 273 . High doses of $\underline{\mathrm{d}}$-amphetamine decreased terminal response rates relative to saline for pigeons 241 and 273 . There were no readily apparent differences between body weights.

Indexes of curvature are presented for both the FI and Concurrent FI schedules at both body weights (Figure 33). At 82.5/85\% FFW, neither schedule reliably produced higher indexes of curvature. Within subjects, the index of curvature for the FI schedule decreased as a function of dose for 2 of 3 pigeons ( $241 \& 273$ ), with the index remained constant for the remaining pigeon (740) with a slight increase at a dose of $1.7 \mathrm{mg} / \mathrm{kg}$. The index of curvature for the concurrent FI schedule decreased as a function of dose for pigeon 241 and had a bitonic function with respect to dose for pigeons 740 and 273. That is, the index first increased and then decreased as a function of dose. At $70 \% \mathrm{FFW}$, neither schedule reliably produced higher indexes of curvature. Within subjects, the index of curvature decreased as a function of dose for one pigeon (241), was relatively constant for pigeon 740 and for pigeon 273 (FI schedule), and was constant for pigeon 273 (concurrent FI schedule).

In the VI schedule (Figures 34 \& 35), response rates following saline administration began at a high level and decreased throughout the interval, ending at a moderate terminal rate at both levels of food deprivation. At 82.5/85\% FFW, response rates following low doses of $\underline{\mathrm{d}}-$ amphetamine were not altered relative to saline. Response rates increased slightly following the lowest dose $(0.3 \mathrm{mg} / \mathrm{kg})$ and were either decreased slightly or unaltered following a dose of 1.0 $\mathrm{mg} / \mathrm{kg}$. Response rates were more substantially decreased at higher doses $(1.7 \& 3.0 \mathrm{mg} / \mathrm{kg})$. At $70 \% \mathrm{FFW}$, response rates following $\underline{\mathrm{d}}$-amphetamine increased for 1 pigeon (740), were unaltered in a second (273), and were decreased in the third pigeon (241) relative to response rates 
$82.5 / 85 \%$ FFW
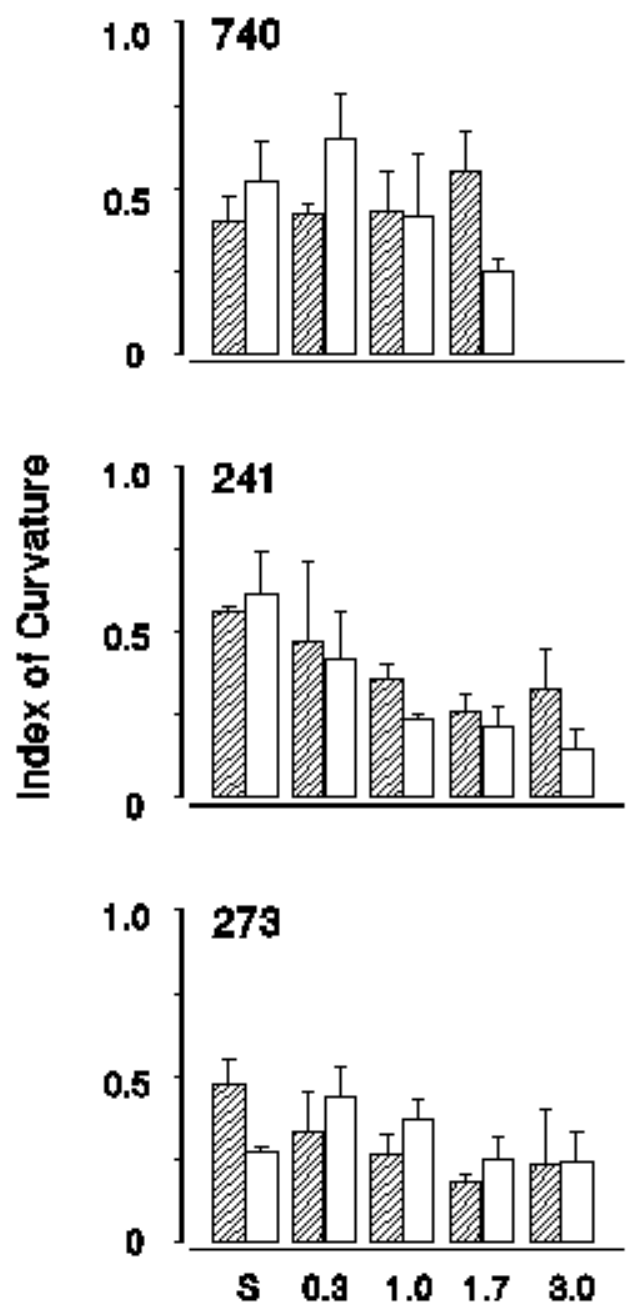

\section{$70 \%$ FFW}
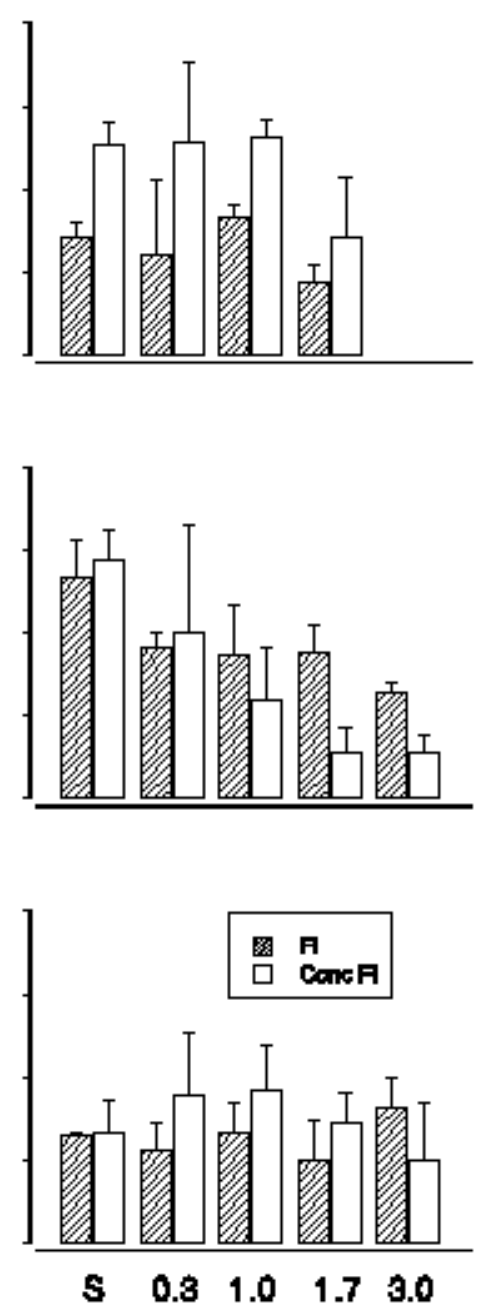

$\mathrm{mg} / \mathrm{kg}$ d-Amphetemine

Figure 33. Indexes of curvature in FI 5-min and concurrent FI 5-min intervals for saline and $\underline{\mathrm{d}}$ amphetamine conditions for each pigeon. Large bars represent means. Error bars represent standard deviations. 

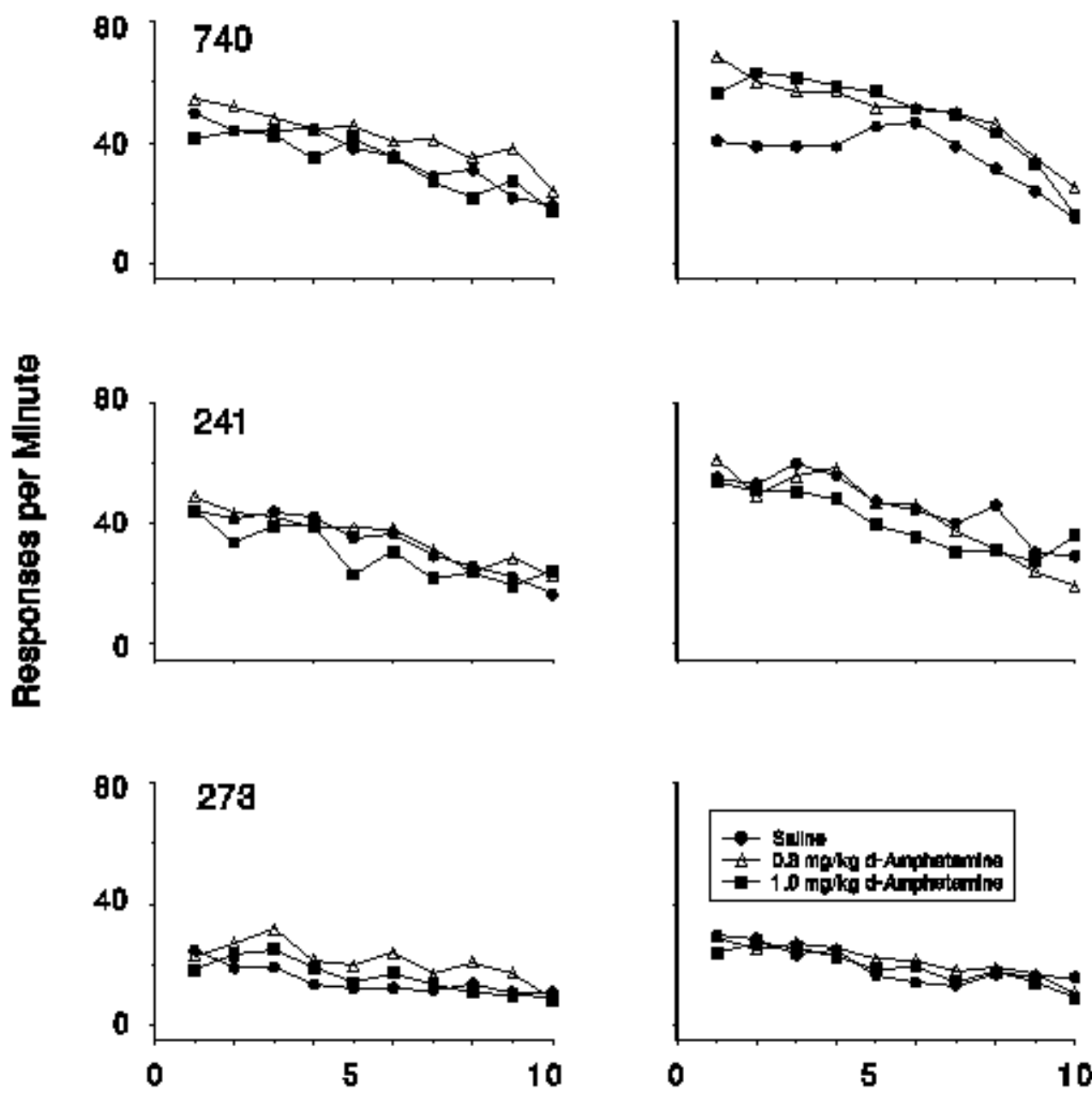

30-s segment of trlal

Figure 34. Response rates in consecutive 30-s bins of concurrent VI 150-s intervals for saline and low doses of $\underline{d}$-amphetamine for each pigeon. Points represent means of determinations of each dose. 

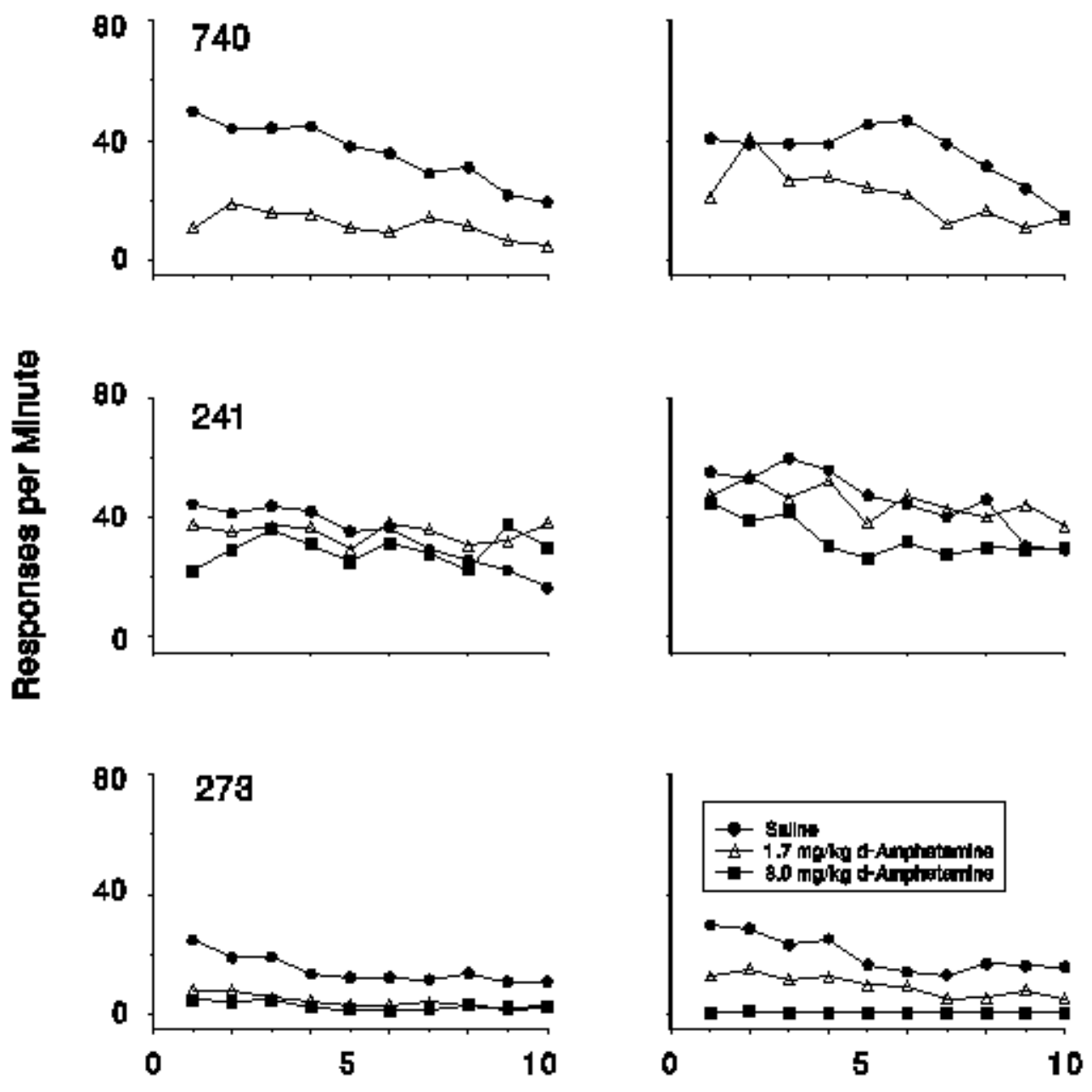

30-s segment of trlal

Figure 35. Response rates in consecutive 30-s bins of concurrent VI 150-s intervals for saline and high doses of $\underline{\mathrm{d}}$-amphetamine for each pigeon. Points represent means of determinations of each dose. 
following saline. Response rates were more reliably suppressed by higher doses. The 70\% FFW maintained higher rates of responding at any given dose of drug, or saline administration, than did $82.5 / 85 \%$ FFW.

The rate-dependency plots (Figure 36) only present data from the $70 \%$ FFW condition, similar to Experiment 1. In the FI schedule, low saline response rates were increased in 9 of 11 panels, the exceptions being $1.0 \mathrm{mg} / \mathrm{kg}$ for pigeon 740 and $3.0 \mathrm{mg} / \mathrm{kg}$ for pigeon 273 . For pigeon 740, a few responses occurred during the initial segments used to calculate the $1.0 \mathrm{mg} / \mathrm{kg}$ plot, whereas no responses occurred in the beginning of the interval following drug administration, producing this difference at low saline response rates relative to the other plots. Following a dose of $3.0 \mathrm{mg} / \mathrm{kg}$, responding was completely suppressed. Other than these exceptions, moderate saline response rates increased following $\underline{\mathrm{d}}$-amphetamine, but to a lesser extent than lower response rates. High saline response rates were decreased slightly or were not altered following d-amphetamine. In the concurrent FI schedule, low saline response rates were reliably increased for pigeon 241 but not for pigeons 740 and 273. Similarly, moderate response rates were affected in a mixed manner, with response rates only reliably increasing for pigeon 241 following $\underline{\mathrm{d}}-$ amphetamine. In contrast, high saline response rates were decreased slightly or not altered following $\underline{\mathrm{d}}$-amphetamine for all subjects. In the VI schedule, all response rates were high compared to the FI-based schedules. These high response rates were decreased slightly or not altered following drug administrations. Rate decreases were more likely at higher doses of $\underline{\mathrm{d}}-$ amphetamine. 


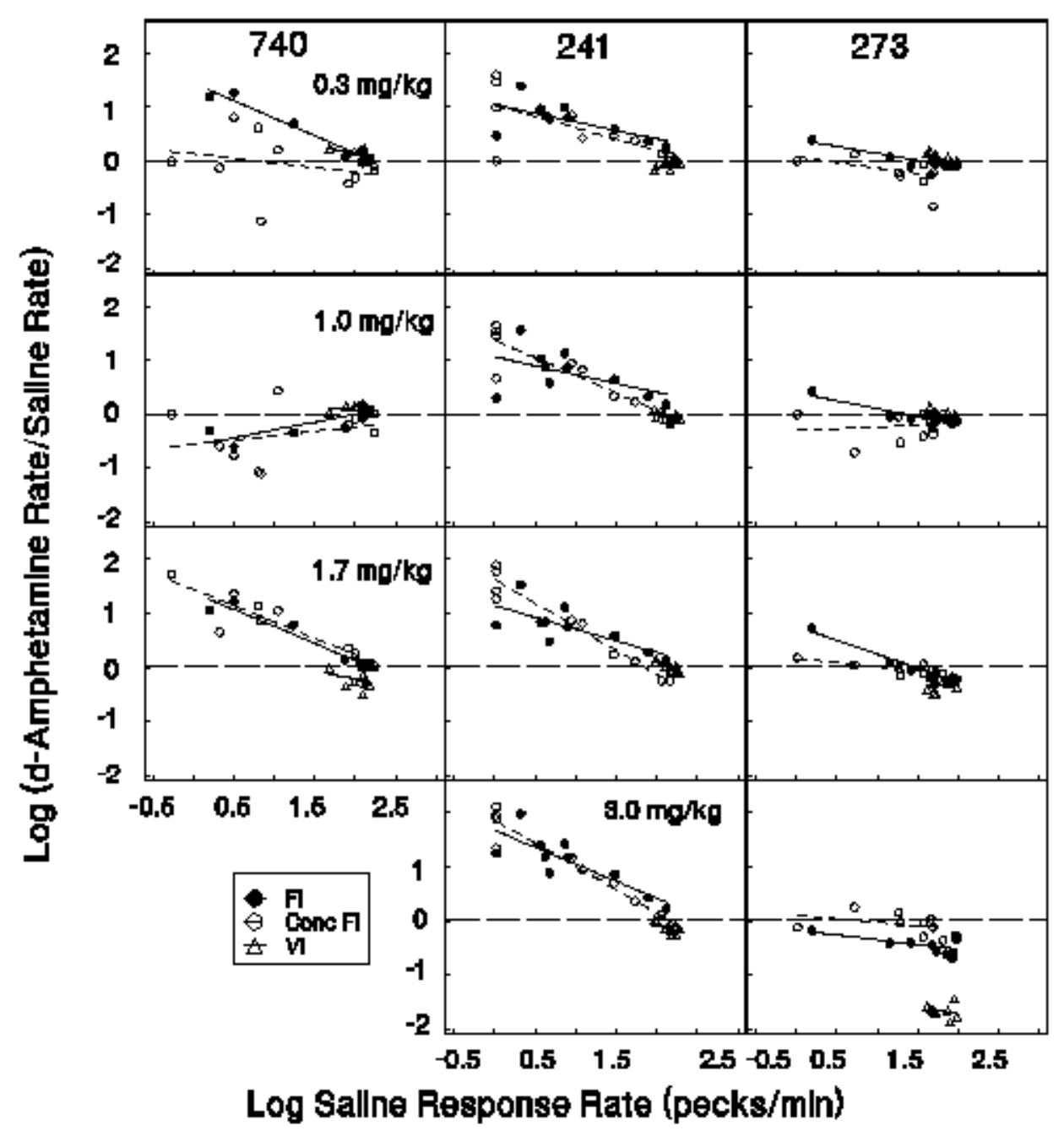

Figure 36. Rate-dependency plots for fixed-interval, concurrent fixed-interval, and concurrent variable-interval schedules for each pigeon following d-amphetamine administration. Dashed lines indicate saline response rates. Points falling above the dashed line indicate rate increases, points falling below the dashed line represent rate decreases relative to saline response rates. 


\section{Discussion}

Experiment 2 was devised to examine the result shown in Experiment 1, where pigeons would leave a source of reinforcement (the left key) in the two-key task to respond to an alternative that was not yet a source of reinforcement (the right key). Would pigeons similarly leave a VI schedule to respond early to an FI schedule of reinforcement? Morphine and $\underline{\mathrm{d}}-$ amphetamine altered the patterns of responding established by the FI and by the concurrent FI VI schedules in a manner consistent with the results of Experiment 1. Pigeons responded earlier on an FI schedule, with a concurrent VI schedule, following drug administration relative to following saline administration. However, pigeons did not reliably respond sooner to the concurrent FI than the single FI schedule. Low rates of responding early in FI trials and in concurrent FI trials were increased following drug administration and high rates of responding late in FI trials were decreased (especially at high drug doses). This was reflected in decreases in the index of curvature, which were common following morphine and less common following $\underline{\mathrm{d}}$ amphetamine. Rates of responding maintained by the VI schedule were similarly affected. High rates of responding early in the interval were decreased following drug and moderate rates towards the end of the interval were increased or not affected. The effects of both drugs were largely rate-dependent though this was more clear with morphine than with $\underline{\mathrm{d}}$-amphetamine; low baseline rates were increased and higher baseline rates were less affected or reduced by low to moderate doses of drug.

Two principal comparisons will be made in evaluating these results. First, FI and concurrent FI patterns of responding will be compared, along with any changes in their respective indexes of curvature. Second, a comparison will be made between the effects of the drugs at the different body weights. 
Following morphine, the index of curvature reliably decreased as a function of dose for both the FI and the concurrent FI schedules. At 70\% FFW, however, decreases in the index were attenuated in subjects 740 and 273 . That is, the index decreased, but not nearly so greatly as it did in the other 2 subjects. However, following $\underline{\mathrm{d}}$-amphetamine, the decreasing trend of the index was not reliable. The most reliable general effect was that the highest doses of $\underline{\mathrm{d}}$-amphetamine reduced indexes of curvature for the two schedules. No reliable differences between the indexes for the 2 schedules were found. That is, neither schedule maintained a higher overall index of curvature.

The second comparison is of the effects of body weight differences. Overall response rates were higher after drug administration when pigeons were maintained at $70 \% \mathrm{FFW}$, with the exception of pigeon 273 ( $\underline{\mathrm{d}}$-amphetamine), whose response rates were roughly the same. Response rates did not differ systematically between body weights under control or saline conditions. Low response rates maintained by both the FI and concurrent FI schedules tended to be more robustly increased across doses (especially higher doses) at 70\% FFW.

Reliable differences between the FI and the concurrent FI schedules were not found. An initial assumption was that the concurrent VI schedule should affect performance under the concurrently available FI. Either the VI would further disrupt FI performance, leading to even greater decreases in the index of curvature relative to the FI alone or the VI schedule might function as a competing response and help to maintain higher indexes of curvature, as it did in subjects 740 and 273 (Figure 25, 70\% FFW). The lack of difference in the FI schedules may have been produced by a difference between this procedure and that of the two-key timing task. The two-key task was $50 \mathrm{~s}$ long (with a change in contingencies $25 \mathrm{~s}$ into a trial), while the concurrent schedule was $5 \mathrm{~min}$ in duration. If one assumes that any sort of temporal 
discrimination errors are likely to occur relatively near to the time at which contingencies change or consequences are delivered, then errors would be most likely nearer the end of the 5-min interval (e.g., perhaps only the last minute), where response rates already tend to be high, and thus less prone to any rate-increasing effects of drugs. In the two-key procedure, errors would be most likely near the middle of the trial (e.g., 15 to $25 \mathrm{~s}$ into a trial) where response rates on the right key were low or moderate and thus potentially prone to rate-increasing effects of drugs.

Experiment 2 may have been improved if more than one VI value could have been tested. It may have been the case that the VI value selected was too rich in comparison to the concurrent FI 5-min schedule. Pigeons may have pecked the key associated with the FI schedule earlier if the VI were leaner (i.e., VI 5-min schedule) or later had the VI been even richer (i.e., VI 30-s schedule). Despite this the patterns of responding maintained by both FI schedules were altered following drug administration. Patterns of responding were altered in a manner consistent with the rate-dependency hypothesis. Low response rates (early in the FI) were increased and high response rates (late in the FI) were decreased or unaltered. No reliable difference was obtained in response rates, patterns, or indexes of curvature between the two FI schedules. Also, in general, $70 \%$ FFW tended to maintain higher rates of responding following drug administration.

\section{General Discussion}

The present study was designed to assess whether different indexes of temporal discrimination were similarly affected following administration of morphine and $\underline{\mathrm{d}}$-amphetamine. Both drugs produced rate-dependent effects that were clearest following morphine. Indexes of temporal discrimination were altered by drugs in both studies, with decreases in the index of curvature occurring in all conditions. Although alterations in the indexes were not always strictly similar, alterations in the patterns of responding under different procedures were found to be 
similar. These alterations were most robust when the pigeons were maintained at a lower $(70 \%$ FFW) body weight. Due to a lack of clear, consistent results in Experiment 2, this discussion will focus primarily on results obtained in Experiment 1.

\section{$\underline{\text { Scalar Expectancy Theory }}$}

It has become common to attribute the changes produced by drugs on behavior in procedures such as these to cognitive processes such as internal clocks. Scalar expectancy theory (SET; Gibbon, 1977; Church \& Gibbon, 1982; Gibbon \& Church, 1992) has most often been employed in this capacity. According to SET, experience with reinforcers distributed regularly in time results in behavior that reflects control by an underlying timing process. This process includes a distribution of remembered reinforcement times from which subjects draw when a to-be-timed interval begins, and an internal clock, or pacemaker, which starts when a tobe-timed interval begins. The pacemaker generates pulses at a very high rate that are passed to an accumulator, which thus keeps track of current clock time. At any point a decision to respond (or not) depends on the discrepancy between the remembered time and the current clock time. When the discrepancy is proportionally small enough, according to a criterion that may vary itself, animals respond (Church \& Gibbon, 1982).

Most often, alterations by drugs in temporally organized behavior have been attributed to changes in pacemaker rate. For example, Maricq, Roberts, and Church (1981) trained 2 groups of rats, one group to respond under the control of an FI 40 s schedule and the other group under an FI 20 s schedule. Occasional peak trials were then inserted, with a stimulus duration of $80 \mathrm{~s}$. A $1.9 \mathrm{mg} / \mathrm{kg}$ dose of methamphetamine produced decreases in the time of peak responding and an increase in the peak spread of the function in both groups of rats. These shifts were explained by supposing that methamphetamine increased the speed of the internal clock (and, thus, caused on 
overestimation of elapsed time). Changes in clock speed are indicated by fairly uniform, coherent shifts in distributions of temporally organized behavior. Some previous studies (Maricq et al., 1981; Bayley et al., 1998) obtained a decrease in the peak time, but there was not actually a coherent shift of the entire function. The entire function broadened, such that response rates increased earlier, but they were also higher later in a trial following drug compared to vehicle. The increase on the early side tended to be greater. This was not the case with Kraemer et al. (1997), who did demonstrate coherent shifts without a broadening of the peak function.

Changes such as these were apparently observed in all pigeons in the two-key task (Experiment 1). That is, coherent leftward shifts in the psychophysical functions were obtained. This is consistent with notions of an internal clock that has been sped up for both morphine and d-amphetamine. A closer analysis, however, reveals that what was obtained may not merely reflect increases in pacemaker rate. Rate-dependency plots can be used to distinguish a change in clock speed from a more general, rate-dependent effect. A general, rate-dependent effect produces linear, decreasing functions, whereas a change in clock speed produces a more distinctive pattern dependent on the procedure. In a two-key procedure, a faster clock should produce data with right key response rates being increased (or unchanged) relative to baseline and left key response rates being reduced (or unchanged) relative to baseline. Response patterns for subject 4438 in two-key trials are shown in Figure 37, along with the pattern that would be produced if pacemaker speed were altered to shift the T-50 and other responding to the left by 5 s. Below those panels are the hypothetical rate-dependency plot that would be produced along with a reproduction of an obtained rate-dependency plot following $\underline{\mathrm{d}}$-amphetamine administration. The rate-dependency plot that would occur if pacemaker speed had been altered is quite distinct, and is not what was actually obtained. If the rate of a hypothetical pacemaker 

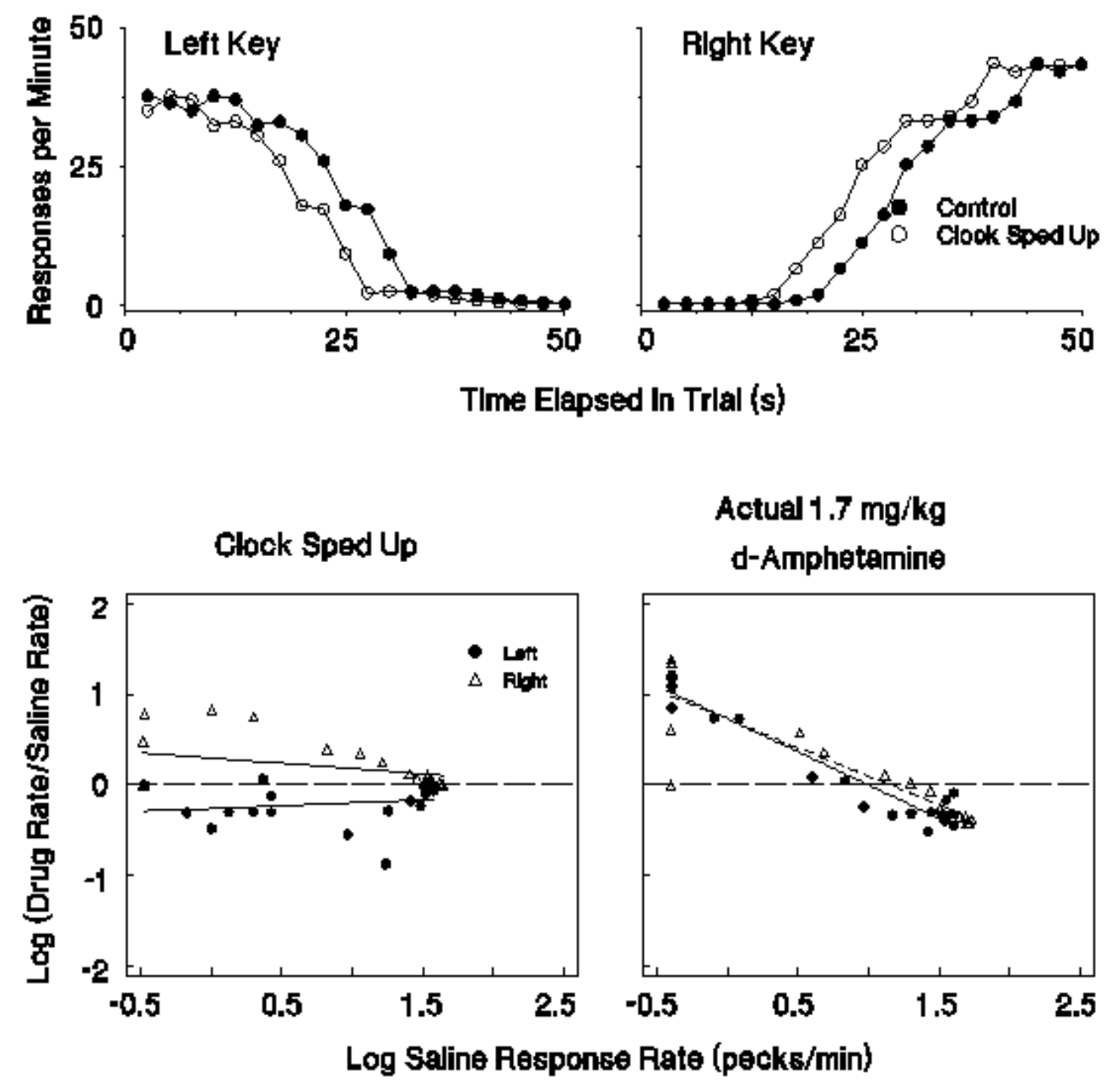

Figure 37. Comparison of obtained data in the two-key procedure with hypothetical data where a hypothetical clock had been sped up by $5 \mathrm{~s}$. Response rates of control (obtained) and clock sped up (hypothetical) performance are plotted for left and right keys in the top panels. The ratedependency plot based on the hypothetical data and an actual, obtained rate-dependency plot are in the bottom panels. Dashed lines indicate saline response rates. Points falling above the dashed line indicate rate increases, points falling below the dashed line represent rate decreases relative to saline response rates. 
had been increased, right-key and left-key responding would be differentially affected (with one increasing and the other decreasing). However, obtained plots indicate that responding on the two keys is similarly affected by drug administration. An inspection of other two-key ratedependency plots reveals that only rarely are left-key response rates all decreased, suggesting that although changes in the timing index may be observed, those changes do not always indicate a change in the pacemaker rate.

Similar hypothetical plots are presented for peak trials (Figure 38). If clock speed were increased, a distinctive, fishing hook-like plot of data would be obtained; whereas a more general, rate-dependent change would produce a more strictly linear function. Obtained results as shown in Figure 38 clearly differ from results that would be expected due to changes in pacemaker speed. An inspection of the other rate-dependency plots shows that a linear function is most commonly obtained. However, plots for P2238 following morphine (Figure 8) appear similar to hypothetical clock plots. Thus, although changes in the time of peak responding may be obtained, they do not always necessarily indicate a change in pacemaker rate.

The changes in peak performance produced by drug in the present study can be attributed neither solely to alterations in clock speed nor to changes in the distribution of remembered reinforced durations because, although peak patterns of responding were robustly changed by drug, the peak time was not reliably changed as it was in the two-key task. If the distribution of remembered times were shifted leftward (shorter remembered durations) or rightward (longer remembered durations), the peaks of the functions would have been similarly affected. Two other possibilities are suggested by SET, however. One is that a drug alters the discrepancy between the current clock time and the remembered reinforcement time that is deemed by subjects as "close enough" to respond, i.e., the threshold. Threshold variance may be assumed in 

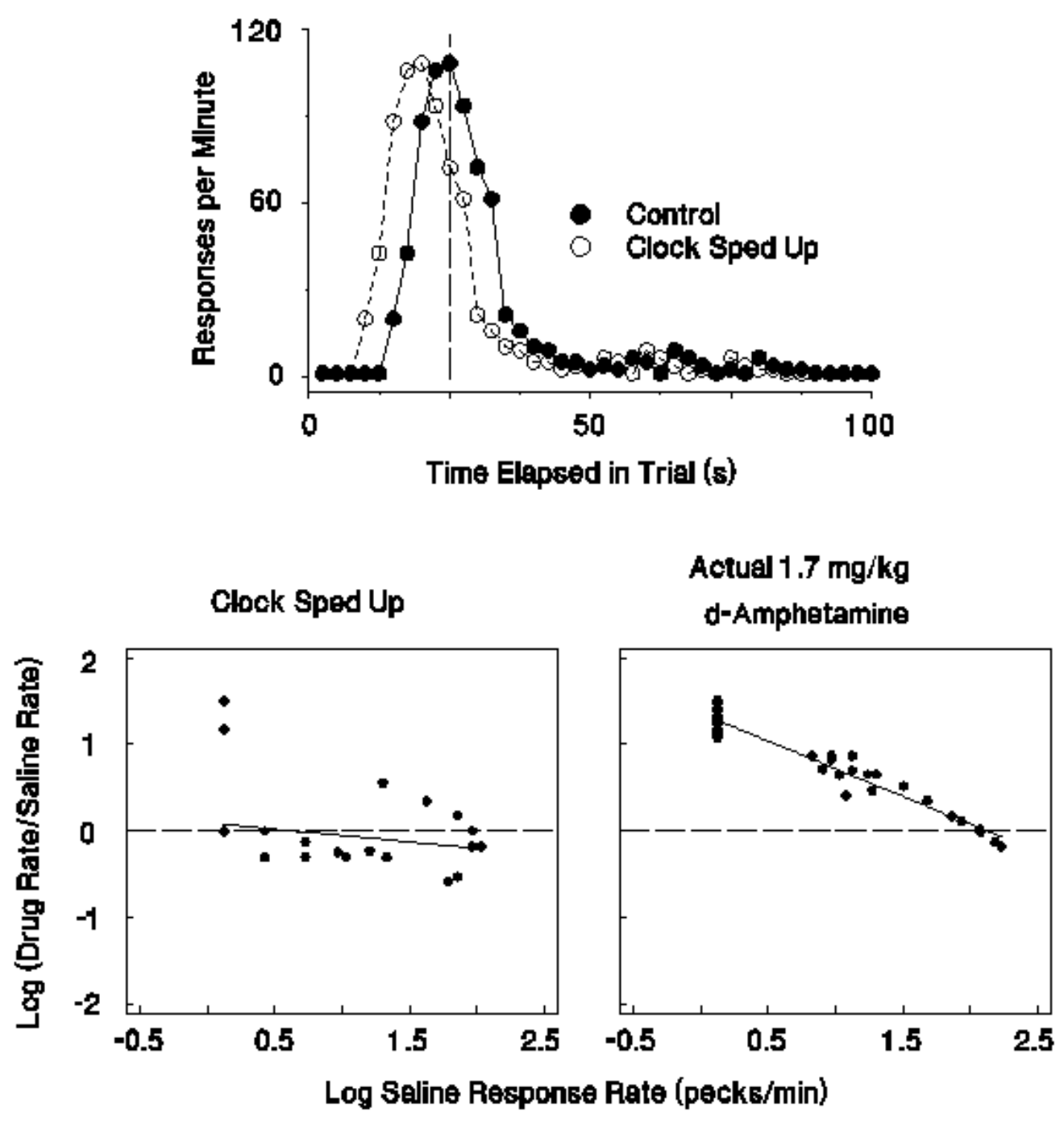

Figure 38. Comparison of obtained data in the peak procedure with hypothetical data where a hypothetical clock had been sped up by $5 \mathrm{~s}$. Response rates of control (obtained) and clock sped up (hypothetical) performance are plotted in the top panel. The dashed line indicates the point 25 $\mathrm{s}$ into the trial. The rate-dependency plot based on the hypothetical data and an actual, obtained rate-dependency plot are in the bottom panels. Dashed lines indicate saline response rates. Points falling above the dashed line indicate rate increases, points falling below the dashed line represent rate decreases relative to saline response rates. 
those conditions in which the "middle" of a trial (the "peak time") is unaltered and the "start" and "stop" times (in PI trials) change in oppo site directions (Gibbon \& Church, 1992). In the present results, the drugs may have lowered the start time and raised the stop time (i.e., the drugs may have greatly expanded the threshold). The increased tendency to respond earlier and later in PI trials after drug, in particular during the $70 \%$ FFW condition, is consistent with this interpretation. A decrease in the start time is also consistent with the obtained shifts to the left of the functions in the two-key procedure, where there is no "stopping" $r$ equired.

Church and Gibbon (1982) suggested another interesting possibility. In their application of SET to temporal generalization gradients, they made clear that the timing process that SET describes depends on subjects attending to the temporal stimulus. If the subject fails to attend to the stimulus (i.e., if the probability of attending, or $\mathrm{p}(\mathrm{A})$, falls to low levels) it may nevertheless respond with some probability which is dependent on the subject's motivational level, the value of the reinforcer, the effort of the response, etc. The overall probability of responding is called the subject's 'responsiveness" (Church \& Gibbon, 1982). It can be assumed of pigeons in the current experiment, particularly in the $70 \%$ FFW condition, that they were fairly responsive. Thus, the probability of a response when pigeons failed to attend (indicated as $\mathrm{p}(\mathrm{R} \mid \sim \mathrm{A})$ in Church \& Gibbon, 1982) was, presumably, fairly high. A complete absence of attention to the duration of the FI/PI stimulus $(\mathrm{p}(\mathrm{A})=0)$ would result in pecking that was undifferentiated in time and the rate of which was determined by $\mathrm{p}(\mathrm{R} \mid \sim \mathrm{A})$. This was observed in $\mathrm{P} 4244$ following high doses of morphine while maintained at 70\% FFW (Figure 4). However, in general, neither drug produced reliable, undifferentiated responding across the peak interval, although higher doses did seem to make behavior less differentiated, that is flatter. It may be that morphine and $\underline{\mathrm{d}}$-amphetamine caused a decrease in attention, or a fading in and out of attention, or attention 
during some trials but not during others, so that the distribution of pecking was still roughly inverted U-shaped while the tendency to respond early and later in the trials was increased. This is not inconsistent with Meck and Church's (1984) observation reg arding attention following morphine administration, where they noted that attention, in general, decreased following drug administration. Other drugs have also been shown to alter sustained attention (it is assumed that attending to a temporal stimulus is a sustained attention task) as measured using variations on vigilance tasks (Givens \& McMahon, 1997; Grilly, Gowans, McCann \& Grogan, 1989; Koelega, 1993; McGaughy \& Sarter, 1995). These experiments have shown that psychomotor stimulants often enhance measures of sustained attention (Grilly et al., 1989; Koelega, 1993) and that drugs such as chlordiazepoxide (McGaughy \& Sarter, 1995) and ethanol (Givens \& McMahon, 1997) disrupt it. Morphine may, thus, have altered FI/PI performance either by greatly expanding the pigeons' criterion for responding based on the discrepancy between the current clock time and remembered reinforcement times, or by, in a sense, taking the timing process "off -line" by reducing attention to the temporal stimulus. The account does not apply as clearly to $\underline{\mathrm{d}}-$ amphetamine, given that $\underline{\mathrm{d}}$-amphetamine can actually improve attention and not reduce it.

The attention interpretation is consistent with recent experiments by Odum and Schaal (1999, 2000). In Odum and Schaal (1999), the effects of morphine were tested in pigeons pecking for food under a multiple FI 5-min clocked FI 5-min schedule (similar to the procedure of Laties \& Weiss, 1966). During the clocked FI schedule, different external stimuli were presented during each successive fourth (75 s) of the interval. Morphine produced the typical effects on performance in the FI component, as indicated by reductions in the index of curvature, but did not alter the temporal pattern of responding in the clocked FI component. Reductions in the index of curvature during the final 75 s of the clocked FI (i.e., during the last clock stimulus) 
were comparable, however, to the reductions in the index of curvature during the entire FI 5-min schedule. In the terms of the present interpretation, attention to the time since the last reinforcer was eliminated during the first three stimuli of the clocked FI schedule, i.e., timing was not necessary. Attention was required during the last clock stimulus, however. A morphine-induced reduction in attention to the to-be-timed interval should have no effect on performance during the first three clock stimuli because pigeons were not timing them in the first place. It would be expected to alter performance during the last stimulus, however, because timing was required then.

In the Odum and Schaal (2000) experiment, temporal discrimination was assessed more directly. Pigeons were trained to peck on an FI 60-s schedule. Occasionally during fixed intervals, the center key was turned off and the side keys were lit green or red. If a short time had passed since the last reinforcer, a peck to the green key was reinforced; if a long time had passed since the last reinforcer, a peck to the right key was reinforced (i.e., an interval bisection procedure was superimposed on an FI schedule; Stubbs, Vautin, Reid \& Delehanty, 1978). Thus, performance on the FI schedule was assessed at the same time as discrimination of the time since the last reinforcer. Morphine produced the same effect on the temporal distribution of behavior under the FI schedule as it did in the current experiment (and as it did in Odum et al., 1998). The disruption in the temporal pattern of performance was accompanied by general disruptions in accuracy on the timing trials. The timing function did not shift uniformly left or right, but rather timing accuracy was reduced at each tested interval. This is precisely the kind of effect one would predict based on an assumption that morphine reduced $p(A)$, or the probability of attending to the time since the last reinforcer. Thus, an attention mechanism would seem to 
explain both the disruption in the temporal pattern of behavior on the FI schedule and the disruption in accuracy on the timing trials.

If the alterations in FI/PI performance produced by drugs can not be explained in terms of changes in clock speed or the distribution of remembered reinforcement times, can such mechanisms be held responsible for the largely uniform shifts to the left of the timing functions obtained in the two-key procedure? If we had only tested drugs on behavior in this procedure we might be led to conclude that an increase in clock speed caused pigeons to overestimate elapsed time, thus causing them to switch from the left to the right key much earlier than they did in the absence of drug. Because drugs did not reliably change peak time in the FI/PI trials it is worth considering whether the effects of drugs on performance in the two-key procedure were fundamentally different or the same. A possibility is that the processes controlling the two performances under baseline conditions were themselves different, and as such, they were altered differently by the addition of either drug.

However, as outlined in the Discussion for Experiment 1, it seems much more parsimonious to suggest that the same mechanism underlies the effects of the two drugs in both procedures. That is, rather than asserting that clock speed was increased, and therefore timing functions were shifted left, in the two-key procedure, but clock speed was not altered in the FI/PI procedure, it could be suggested that the probability of attending to time in the trial was reduced by drugs, especially at higher doses. What is left is to explain why a reduction in $\mathrm{p}(\mathrm{A})$ would cause pigeons to switch to the right key so much earlier in the trial. To do that it is necessary to consider the similarities between the contingencies maintaining right-key pecking in the two-key procedure and those maintaining center-key pecking in the FI (and PI) procedure. In both cases reinforcement was not available until $25 \mathrm{~s}$ had elapsed. In the FI/PI trials, most frequently that 
reinforcer was delivered shortly thereafter, but because occasionally the PI trials were presented, reinforcement was not guaranteed. In the two-key procedure, reinforcement for right-key responding was also available after $25 \mathrm{~s}$, sometimes very shortly after the $25 \mathrm{~s}$ had elapsed, but sometimes not at all. During FI trials pigeons "\$witched" from not -pecking to pecking as the 25 $\mathrm{s}$ elapsed; during the two-key trials pigeons switched from left- to right-key pecking as the $25 \mathrm{~s}$ elapsed. Drug administration may have hastened the point in the trial at which this switch was made, perhaps by reducing attention to the trial stimuli. With a lack of attention, there is a tendency for responding to occur at some default rate. The shift to the left of the two-key timing functions, as opposed to a shift to the right or undifferentiated switching, occurred because under baseline conditions "switching -from-left-to-right" was the most probable behavior of the pigeon. Switching back the other way almost never occurred, so would have had a default response rate of almost zero that would occur in times where the probability of attending was zero.

\section{Rate-Dependency and Stimulus Control}

The present experiments provided rate-dependency plots for each drug and for each procedure at $70 \% \mathrm{FFW}$. In each case, the results conformed to the general rate-dependency hypothesis. That is, rates of responding following drug administration were inversely related to control (saline) response rates. Low response rates following saline administration tend to be increased following drug administration and high response rates following saline administration tend to be decreased or maintained following drug administration.

The present experiments, however, also may have provided a further demonstration of a well-established exception to rate dependency, that low response rates under strong stimulus control are often resistant to the rate-increasing effects of drugs (Laties \& Weiss, 1966; Odum \& Schaal, 1999; for review see Kelleher \& Morse, 1968; Robbins, 1981). These exceptions are 
observed in the previously mentioned 'tail" of PI rate -dependency plots (Figures $8 \& 20$ ) and differential drug effects to similar response rates in the two-key procedure (Figures $9 \& 21$ ). Temporal stimulus control may have been stronger, and less likely to be altered by drugs, under certain situations in the present experiments. In particular, responding was less likely to be altered in a rate-dependent manner in the periods following the peak-time in peak trials, following the switch between keys in two-key trials, and early in concurrent FI VI intervals. The time that reinforcement occurs in FI trials serves to establish a strong stimulus context for responding to decrease late in PI trials, because reinforcement never occurs so late in an interval with the red, center key. Similarly, in two-key trials, switches occurred from the left to the right key, and a switch back was uncommon. Perhaps this behavior pattern helped to produce a temporal stimulus context strong enough to attenuate the rate-increasing effect of morphine and d-amphetamine on low baseline rates of responding on the left key late in two-key trials.

Behavior maintained by the concurrent FI VI schedule may have been similarly affected. That is, the concurrently available VI schedule and the strong behavior it generated may have served to protect the low-rate responding generated by the FI schedule.

It is worth noting that some of the small differences in behavior maintained by the different schedules based on which drug has been administered may be due to the nature of the interaction of that drug's rate-dependent effects and stimulus control. It might be that the ratedependent effects of $\underline{\mathrm{d}}$-amphetamine are less influenced by stimulus control, whereas morphine might be more subject to stimulus control. That is, the extent of stimulus control can attenuate a drug's disruptive, rate-dependent effects on behavior, with behavior under strong stimulus control being resistant to alteration by drugs (Sanger \& Blackman, 1976). The “tail' observed in the rate-dependency plots for peak trials seems to support this (Figures $8 \& 20$ ). The "tail" is 
much larger (top to bottom) following morphine administration than following $\underline{\mathrm{d}}$-amphetamine and it might also help to explain why right-key responding seems to be more affected by rateincreases following morphine than it is following $\underline{\mathrm{d}}$-amphetamine. However, this is not to say that the behavioral effects of $\underline{\mathrm{d}}$-amphetamine cannot be altered by stimulus control (see Laties, Wood, \& Rees, 1981; Rees, Wood, \& Laties, 1985).

It is also possible that rates of responding that are under discriminative stimulus control, whether it is a temporal or other stimulus, can be altered by drug without altering stimulus control itself. Effects such as these have previously been described in work conducted by Katz (1982, 1983, 1988). Katz trained pigeons to peck at either an amber-colored key or a red-colored key, both of which were available during any given component. A multiple schedule was arranged, during one component the houselight was on and red key-pecks were reinforced according to an FI 5-min schedule, during the other component the houselight was off and amber key-pecks were reinforced according to an FI 5-min schedule. Rates of responding to the two keys and the stimulus control over responding by the houselight were assessed. Stimulus control was measured using a signal-detction/matching-type analysis to separate sensitivity (stimulus control) from bias. Katz found that a number of drugs (ㅁ-amphetamine, cocaine, pentobarbital, promazine) produced clear alterations in response rates at doses below those that affected stimulus control, and that stimulus control only tended to decrease at the highest drug doses. Katz concluded, 'These studies, although implicating stimulus control as an important feature in determining the way the drug affected behavior, did not, however, demonstrate that the drug affected stimulus control"'(Katz, 1982, p. 622). The effects of drugs on response rates under discriminative stimulus control helps to demonstrate that the stimuli had a role, but it does not suggest that the discriminative stimuli fully controlled behavior. Applied to the present findings, 
schedules of reinforcement establish rates of responding that change (differ) with the passage of time. Drugs then act on these established baselines of responding but do not act on the variables that control the baseline performance (timing). 


\section{References}

Bayley, P. J., Bentley, G. D., \& Dawson, G. R. (1998). The effects of selected antidepressant drugs on timing behavior in rats. Psychopharmacology, 136, 114-122.

Bizo, L. A., \& White, K. G. (1994a). The behavioral theory of timing: Reinforcer rate determines pacemaker rate. Journal of the Experimental Analysis of Behavior, 61, 19-33.

Bizo, L. A., \& White, K. G. (1994b). Pacemaker rate in the behavioral theory of timing. Journal of Experimental Psychology: Animal Behavior Processes, 20, 308-321.

Bizo, L. A., \& White, K. G. (1995). Biasing the pacemaker in the behavioral theory of timing. Journal of the Experimental Analysis of Behavior, 64, 225-235.

Branch, M. N., \& Gollub, L. R. (1974). A detailed analysis of the effects of damphetamine on behavior under fixed-interval schedules. Journal of the Experimental Analysis of Behavior, 21, 519-539.

Carroll, M. E., \& Meisch, R. A. (1984). Increased drug-reinforced behavior due to food deprivation. In T. Thompson, P. B. Dews, \& J. E. Barrett (Eds.), Advances in behavioral pharmacology (Vol. 4, pp. 47-88). New York: Academic Press.

Catania, A. C. (1970). Reinforcement schedules and psychophysical judgments: A study of some temporal properties of behavior. In W. N. Schoenfeld (Ed.), The theory of reinforcement schedules. New York: Appleton-Century-Crofts.

Chiang, T. -J., Al-Ruwaitea, A. S. A., Ho, M. -Y., Bradshaw, C. M., \& Szabadi, E. (1998). The influence of ' switching' on the psychometric function in the freperant psychophysical procedure. Behavioural Processes, 44, 197-209.

Chiang, T. -J., Al-Ruwaitea, A. S. A., Ho, M. -Y., Bradshaw, C. M., \& Szabadi, E. (1999). Effect of central 5-hydroxytryptamine depletion on performance in the free-operant 
psychophysical procedure: facilitation of switching, but no effect on temporal differentiation of responding. Psychopharmacology, 143, 166-173.

Chiang, T. -J., Al-Ruwaitea, A. S. A., Mobini, S., Ho, M. -Y., Bradshaw, C. M., \& Szabadi, E. (2000). The effect of $\underline{\mathrm{d}}$-amphetamine on performance on two operant timing schedules. Psychopharmacology, 150, 170-184.

Church, R.M., \& Gibbon, J. (1982). Temporal generalization. Journal of Experimental Psychology: Animal Behavior Processes, 8, 165-186.

Cole, S. O. (1967). Experimental effects of amphetamine: A review. Psychological Bulletin, 68, 81-90.

Dews, P. B. (1955a). Studies on behavior. I. Differential sensitivity to pentobarbital of pecking performance in pigeons depending on schedule of reward. Journal of Pharmacology and Experimental Therapeutics, 113, 393-401.

Dews, P. B. (1955b). Studies on behavior. II. The effects of pentobarbital, methamphetamine and scopolamine on performance in pigeons involving discriminations. Journal of Pharmacology and Experimental Therapeutics, 115, 380-389.

Dews, P. B. (1957). Studies on behavior. III. Effects of scopolamine on reversal of a discriminatory performance in pigeons. Journal of Pharmacology and Experimental Therapeutics, 119, 343-353.

Dews, P. B. (1958a). Studies on behavior. IV. Stimulant actions of methamphetamine. Journal of Pharmacology and Experimental Therapeutics, 122, 137-147.

Dews, P. B. (1958b). Analysis of effects of psychopharmacological agents in behavioural terms. Federation Proceedings, 17, 1024-1030. 
Dews, P. B., \& Wenger, G. R. (1977). Rate-dependency of the behavioral effects of amphetamine. In T. Thompson \& P. B. Dews (Eds.), Advances in behavioral pharmacology (Vol. 1, pp. 167-227). New York: Academic Press.

Ferster, C. B., \& Skinner, B. F. (1957). Schedules of reinforcement. Acton, MA: Copley Publishing Group.

Fleshler, M., \& Hoffman, H. S. (1962). A progression for generating variable-interval schedules. Journal of the Experimental Analysis of Behavior, 5, 529-530.

Fry, W., Kelleher, R. T., \& Cook, L. (1960). A mathematical index of performance on fixed-interval schedules of reinforcement. Journal of the Experimental Analysis of Behavior, 3, 193-199.

Gibbon, J. (1977). Scalar expectancy theory and Weber's law in animal timing. Psychological Review, 84, 279-325.

Gibbon, L., \& Church, R. M. (1992). Comparison of variance and covariance patterns in parallel and serial theories of timing. Journal of the Experimental Analysis of Behavior, 57, 393406.

Gillette, M. U., \& Tischkau, S. A. (1999). Suprachiasmatic nucleus: the brain's circadian clock. Recent Progress in Hormone Research, 54, 33-58.

Givens, B., \& McMahon, K. (1997). Effects of ethanol on nonspatial working memory and attention in rats. Behavioral Neuroscience, 111, 275-282.

Gollub, L. R., \& Mann, W. G. (1969). The interaction of amphetamine and body weight on a food-reinforced operant. Psychopharmacologia, 15, 64-72.

Gonzalez, F. A., \& Byrd. L. D. (1977). Mathematics underlying the rate-dependency hypothesis. Science, 195, 546-550. 
Grilly, D. M., Gowans, G. C., McCann, D. S., \& Grogan, T. W. (1989). Effects of cocaine and d-amphetamine on sustained and selective attention in rats. Pharmacology, Biochemistry, and Behavior, 33, 733-739.

Heffner, T. G., Drawbaugh, R. B., \& Zigmond, M. J. (1974). Amphetamine and operant behavior in rats: Relationship between drug effect and control response rate. Journal of Comparative and Physiological Psychology, 86, 1031-1043.

Heifertz, S. A., \& McMillan, D. E. (1971). Development of behavioral tolerance to morphine and methadone using the schedule-controlled behavior of the pigeon. Psychopharmacologia, 19, 40-52.

Hill, R. T. (1970). Facilitation of conditioned reinforcement as a mechanism of psychomotor stimulation. In E. Costa and S. Garattini (Eds.), Amphetamines and related compounds (pp. 781-795). New York: Raven Press.

Howell, L. L., Byrd, L. D., \& Marr, M. J. (1986). Similarities in the rate-altering effects of white noise and cocaine. Journal of the Experimental Analysis of Behavior, 46, 381-394.

Katz, J. L. (1982). Effects of drugs on stimulus control of behavior. I. Independent assessment of effects on response rates and stimulus control. Journal of Pharmacology and Experimental Therapeutics, 223, 617-623.

Katz, J. L. (1983). Effects of drugs on stimulus control of behavior. II. Degree of stimulus control as a determinant of effect. Journal of Pharmacology and Experimental Therapeutics, 226, 756-763.

Katz, J. L. (1988). Effects of drugs on stimulus control of behavior. III. Analysis of effects of pentobarbital and $\underline{\text { d}}$-amphetamine. Journal of Pharmacology and Experimental Therapeutics, 246, 76-83. 
Katz, J. L., \& Goldberg, S. R. (1986). Effects of ethyl-ketazocine and morphine on schedule-controlled behavior in pigeons and squirrel monkeys. Journal of Pharmacology and Experimental Therapeutics, 239, 433-441.

Kelleher, R. T., \& Morse, W. H. (1968). Determinants of the specificity of the behavioral effects of drugs. Ergebnisse der Physiologie Biologischen Chemie und Experimentallen Pharmakologie, 60, 1-56.

Kelly, T. H., \& Thompson, T. (1988). Food deprivation and methadone effects on fixedinterval performance by pigeons. Archives Internationales de Pharmacodynamie et de Therapie, 293, 20-36.

Koelega, H. S. (1993). Stimulant drugs and vigilance performance: a review. Psychopharmacology, 111, 1-16.

Kraemer, P. J., Randall, C. K., Dose, J. M., \& Brown, R. W. (1997). Impact of $\underline{\mathrm{d}}-$ amphetamine on temporal estimation in pigeons tested with a production procedure. Pharmacology, Biochemistry, and Behavior, 58, 323-327.

Ksir, C. (1981). Rate-convergent effects of drugs. In T. Thompson and P. B. Dews (Eds.), Advances in behavioral pharmacology (Vol. 3, pp. 39-59). New York: Academic Press.

Laties, V. G., \& Weiss, B. (1966). Influence of drugs on behavior controlled by internal and external stimuli. Journal of Pharmacology and Experimental Therapeutics, 152, 388-396.

Laties, V. G., Wood, R. W., \& Rees, D. C. (1981). Stimulus control and the effects of $\underline{\text { d- }}$ amphetamine in the rat. Psychopharmacology, 75, 277-282.

Leander, J. D. (1975). Rate-dependent effects of drugs. II. Effects of some major tranquilizers on multiple fixed-ratio, fixed-interval schedule performance. $\underline{\text { Journal of }}$ Pharmacology and Experimental Therapeutics, 193, 689-700. 
Leander, J. D., \& McMillan, D. E. (1974). Rate-dependent effects of drugs. I. Comparisons of $\underline{\mathrm{d}}$-amphetamine, pentobarbital and chlorpromazine on multiple and mixed schedules. Journal of Pharmacology and Experimental Therapeutics, 188, 726-739.

Lucki, I., \& DeLong, R. E. (1983). Control rate of response or reinforcement and amphetamine's effect on behavior. Journal of the Experimental Analysis of Behavior, 40, 123132.

Lyon, M., \& Robbins, T. (1975). The action of central nervous system stimulant drugs: a general theory concerning amphetamine effects. In W. B. Essman and L. Valzelli (Eds.), Current developments in psychopharmacology (Vol. 2, pp. 80-163). New York: Spectrum Publications. Machado, A., \& Guilhardi, P. (2000). Shifts in the psychometric function and their implications for models of timing. Journal of the Experimental Analysis of Behavior, 74, 25-54.

Maricq, A. V., Roberts, S., \& Church, R. M. (1981). Methamphetamine and time estimation. Journal of Experimental Psychology: Animal Behavior Processes, 7, 18-30.

McGaughy, J., \& Sarter, M. (1995). Behavioral vigilance in rats: task validation and effects of age, amphetamine, and benzodiazepine receptor ligands. Psychopharmacology, 117. 340-357.

McKearney, J. W. (1974). Effects of $\underline{\mathrm{d}}$-amphetamine, morphine, and chlorpromazine on responding under fixed-interval schedules of food presentation or electric shock presentation. Journal of Pharmacology and Experimental Therapeutics, 190, 141-153.

McKearney, J. W. (1981). Rate-dependency: scope and limitations in the explanation and analysis of the behavioral effects of drugs. In T. Thompson and P. B. Dews (Eds.), Advances in behavioral pharmacology (Vol. 3, pp. 91-109). New York: Academic Press. 
McKim, W. A. (1981). Rate-dependency: a non-specific behavioral effect of drugs. In T. Thompson and P. B. Dews (Eds.), Advances in behavioral pharmacology (Vol. 1, pp. 61-73). New York: Academic Press.

McMillan, D. E. (1969). Effects of d-amphetamine on performance under several parameters of multiple fixed-ratio, fixed-interval schedules. Journal of Pharmacology and Experimental Therapeutics, 167, 26-33.

Meck, W. H. (1983). Selective adjustment of the speed of internal clock and memory processes. Journal of Experimental Psychology: Animal Behavior Processes, 9, 171-201.

Meck, W. H., \& Church, R. M. (1984). Opiod effects on timing behavior in the rat: possible actions on dopaminergic and GABAergic neurons. $\underline{\text { Society for Neuroscience Abstracts, }}$ $\underline{10,} 1103$.

MED Associates, Inc., \& Tatham, T. A. (1991). MED-PC Medstate Notation. East Fairfield, NH: MED Associates, Inc.

Morrisey, G., Ho, M.-Y., Wogar, M. A., Bradshaw, C. M., \& Szabadi, E. (1994). Effects of lesions of the ascending 5-hydroxytryptaminergic pathways on timing behaviour investigated with the fixed-interval peak procedure. Psychopharmacology, 114, 463-468.

Morrisey, G., Wogar, M. A., Bradshaw, C. M., \& Szabadi, E. (1993). Effects of lesions of the ascending 5-hydroxytryptaminergic pathways on timing behaviour investigated with an interval bisection task. Psychopharmacology, 112, 80-85.

Odum, A. L., Haworth, S. C., \& Schaal, D. W. (1998). Food deprivation level alters the effects of morphine on pigeons' key pecking. Journal of the Experimental Analysis of Behavior, 69, 295-310. 
Odum, A. L., \& Schaal, D. W. (1999). The effects of morphine on clocked fixed-interval performance: stimulus function or strength of stimulus control? Behavioural Pharamacology, 10, 243-255.

Odum, A. L., \& Schaal, D. W. (2000). The effects of morphine on fixed-interval patterning and temporal discrimination. Journal of the Experimental Analysis of Behavior, 74 , 229-243.

Pavlov, I. P. (1927). Conditioned Reflexes. London: Oxford University Press.

Rees, D. C., Wood, R. W., \& Laties, V. G. (1985). The roles of stimulus control and reinforcement frequency in modulating the behavioral effects of $\underline{\mathrm{d}}$-amphetamine in the rat. Journal of the Experimental Analysis of Behavior, 43, 243-255.

Rhodus, D. M., Elsmore, T. F., \& Manning, F. J. (1974). Morphine and heroin effects on multiple fixed-interval schedule performance in rats. Psychopharmacologia, 40, 147-155.

Robbins, T. W. (1981). Behavioural determinants of drug action: rate-dependency revisited. In S. J. Cooper (Ed.), Theory in psychopharamacology (Vol. 1, pp. 1-63). New York: Academic Press.

Roberts, S. (1981). Isolation of an internal clock. Journal of Experimental Psychology: Animal Behavior Processes, 7, 242-268.

Sanger, D. J., \& Blackman, D. E. (1976). Rate-dependent effects of drugs: a review of the literature. Pharmacology, Biochemistry, \& Behavior, 4, 73-83.

Schaal, D. W., \& Branch, M. N. (1992). The effects of cocaine on the responding of pigeons under different levels of food deprivation. Behavioural Pharmacology, 3, 5-9. 
Schaal, D. W., Miller, M. A., \& Odum, A. L. (1995). Cocaine's effects on food reinforced pecking in pigeons depend on food-deprivation level. Journal of the Experimental Analysis of Behavior, 62, 61-73.

Skinner, B. F. (1938). The behavior of organisms. Acton, MA: Copley Publishing Group. Stubbs, A. (1968). The discrimination of stimulus duration by pigeons. Journal of the Experimental Analysis of Behavior, 11, 223-258.

Stubbs, D. A., Vautin, S. J., Reid, H. M., \& Delehanty, D. L. (1978). Discriminative functions of schedule stimuli and memory: A combination of schedule and choice procedures. Journal of the Experimental Analysis of Behavior, 29, 167-180.

Thompson, T., Trombley, J., Luke, D., \& Lott, D. (1970). Effects of morphine on behavior maintained by four simple food-reinforcement schedules. Psychopharmacologia, 17. $182-192$.

Wenger, G. R. (1976). The effect of phencyclidine and ketamine on schedule-controlled behavior in the pigeon. Journal of Pharmacology and Experimental Therapeutics, 196, 172-179.

Wilkie, D. M. (1974). Stimulus control of responding during a fixed-interval reinforcement schedule. Journal of the Experimental Analysis of Behavior, 21, 425-432. 